EMSP Project 70070

\title{
Reactivity of Primary Soil Minerals and Secondary Precipitates beneath Leaking Hanford Waste Tanks
}

FINAL REPORT

\author{
Recipient: \\ University of Colorado at Boulder \\ Award Number: \\ DE-FG07-99ER15009 \\ Principal Investigator: \\ Kathryn L. Nagy \\ University of Colorado \\ now at University of Illinois at Chicago \\ 312-355-3276, klnagy@uic.edu \\ Project Team: \\ Barry R. Bickmore \\ University of Colorado \\ now at Brigham Young University \\ Sherry D. Samson \\ University of Colorado \\ now at University of Illinois at Chicago \\ R. Jeff Serne and Steven B. Yabusaki \\ Pacific Northwest National Laboratory
}




\section{EXECUTIVE SUMMARY}

Since the late 1950s, leaks from 67 single-shell tanks at the Hanford Site have released about 1 million curies to the underlying sediments. The radioactive material was contained in water-based solutions generally characterized as having high $\mathrm{pH}$ values (basic solutions), high nitrate and nitrite concentrations, and high aluminum concentrations. The solutions were also hot, in some cases at or near boiling, as well as complex and highly variable in composition reflecting solutions obtained from multiple methods of reprocessing spent nuclear fuel. In order to understand the observed and probable distribution of radionuclides in the ground at Hanford, major reactions that likely occurred between the leaked fluids and the sediment minerals were investigated in laboratory experiments simulating environmental conditions. Reactions involving the dissolution of quartz and biotite and the simultaneous formation of new minerals were quantified at controlled $\mathrm{pH}$ values and temperature. Results show that the dissolution of quartz and formation of new zeolite-like minerals could have altered the flow path of ground water and contaminant plumes and provided an uptake mechanism for positively-charged soluble radionuclides, such as cesium. The dissolution of biotite, a layered-iron-aluminum-silicate mineral, provided iron in a reduced form that could have reacted with negatively-charged soluble chromium, a toxic component of the wastes, to cause its reduction and precipitation as a new reduced-chromium mineral. The quantity of iron released in the experiments is sufficient to explain observations of reductions in dissolved chromium concentration in a plume beneath one Hanford tank. Fundamental data obtained in the project are the rates of the reactions at variable temperatures and $\mathrm{pHs}$. Fundamental data were also obtained on aspects of the surface reactivity of clay or layered-silicate minerals, a small proportion of the total mass of the sediment minerals, but a large proportion of the number of sites where reactions can occur. Results were also finalized on a component of a previous project related to the Hanford waste tanks that had the goal of measuring the incorporation of rhenium, an analogue of radioactive technetium, in iron and aluminum-oxides minerals as they aged in tank sludges at higher temperatures. Small amounts of rhenium were occluded in the iron-rich solids and the amount increased with aging time. Results from the quartz and biotite experiments are in a form that can be used in models of fluid flow in the Hanford subsurface. Results from the rhenium experiments can be used to understand aspects of closing certain of the Hanford tanks.

\section{PROJECT OBJECTIVES}

Since the late 1950s, leaks from 67 single-shell tanks at the Hanford Site have released about 1 million curies to the underlying sediments. At issue is the distribution of contaminants beneath the tanks, and the processes that led to their current disposition and will control their future mobility. The high ionic strength, high $\mathrm{pH}$, and high aluminum concentrations in the tank liquids can significantly alter the vadose zone sediments through dissolution of primary minerals and precipitation of secondary minerals. Dissolution and precipitation directly influence (1) the flow paths that control contaminant transport and (2) the reactivity of the solid matrix that controls contaminant mobility. The impact of these processes, however, depends on mineral reaction kinetics and the dynamic interaction of the reactions with the flow field and contaminant 
sorption, neither of which are well known for this extreme chemical system. Data obtained will be directly useful to other EMSP projects addressing contaminant mobility in the vadose zone.

We are addressing three specific issues:

(1) Recognized factors that control the kinetics of dissolution and precipitation must be quantified for the unnatural system of tank solutions mixing with soils, including effects of high $\mathrm{pH}$, high ionic strength (especially $\mathrm{NaNO}_{3}$ solutions), temperature, and saturation state.

(2) A clear understanding of the roles of nucleation mechanism, nucleation sites on soils minerals, and the role of reactive surface area in simultaneous dissolution and precipitation reactions are the key unknown components in comprehending this contaminated soil system.

(3) Results obtained will help build a mechanistic understanding of how tank fluids migrate through the vadose zone. Local changes in porosity and permeability will dictate preferential flow paths which directly regulate the transport of later arriving chemical species. Changes in mineral surface area affect sorption site distribution. A comprehensive model is needed that integrates these feedback mechanisms with all the critically available data.

\section{BACKGROUND}

During the first three years of research funded by the Environmental Management Science Program, field observations on Hanford sediments and fluids beneath the S-SX tank farms have been useful in identifying a number of important reactions controlling the distribution of contaminants beneath the tanks (e.g., McKinley et al., 2001; Zachara et al., 2002; 2004). In particular, radioactive cesium uptake on primary sediment minerals seems to occur largely on micas with a general uptake associated with amorphous-like secondary aluminosilicate precipitates. Also, results of column experiments on Hanford sediments suggest strongly that colloids may have been mobilized during contact with leaked tank fluids (Flury et al., 2002). These colloids consist of remobilized clay minerals and also new secondary zeolite-like precipitates that can take up cesium from solution (Chorover et al., 2003). Chromate immobilization is considered to occur via reduction of chromate $(\mathrm{Cr}(\mathrm{VI}))$ to insoluble chromiumoxyhydroxides ( $\mathrm{Cr}(\mathrm{III})$ ) by $\mathrm{Fe}(\mathrm{II})$ released during the dissolution of biotite grains (Zachara et al., 2004). The work supported under this EMSP project (70070) has evolved during the lifetime of the project in order to stay directed at investigating the fundamental nature and rates of reactions pertinent to the field observational data.

\section{APPROACH AND METHODS}

At the start of the project, there was no observational data on what actually happened to minerals and solutions beneath the Hanford tanks. Gamma-logging in well-bores drilled laterally to certain tanks showed the shapes of some cesium-containing contaminant plumes, for example, but no actual samples of sediment and solutions directly beneath the tanks had been collected. During the project period, data were obtained from a slant well-bore beneath the SX tank farm (e.g., McKinley et al., 2001; Zachara et al., 2002; Zachara et al., 2004). As these data were analyzed and released to the public, we redirected our experimental efforts to focus on 
quantifying rates and reaction mechanisms that could explain the observations of these investigations with the overall goal of addressing geochemical and mineralogical controls on contaminant mobility in the Hanford subsurface.

Along the same lines, the work that was started under another EMSP project, but finished under this one, to simulate solid-contaminant interactions within the Hanford tank sludges was conducted without much knowledge at the time of specific sludge solids in the tanks. General compositional inventories were available for the entire Hanford site, but specific tank information was lacking. It had been generally thought that technetium- 99 was dominantly portioned into the liquid phases in the tanks, and this is true for many specific tanks. Technetium-99 is one of the primary subsurface contaminants from the leaked tanks, for example. However, only recently has it been determined that there is at least one, if not some subset, of tanks that may have most of their technetium-99 somehow incorporated in iron-rich solid phases (K. Krupka, personal communication). The experimental results summarized in this report have proven useful towards understanding tank sludges where the ultimate goal is to complete tank closure. However, it is important to realize that at the time the experiments were conducted, the majority of the information available suggested that solid-phase incorporation of technetium was much less important than the solution-phase technetium.

The methods used in the experimental parts of the study were based on standard batch and stirred-reactor designs and full characterization of substrate solids and reacted solutions and solids. Probably one of the most challenging aspects of the research was developing approaches to work with high ionic strength solutions at high $\mathrm{pH}$ values. With time, the methodologies and approaches evolved to the use of solid-state electrodes for the measurement of $\mathrm{pH}$ with calibrations performed in solutions of known hydroxyl concentration. In all cases various plastics were used to contain the high $\mathrm{pH}$ solutions. When possible, Pitzer models developed largely by Andy Felmy at PNNL were used to model solution compositions.

Solids were characterized using various bulk and surface analytical techniques. This included using facilities and researchers (Field Emission Scanning Electron Microscopy and Xray Diffraction) at the William R. Wiley Environmental Molecular Sciences Laboratory at Pacific Northwest National Laboratory.

Molecular modeling of mica reactivity was conducted in collaboration with Kevin Rosso of Pacific Northwest National Laboratory.

\section{RESULTS OVERVIEW}

The goal of the research was to obtain kinetic rate laws to describe the dissolution of primary minerals, as well as the precipitation of secondary phases, as they contact high $\mathrm{pH}$, high ionic strength, high aluminum fluids. Results include data on the kinetics and thermodynamics of the precipitation of secondary nitrate-cancrinite during quartz dissolution (Bickmore et al., 2001); a study showing that the surface area of a clay can be obtained on picogram quantities of material using images obtained by atomic force microscopy (Bickmore et al., 2002), and a modeling approach to quantifying the thermodynamics of acid-base reactive sites on micas (Bickmore et al., 2003). The latter two manuscripts were not direct results of the specific kinetics experiments of this project, but are relevant to surface reactions occurring at Hanford with respect to cesium uptake by micas and clays (Zachara et al., 2002; Chorover et al., 2003). Data on the dissolution kinetics of biotite in Hanford tank simulants at $25^{\circ} \mathrm{C}$ and on the 
dissolution kinetics of quartz in Hanford tank simulants at $59-89{ }^{\circ} \mathrm{C}$ are in the process of being published as journal articles (Samson et al., in revision; Bickmore et al., in prep.). Finally, a results on measuring rhenium uptake in aging iron- and aluminum oxide minerals in tank simulants showed that a finite amount of rhenium was irreversibly sorbed in these materials and that the amount increased with aging time (Wakoff and Nagy, 2004).

Results on each of these topics are summarized below.

Cancrinite Formation on Quartz (Bickmore et al., 2001c): High pH, high $\mathrm{NaNO}_{3}$ solutions with varying amounts of dissolved $\mathrm{Al}$ were reacted with quartz sand at $88.7^{\circ} \mathrm{C}$. After $2-10$ days, nitrate-cancrinite, a feldspathoid mineral with a zeolite-like crystal structure, precipitated onto the quartz surfaces, cementing the grains together. Estimates of the $\mathrm{K}_{\mathrm{eq}}$ for the precipitation reaction differ for solutions with 0.1 or $1.0 \mathrm{~m} \mathrm{OH}^{-}\left(\log \mathrm{K}_{\mathrm{eq}}=30.4 \pm 0.8\right.$ and $36.2 \pm 0.6$, respectively). The solubility difference is attributed to more perfect crystallinity (i.e., fewer stacking faults) in the higher-pH cancrinite structure. Precipitate crystallinity may be important for radionuclide mobility, because stacking faults in the cancrinite structure can reduce its zeolitic cation exchange properties. The evolution of Si concentration in the solutions was modeled by considering the dependence of quartz dissolution rate on $\mathrm{Al}(\mathrm{OH})_{4}{ }^{-}$activity, cancrinite precipitation, and the reduction of reactive surface area of quartz due to coverage by cancrinite.

Clay Surface Area (Bickmore et al., 2002): Rapid and accurate determination of the surface area of three kaolinite clay standards, taking into account the complex microtopography of the particles, was achieved using atomic force microscopy images and computerized image analysis. All surface areas were determined to within 3\%. Edge surface area is $18.2-30.0 \%$ of the total surface area depending on the particular kaolinite standard. Specific surface areas agree to within $4 \%$ of published values determined by the BET method. The approach can be applied to clay and nanoparticle samples too small in quantity for BET analysis, since it requires $\sim 11$ orders of magnitude less material.

Mica Edge Surface Reactivity (Bickmore et al., 2003): The atomic structure of dioctahedral 2:1 phyllosilicate edge surfaces was calculated using pseudopotential planewave density functional theory. Bulk structures of pyrophyllite and ferripyrophyllite were optimized using periodic boundary conditions, after which crystal chemical methods were used to obtain initial terminations for ideal (110)- and (010)-type edge surfaces. The edge surfaces were protonated using various schemes to neutralize the surface charge, and total minimized energies were compared to identify which schemes are the most energetically favorable. The calculations show that significant surface relaxation should occur on the (110)-type faces, as well as in response to different protonation schemes on both surface types. This result is consistent with atomic force microscopy observations of phyllosilicate dissolution behavior. Bond-valence methods incorporating bond lengths from calculated structures can be used to predict intrinsic acidity constants for surface functional groups on (110)- and (010)-type edge surfaces. However, the occurrence of surface relaxation poses problems for applying current bond-valence methods. An alternative method is proposed that considers bond relaxation, and accounts for the energetics of various protonation schemes on phyllosilicate edges. 
Quartz Dissolution Kinetics (Bickmore et al., 2001a,b; Bickmore et al., in prep.): The influence of $\mathrm{Al}(\mathrm{OH})_{4}{ }^{-}$on the dissolution rate of quartz at $\mathrm{pH} 10-13$ and $59-89{ }^{\circ} \mathrm{C}$ was determined using batch experiments. $\mathrm{Al}(\mathrm{OH})_{4}{ }^{-}$at concentrations below gibbsite solubility depressed the dissolution rate by as much as $85 \%$, and this effect was greater at lower $\mathrm{pH}$ and higher $\mathrm{Al}(\mathrm{OH})_{4}{ }^{-}$ concentration. For a given $\mathrm{H}^{+}$activity, the degree of rate depression due to the presence of $\mathrm{Al}(\mathrm{OH})_{4}{ }^{-}$was invariant with temperature. That is, while dissolution rates did vary with temperature, the percent decrease in rate due to the presence of $\mathrm{Al}(\mathrm{OH})_{4}{ }^{-}$was the same for a given $\mathrm{H}^{+}$activity and $\mathrm{Al}(\mathrm{OH})_{4}{ }^{-}$concentration. These data, along with what is known about Al-Si interactions at high $\mathrm{pH}$, are consistent with $\mathrm{Al}(\mathrm{OH})_{4}{ }^{-}$and $\mathrm{Na}^{+}$coadsorbing on neutral silanol sites and passivating the surrounding quartz surface. The observed $\mathrm{pH}$ dependence, and lack of temperature dependence, of $\mathrm{Al}(\mathrm{OH})_{4}{ }^{-}$sorption also supports the inference that the acid-base behavior of the surface silanol groups has only a small temperature dependence in this range. A Langmuir-type adsorption model was used to predict the degree of rate depression for a given in situ $\mathrm{pH}$ and $\mathrm{Al}(\mathrm{OH})_{4}{ }^{-}$concentration. Attempts to incorporate the baseline rate data into models that assume a first order dependence of the rate on the fraction of deprotonated silanol sites were unsuccessful. However, the data are consistent with the hypothesis proposed in the literature that two mechanisms may be operative. Nucleophilic attack of water on siloxane bonds catalyzed by the presence of a deprotonated silanol group and $\mathrm{OH}^{-}$attack catalyzed by the presence of a neutral silanol group may operate in alkaline solutions. The second mechanism dominates at higher $\mathrm{pH}$ and temperature.

Biotite Dissolution Kinetics (Samson and Nagy, 2002a,b; Samson et al., in revision): Biotite dissolution under conditions of high $\mathrm{pH}$ and high $\mathrm{Al}$ and $\mathrm{NaNO}_{3}$ concentrations was investigated using continuously stirred flow-through reactors at $22-25^{\circ} \mathrm{C}$ (Samson and Nagy, 2002). At the onset of each experiment, inlet solutions were $\mathrm{pH} 8$ and free of nitrate and added Al. There were initial transients (i.e., initially rapid dissolution rates decaying to slower steady-state rates) and dissolution was non-stoichiometric with rapid preferential release of $\mathrm{K}$ followed by nearstoichiometric release of $\mathrm{Si}, \mathrm{Al}$, and $\mathrm{Mg}$; release of $\mathrm{Fe}$ was much slower. Following a conditioning (aging) interval ranging from 96 to 500 hours, the $\mathrm{pH} 8$ inlet solutions were replaced with solutions of higher $\mathrm{pH}(10-14)$, some including $0.055 \mathrm{M} \mathrm{Al}\left(\mathrm{NO}_{3}\right)_{3}$ and/or $2 \mathrm{M}$ or 6 $\mathrm{M} \mathrm{NaNO}_{3}$. Each increase in the $\mathrm{pH}$ of the inlet solutions resulted in a second transient, i.e., a peak in the release rates decaying to new steady-state rates. The transients were $\mathrm{pH}$-dependent; the amounts of $\mathrm{Si}, \mathrm{Al}, \mathrm{Fe}$, and $\mathrm{K}$ released during the transient interval were greatest at $\mathrm{pH} 14$, followed by $\mathrm{pHs} 13,12,11$, and 10 . Steady-state dissolution rates were at a minimum at $\mathrm{pH}$ 1112 for $\mathrm{Si}, \mathrm{Al}, \mathrm{Mg}$, and $\mathrm{K}$, and at $\mathrm{pH} 10$ for $\mathrm{Fe}$, and increased in either direction in $\mathrm{pH}$ away from this minimum, but the total range in dissolution rates for Si and Al was only an order of magnitude $\left(10^{-12.0}\right.$ to $10^{-11.0}$ and $10^{-11.9}$ to $10^{-10.9}$, respectively, in units of moles biotite $\left.\mathrm{m}^{-2} \mathrm{~s}^{-1}\right)$. Normalized dissolution rates for $\mathrm{K}$ and $\mathrm{Mg}$ covered a range of approximately two orders of magnitude $\left(10^{-11.6}\right.$ to $10^{-9.8}$ and $10^{-13.5}$ to $10^{-11.0}$, respectively), while the range for Fe was nearly 3 orders of magnitude $\left(10^{-13.4}\right.$ to $\left.10^{-10.6}\right)$. The effects of $\mathrm{Al}$ and $\mathrm{NaNO}_{3}$ on dissolution rate were highly variable and generally outweighed by the effect of $\mathrm{pH}$. The most extensive solid-phase alterations, however, were consistently observed in solids reacted in sodium-enriched solutions.

Rhenium Uptake in Iron- and Aluminum Oxides (Wakoff and Nagy, 2004): This manuscript describes results of aging of iron and aluminum oxyhydroxides and concomitant uptake of perrhenate anion. The main result is that with aging in the iron system, the amount of perrhenate 
incorporated irreversibly in the solids increases. No systematic effect as well as a smaller effect is observed in the aluminum system. Results imply that pertechnetate may be associated with iron-oxide phases in the tanks and may not have been partitioned completely into the tank solutions.

\section{CONCLUSIONS}

Experiments conducted to quantify rates of reactions between primary minerals in Hanford sediments and leaked waste tank simulants have provided information that should be useful for reactive-transport modeling of waste mobility in the Hanford subsurface.

\section{PRODUCTS}

\section{Published and Submitted Manuscripts}

Wakoff B. and Nagy K. L., 2004, Perrhenate uptake by Fe and Al oxyhydroxides: An analogue for pertechnetate incorporation in Hanford waste tank sludges, Environmental Science \& Technology 38, 1765-1771.

Bickmore B. R., Rosso K. M., Nagy K. L., Cygan R. T., and Tadanier C. J., 2003, Ab initio determination of edge surface structures for dioctahedral 2:1 phyllosilicates: implications for acid-base reactivity. Clays and Clay Minerals, 4, 359-371.

Bickmore B. R., Nagy K. L., Sandlin P. E., and Crater T. S., 2002, Quantifying surface areas of clays by atomic force microscopy, American Mineralogist 87, 780-783.

Bickmore B. R., Nagy K. L., Young J. S., and Drexler J. W., 2001c, Nitrate-cancrinite precipitation on quartz sand in simulated Hanford tank solutions, Environmental Science \& Technology, 35, 4481-4486.

Samson S. D., Nagy K. L., and Cotton, Worth B., III., 2004, Transient and steady-state dissolution of biotite at $22-25^{\circ} \mathrm{C}$ in high $\mathrm{pH}$, sodium, nitrate, and aluminate solutions. Geochimica et Cosmochimica Acta, submitted 12/03; in revision.

Bickmore B. R., Nagy K. L., and Gray A. K., The effect of adsorbed $\mathrm{Al}(\mathrm{OH})_{4}{ }^{-}$on the dissolution rate of quartz, to be submitted to Geochimica et Cosmochimica Acta.

\section{Conference Abstracts}

Samson, S.D. and Nagy, K.L, 2002a, Biotite dissolution in simulated Hanford tank waste. Twelfth Annual V.M. Goldschmidt Conference, Davos, Switzerland. Geochimica et Cosmochimica Acta 66:A665 (abstr.).

Samson, S.D. and Nagy, K.L., 2002b, Biotite dissolution at $\mathrm{pH} 11-14$ and $25{ }^{\circ} \mathrm{C}$ : The effects of $\mathrm{pH}, \mathrm{Al}$, and $\mathrm{NaNO}_{3} .39^{\text {th }}$ Annual Meeting of The Clay Minerals Society, Boulder, CO.

Bickmore B. R. and Nagy K. L., 2001a, Dissolution of quartz and precipitation of cancrinite in contact with Hanford tank simulants, Fall Meeting of the American Chemical Society.

Bickmore B. R., Nagy K. L., Gray A. K., and Moschetti M., 2001b, The effect of adsorbed $\mathrm{Al}(\mathrm{OH})_{4}{ }^{-}$on the dissolution rate of quartz. In Eleventh Annual V. M. Goldschmidt 
Conference, Abstract \#3296. LPI Contribution No. 1088, Lunar and Planetary Institute, Houston (CD-ROM).

Wakoff B. and Nagy K. L., 2001, Re Uptake by precipitating Fe and Al oxy(hydr)oxides: An analog for the fate of ${ }^{99} \mathrm{Tc}$ in high level nuclear waste. In Eleventh Annual V. M.

Goldschmidt Conference, Abstract \#3296. LPI Contribution No. 1088, Lunar and Planetary Institute, Houston (CD-ROM).

Bickmore B., Nagy K. L., Serne J., and Yabusaki, S., 2000, Reactivity of primary soil minerals and secondary precipitates beneath leaking Hanford waste tanks, Environmental Management Science Program National Workshop, Poster 76, p. 191-192.

Wakoff B. and Nagy K. L., 2000, Aging behavior and rhenium partitioning in simplified Hanford waste-tank sludges, Environmental Management Science Program National Workshop, Poster 199, p. 495-496.

\section{REFERENCES CITED}

Chorover J., Choi S., Amistadi M. K., Crosson G., and Mueller K. T., 2003, Linking cesium and strontium uptake to kaolinite weathering in simulated tank waste leachate. Environmental Science \& Technology 37, 2200-2208.

Flury M., Mathison J. B., Harsh J. B., 2002, In situ mobilization of colloids and transport of cesium in Hanford sediments, Environmental Science \& Technology, 36, 5335-5341.

McKinley J. P., Zeissler C. J., Zacahara J. M., Serne R. J., Lindstrom R. M., Schaef H. T., Orr R. D. (2001) The distribution and retention of ${ }^{137} \mathrm{Cs}$ in sediments beneath leaked waste at the Hanford site. Environmental Science and Technology 35, 3433-3441.

Samson S. D. and Nagy K. L., 2002, Biotite dissolution in simulated Hanford tank waste, Geochimica et Cosmochimica Acta 66, A665-A665 (abstract, 2002 Goldschmidt Conference).

Zachara J. M., Smith S. C., Liu C., McKinley J. P., Serne R. J., and Gassman P. L., 2002, Sorption of $\mathrm{Cs}^{+}$to micaceous subsurface sediments from the Hanford site, USA. Geochimica et Cosmochimica Acta 66, 193-212.

Zachara J. M., Ainsworth C. C., Brown G. E., Jr., Catalano J. G., McKinley J. P., Qafoku O., Smith S. C., Szecsody J. E., Traina S. J., and Warner J. A., 2004, Chromium speciation and mobility in a high level nuclear waste vadose zone plume. Geochimica et Cosmochimica Acta, in press. 


\section{APPENDIX OF PUBLICATIONS}

All published journal papers are included in this appendix. Papers in revision or in preparation are not included and will be submitted at a later date as part of the annual reports for EMSP Project 86898, which is a continuation of EMSP Project 70070.

The Appendix contents are given in the order:

\begin{tabular}{|l|l|}
\hline Page & Paper \\
\hline 10 & $\begin{array}{l}\text { Bickmore B. R., Nagy K. L., Young J. S., and Drexler J. W., 2001c, Nitrate- } \\
\text { cancrinite precipitation on quartz sand in simulated Hanford tank solutions, } \\
\text { Environmental Science \& Technology, 35, 4481-4486. }\end{array}$ \\
\hline 16 & $\begin{array}{l}\text { Bickmore B. R., Nagy K. L., Sandlin P. E., and Crater T. S., 2002, } \\
\text { Quantifying surface areas of clays by atomic force microscopy, American } \\
\text { Mineralogist 87, 780-783. }\end{array}$ \\
\hline 20 & $\begin{array}{l}\text { Bickmore B. R., Rosso K. M., Nagy K. L., Cygan R. T., and Tadanier C. J., } \\
\text { 2003, Ab initio determination of edge surface structures for dioctahedral 2:1 } \\
\text { phyllosilicates: implications for acid-base reactivity. Clays and Clay } \\
\text { Minerals, 4, 359-371. }\end{array}$ \\
\hline 42 & $\begin{array}{l}\text { Wakoff B. and Nagy K. L., 2004, Perrhenate uptake by Fe and Al } \\
\text { oxyhydroxides: An analogue for pertechnetate incorporation in Hanford waste } \\
\text { tank sludges, Environmental Science \& Technology 38, 1765-1771 }\end{array}$ \\
\hline
\end{tabular}




\section{Nitrate-Cancrinite Precipitation on Quartz Sand in Simulated Hanford Tank Solutions}

\author{
BARRY R. B I C KMORE, ${ }^{*}{ }^{\dagger}$ \\ KATHRYN L. NAGY, ${ }^{\dagger}$ \\ JAMES S. YOUNG, ${ }^{\ddagger}$ AND \\ JOHN W. DREXLER ${ }^{\dagger}$ \\ Department of Geological Sciences, University of Colorado, \\ Boulder, Colorado 80309-0399, and William R. Wiley \\ Environmental Molecular Sciences Laboratory, \\ Pacific Northwest National Laboratory, P.O. Box 999 , \\ Richland, Washington 99301
}

Caustic $\mathrm{NaNO}_{3}$ solutions containing dissolved Al were reacted with quartz sand at $89{ }^{\circ} \mathrm{C}$ to simulate possible reactions between leaked nuclear waste and primary subsurface minerals at the U.S. Department of Energy's Hanford site in Washington. Nitrate-cancrinite began to precipitate onto the quartz after $2-10$ days, cementing the grains together. Estimates of the equilibrium constant for the precipitation reaction differ for solutions with 0.1 or 1.0 $\mathrm{m} \mathrm{OH}^{-}\left(\log K_{\text {eq }}=30.4 \pm 0.8\right.$ and $36.2 \pm 0.6$, respectively). The difference in solubility may be attributable to more perfect crystallinity (i.e., fewer stacking faults) in the higher$\mathrm{pH}$ cancrinite structure. This is supported by electron micrographs of crystal morphology and measured rates of $\mathrm{Na}$ volatilization under an electron beam. Precipitate crystallinity may affect radionuclide mobility, because stacking faults in the cancrinite structure can diminish its zeolitic cation exchange properties. The precipitation rate near the onset of nucleation depends on the total $\mathrm{Al}$ and $\mathrm{Si}$ concentrations in solution. The evolution of experimental $\mathrm{Si}$ concentrations was modeled by considering the dependence of quartz dissolution rate on $\mathrm{Al}(\mathrm{OH})_{4}{ }^{-}$ activity, cancrinite precipitation, and the reduction of reactive surface area of quartz due to coverage by cancrinite.

\section{Introduction}

Between 0.6 and 1.4 million gallons of high level nuclear waste, containing 1-2 million curies of radiation (primarily from ${ }^{137} \mathrm{Cs}$ ), may have leaked into the sediments beneath the U.S. Department of Energy's (DOE) Hanford Site in southeast Washington since the late 1950s (1). To predict the fate of the released radionuclides, the thermodynamics and kinetics of reactions that could have occurred between leaked fluids and Hanford sediments must be known.

Leaked nuclear waste fluids are byproducts of Pu production and extraction procedures used from 1944 to 1988 at the Hanford Site. After irradiation of $\mathrm{U}$ fuel rods, various solvent extraction techniques were used to separate the $\mathrm{Pu}$ from $\mathrm{U}$ and other components of the spent fuel. A large amount of $\mathrm{NaOH}$ typically was added to acidified waste,

* Corresponding author phone: (801)378-4680; fax: (801)378-8143; e-mail: Barry_Bickmore@byu.edu. Current address: Department of Geology, Brigham Young University, Provo, UT 84602-4606.

$\dagger$ University of Colorado.

‡ Pacific Northwest National Laboratory. which then was pumped into carbon steel tanks. As a result, the stored waste was strongly basic $(\mathrm{pH} 12-14)$ and often included high concentrations of dissolved $\mathrm{Al}$ and $\mathrm{NaNO}_{3}$. (Inventories of tank components are available from the Tank Waste Information Network System at http://twins.pnl.gov: 8001/.) Various compounds precipitated out of the waste liquid, resulting in stratification. Additionally, self-boiling and waste concentration procedures reduced liquid volumes, resulting in high $\mathrm{Al}$, high $\mathrm{pH}(9-14)$, high ionic strength, high-temperature supernatant in many tanks (1).

The leaked fluid has contacted sediments from the Hanford Formation (coarse-grained glacio-fluvial gravels and sands) and the Middle Ringold Formation (fluvial-lacustrine gravel/sand/silt). Primary silicate minerals in these sediments comprise $80-98 \%$ of the mineral mass as sand-sized grains and include quartz, feldspar (both plagioclase and Kfeldspar), mica (biotite and muscovite), and minor hornblende (2). It is likely that the caustic tank supernatants dissolved some primary minerals $(3-6)$, releasing $\mathrm{Si}$ into solution. This could have caused precipitation of secondary minerals, especially aluminosilicate phases. Recent work showed that cancrinite, a zeolite-like mineral, precipitated after reacting Hanford sediments for 11.7 weeks at 60 and $90{ }^{\circ} \mathrm{C}$ in a complex tank simulant (7). However, only qualitative information was extracted from experiments with high sediment/solution ratios. After 2 weeks, some Cs was taken up in the reacted sediments, hypothetically in the cancrinite phase.

We report results from batch experiments with low solid/ solution ratios in which high $\mathrm{pH}$, high $\mathrm{NaNO}_{3}$ solutions with varying amounts of dissolved $\mathrm{Al}$ were reacted with quartz sand at $89^{\circ} \mathrm{C}$. After $2-10$ days nitrate-cancrinite precipitated onto the quartz surfaces, cementing the grains together. The solubility and initial precipitation rates of nitrate-cancrinite are estimated. We infer that depending on solution conditions, nitrate-cancrinite precipitates may have different effects on the mobility of radionuclides in the Hanford subsurface.

\section{Experimental Section}

Materials. All solutions were prepared using reagent grade $\mathrm{NaOH}, \mathrm{NaNO}_{3}$, and $\mathrm{Al}\left(\mathrm{NO}_{3}\right)_{3}$. Doubly deionized (ddi) water was boiled while being purged with ultrapure Ar gas and then stored in a collapsible plastic container without headspace. Reagents were mixed in the purged water as Ar gas was again bubbled through the solution, after which the solution was immediately poured into reaction vessels, which were then sealed.

White quartz sand was purchased from Aldrich Chemicals. Although small amounts of mineral impurities could be seen in the sand with an optical microscope, they could not be detected via powder X-ray Diffraction (XRD). X-ray Fluorescence (XRF) analysis of the untreated sample indicated that it was $99.8 \% \mathrm{SiO}_{2}$. The sand sample was magnetically separated to remove magnetic impurities. Then $300 \mathrm{~g}$ of sand was placed in a glass bottle with $400 \mathrm{~mL}$ of concentrated $\mathrm{H}_{2} \mathrm{SO}_{4}$ for 2 days to condition the surfaces. The treated sand was gently rinsed 5-10 times and placed in $2 \mathrm{~L}$ ddi water at $75^{\circ} \mathrm{C}$ for 3 days, changing the water daily. Finally, the sand was gently rinsed several times and oven-dried at $80^{\circ} \mathrm{C}$. Auger Electron Spectroscopy (AES) of untreated quartz surfaces with a Perkin-Elmer PHI 600 Scanning Auger Multiprobe revealed no impurities, except for adventitious $\mathrm{C}$ and trace $\mathrm{Ca}$, perhaps from $\mathrm{CaCO}_{3}$. AES spectra of treated quartz surfaces showed no impurities other than adventitious $\mathrm{C}$.

VOL. 35, NO. 22, 2001 / ENVIRONMENTAL SCIENCE \& TECHNOLOGY $\mathbf{4 4 8 1}$ 
Batch Chemical Experiments. Batch experiments (see Table 1, Supporting Information) were designed to measure both the kinetics of quartz dissolution and the conditions under which secondary aluminosilicates might precipitate. In each experiment, $1-3 \mathrm{~g}$ of treated quartz sand was placed in each of eight separate $60 \mathrm{~mL}$ HDPE plastic bottles, which then were filled with solution. Bottles were placed in an 89 ${ }^{\circ} \mathrm{C}$ constant temperature water bath, and one bottle at a time was periodically removed for analysis. The bottles were not shaken to avoid abrasion of the quartz surfaces. The $\mathrm{pH}$ of each sample was measured at a temperature as close to the in situ temperature as possible (see below). Twenty-five milliliter aliquots of the solution were spiked with acid $(0.25$ $\mathrm{mL}$ of $12.1 \mathrm{M} \mathrm{HCl}$ for Al analysis, $0.06 \mathrm{~mL} 4.5 \mathrm{M}^{\circ} \mathrm{H}_{2} \mathrm{SO}_{4}$ for $\mathrm{Si}$ analysis) and then analyzed for $\mathrm{Si}$ (error $\pm 5 \%$ ) and $\mathrm{Al}$ (error $\pm 7 \%$ ) concentration using colorimetry $(8,9)$. Si concentration in the higher $\mathrm{pH}$ solutions was measured using Inductively Coupled Plasma Atomic Emission Spectroscopy (ICP-AES) (error $\pm 3 \%$ ). Colorimetric analyses were performed with a Bausch \& Lomb Spectronic 501 spectrophotometer, and ICP-AES was performed on a Fisons Instruments ARL $3410+$. Reacted sand was dialyzed to a conductivity of $<3$ $\mu \mathrm{S}$ and freeze-dried.

Most solutions contained $2 \mathrm{~m} \mathrm{NaNO}_{3}$, with $0.0001,0.001$, 0.005 , or $0.01 \mathrm{~m} \mathrm{Al}\left(\mathrm{NO}_{3}\right)_{3}$. A free $\mathrm{OH}^{-}$concentration of 0.1 or $1.0 \mathrm{~m}$ (representing $\mathrm{pH}$ values of $\sim 11.3$ and $\sim 12.4$, respectively) was obtained by adding $\mathrm{NaOH}$, taking into account the formation of $\mathrm{Al}(\mathrm{OH})_{4}{ }^{-}$. That is, if the desired free $\mathrm{OH}^{-}$concentration is designated $x$ and the $\mathrm{Al}\left(\mathrm{NO}_{3}\right)_{3}$ concentration is designated $y$, then the amount of $\mathrm{NaOH}$ added was equal to $x+4 y$. In addition, solutions with $0.005 \mathrm{~m}$ $\mathrm{Al}\left(\mathrm{NO}_{3}\right)_{3}$ and $0.1 \mathrm{~m}$ free $\mathrm{OH}^{-}$were made with $0.5,1.0,2.0$, and $4.0 \mathrm{~m} \mathrm{NaNO}_{3}$.

Analysis of Precipitates. Several reacted sand samples were analyzed by powder XRD, Field Emission Scanning Electron Microscopy (FESEM), Energy-Dispersive X-ray Spectroscopy (EDS), and electron microprobe analysis (EMPA). A LEO 982 FESEM system with an Oxford ISIS energy dispersive X-ray detector was used for Scanning Electron Microscopy and EDS analysis. Mineral composition was determined using a JEOL 8600 electron microprobe at $10 \mathrm{kV}$ accelerating voltage, 18-20 nA cup current, and with a focused beam. Spectrometer crystals TAP and LDE1 were used for quantification, and ZAF corrections were applied based on calculated $\mathrm{k}$-ratios from mineral standards (USNM 143966 Microcline for Si and Al, Amelia Albite for Na, and $\mathrm{BN}$ for $\mathrm{N}$.)

pH Measurement. After each sample bottle was removed from the bath, it was opened and partially immersed in a beaker of the hot bath water. The $\mathrm{pH}$ was measured using an Accumet AR-15 pH meter (Fisher) and AccuFet solid state Ion Sensitive Field Effect Transistor (ISFET) electrode with automatic temperature compensation (Fisher) at a temperature as close to the bath temperature as possible, usually above $70^{\circ} \mathrm{C}$. Measured $\mathrm{pH}$ was corrected to $89^{\circ} \mathrm{C}$ using the temperature dependence of the dissociation constant of water. The $\mathrm{pH}$ was measured at high temperature to minimize the effect of $\mathrm{CO}_{2}$, which caused the temperature-corrected $\mathrm{pH}$ to drift downward as the solution cooled. The ISFET electrode was used to eliminate $\mathrm{Na}^{+}$ion error, caused by $\mathrm{Na}^{+}$ions migrating through the gel layer on a standard glass electrode $(10,11)$.

Solution $\mathrm{pH}$ values calculated using the Pitzer model described below differed from the temperature-corrected measured values by +0.2 to $0.3 \mathrm{pH}$ units. However, $\mathrm{pH}$ measurements of alkaline solutions are notoriously difficult, so it was assumed that the modeled values were more accurate. Values were measured only to confirm that the $\mathrm{pH}$ did not drift significantly during the experiments. Reasons for the discrepancy include the following. First, commercial
pH 10.00 buffer (Fisher) and $\mathrm{pH} 13.00$ buffers (12) were used to calibrate the electrode at room temperature. Not only are such buffers prone to $\mathrm{pH}$ drift (10) but also the buffers do not bracket the experimental solution conditions. Second, temperature compensation for $\mathrm{pH}$ electrodes is often slow when the temperature sensor is imbedded within the electrode (as in this case), causing measurement errors (10) Third, large differences in ionic strength between the buffers and samples can lead to errors because of changes in activity coefficients, etc. (13).

Solution Model. The Geochemist's Workbench 3.0 (GWB) (14) was used to model the speciation of the reacting solutions. All equilibrium constants were used as given in the database for GWB except those for Al species, which were modified to be consistent with the data of Wesolowski (15), and that for the polysilicate species $\mathrm{Si}_{4}(\mathrm{OH})_{18}{ }^{2-}$, taken from Busey and Mesmer (16). In fact, a number of polynuclear silicate species are known to be present in solution (17), but Busey and Mesmer (16) assumed the existence of only one, using it to represent all polysilicate species. We have followed Busey and Mesmer (16) because they reported the only thermodynamic data for polysilicate equilibria above $25^{\circ} \mathrm{C}$ Although there was a small amount of carbonate contamination $(0.4 \%)$ in the $\mathrm{NaOH}$ pellets used to make the solutions, $\mathrm{CO}_{3}{ }^{2-}$ was not considered in the solution model.

Interaction parameters for Pitzer's model were taken from the literature. The following ionic interactions were taken into account: $\mathrm{Na}^{+}-\mathrm{OH}^{-}, \mathrm{Na}^{+}-\mathrm{NO}_{3}{ }^{-}(18), \mathrm{Na}^{+}-\mathrm{Al}(\mathrm{OH})_{4}{ }^{-}(15)$ $\mathrm{Na}^{+}-\mathrm{H}_{3} \mathrm{SiO}_{4}^{-}, \mathrm{Na}^{+}-\mathrm{H}_{2} \mathrm{SiO}_{4}{ }^{2-}(19), \mathrm{Na}^{+}-\mathrm{H}_{4} \mathrm{SiO}_{4}{ }^{0}, \mathrm{NO}_{3}{ }^{-}-$ $\mathrm{H}_{4} \mathrm{SiO}_{4}{ }^{0}$, and $\mathrm{OH}^{-}-\mathrm{H}_{4} \mathrm{SiO}_{4}{ }^{0}$ (20). No Pitzer parameters are available for $\mathrm{Na}^{+}-\mathrm{Si}_{4}(\mathrm{OH})_{18}{ }^{2-}$, but the parameters for the $\mathrm{Na}^{+}-\mathrm{HPO}_{4}{ }^{2-}$ interaction were substituted (18), according to the suggestion of Wanner and Forest (21).

Sample solutions from which precipitation had occurred appeared to be in equilibrium with the solid precipitate because ion activity products approached constant values soon after the observed onset of precipitation. Equilibrium constants were calculated from the measured final concentrations of aqueous $\mathrm{Si}$ and $\mathrm{Al}$, and starting concentrations of $\mathrm{NO}_{3}{ }^{-}$and $\mathrm{OH}^{-}$, with respect to the following reaction:

$$
\begin{aligned}
& 8 \mathrm{Na}^{+}+ 6 \mathrm{Al}(\mathrm{OH})_{4}{ }^{-}+6 \mathrm{H}_{2} \mathrm{SiO}_{4}{ }^{2-}+2 \mathrm{NO}_{3}{ }^{-} \leftrightarrow \\
& \mathrm{Na}_{8} \mathrm{Si}_{6} \mathrm{Al}_{6} \mathrm{O}_{24}\left(\mathrm{NO}_{3}\right)_{2} \bullet 4 \mathrm{H}_{2} \mathrm{O}(\mathrm{s})+12 \mathrm{OH}^{-}+8 \mathrm{H}_{2} \mathrm{O}
\end{aligned}
$$

Therefore,

$$
K_{\text {eq }}=\frac{\left\{\mathrm{OH}^{-}\right\}^{12}}{\left\{\mathrm{Na}^{+}\right\}^{8}\left\{\mathrm{Al}(\mathrm{OH})_{4}{ }^{-}\right\}^{6}\left\{\mathrm{H}_{2} \mathrm{SiO}_{4}{ }^{2-}\right\}^{6}\left\{\mathrm{NO}_{3}{ }^{-}\right\}^{2}}
$$

where brackets indicate activities calculated via the Pitzer model described above. Barnes et al. (22) found that the anion present in the cancrinite structure does not strongly affect overall solubility; therefore, $\mathrm{CO}_{3}{ }^{2-}$ was not considered in the cancrinite formula.

The evolution of $\mathrm{Si}$ concentration in experiments with 1.0 $\mathrm{m}$ free $\mathrm{OH}^{-}, 0.01$ or $0.005 \mathrm{~m} \mathrm{Al}\left(\mathrm{NO}_{3}\right)_{3}$, and $2.0 \mathrm{~m} \mathrm{NaNO}_{3}$ was modeled using STELLA 2 (High Performance Systems), a computer program designed to numerically integrate systems of differential equations.

\section{Results and Discussion}

Precipitation from Supersaturated Solutions. When the alkaline solutions contacted the quartz, dissolution proceeded at a rate determined by the solution $\mathrm{pH}$ and $\mathrm{Al}(\mathrm{OH})_{4}^{-}$ concentration (23). Dissolved silica increased until many solutions became supersaturated with respect to an aluminosilicate phase and precipitation occurred. At the onset of precipitation, the silica release rate changed abruptly, and $\mathrm{Al}(\mathrm{OH})_{4}{ }^{-}$concentration simultaneously dropped (Figure 1). 


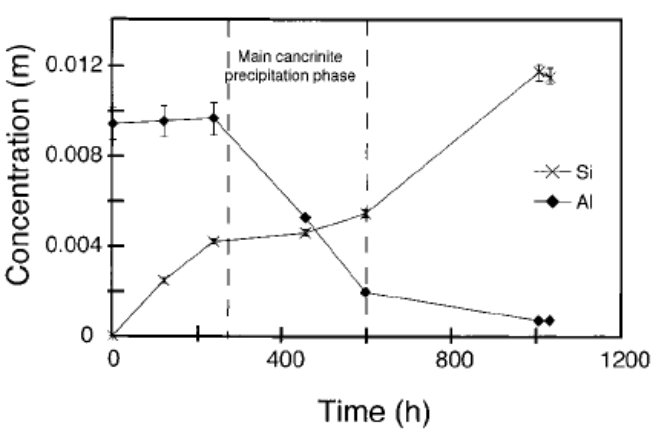

FIGURE 1. Evolution of aqueous Al and Si with time for a $1.0 \mathrm{~m} \mathrm{OH}^{-}$ $3.04 \mathrm{~m} \mathrm{Na}^{+}, 2.03 \mathrm{~m} \mathrm{NO}_{3}{ }^{-}$, and $0.01 \mathrm{~m} \mathrm{Al}(\mathrm{OH})_{4}{ }^{-}$solution in contact with quartz sand.

The precipitate tended to cement the quartz grains together into clumps.

Precipitate Characterization. Precipitates that formed in both the 0.1 and $1.0 \mathrm{~m} \mathrm{OH}^{-}$solutions were identified by $\mathrm{XRD}$ as nitrate-cancrinite, which has an ideal formula of $\mathrm{Na}_{8} \mathrm{Si}_{6} \mathrm{Al}_{6} \mathrm{O}_{24}\left(\mathrm{NO}_{3}\right)_{2} \bullet 4 \mathrm{H}_{2} \mathrm{O}(24,25)$. Cancrinite, a feldspathoid, crystallizes in the space group $P 6_{3}$ with a zeolite-like structure. Its framework is formed of layers of six-membered rings of alternating $\mathrm{SiO}_{4}$ and $\mathrm{AlO}_{4}$ tetrahedra stacked along the $c$-axis in an $\mathrm{AB}-\mathrm{AB}$ sequence (26). Large channels run through the structure and can contain $\mathrm{Na}^{+}$or cations such as $\mathrm{K}^{+}$and $\mathrm{Ca}^{2+}$, along with anions such as $\mathrm{CO}_{3}, \mathrm{OH}^{-}$, and $\mathrm{NO}_{3}{ }^{-}(24-$ 27). Solid solution series are possible between endmember cancrinite compositions with different anions in the channels (e.g. ref 28). Smaller 11-hedral cages in the structure contain $\mathrm{H}_{2} \mathrm{O}$ and cations such as $\mathrm{Na}^{+}(26)$. The ions in the channels appear to be exchangeable, as in zeolites, but stacking faults in the $A B-A B$ sequence can block the channels, which counteracts the zeolitic cation exchange properties of the material (26).

SEM analysis revealed ball-shaped aggregates of precipitate crystals on the quartz surfaces. Precipitate growth proceeded in three main phases: initial nucleation on the quartz surface, growth and aggregation of crystals, and subsequent aggregate growth. The precipitate initially formed in pits or rough areas, rather than on smooth crystal faces of quartz overgrowths present on the sand grains (Figure 2a). The ball-shaped aggregates were able to nucleate on top of each other or grow together laterally (Figure 2b).

In the lower $\mathrm{pH}$ experiments, the precipitate nucleated as a film over a small area of the quartz surface (Figure 3), after which single plate-shaped crystals grew out of the film (Figure 4a). These crystals grew together to form small aggregates (Figure $4 \mathrm{~b}$ ) and eventually the ball-shaped aggregates. Theidentity of both films and crystalline aggregates was confirmed by EDS analysis. In the final stage, the aggregates consisted of plate-shaped crystals intergrown (twinned?) at so many angles that the combined form was nearly spherical (Figure 4c).

In the higher $\mathrm{pH}$ experiments the earliest observed precipitates were tiny aggregates of intergrown crystals, rather than films. Larger, platy, hexagonal crystals grew out of the initial precipitate and then together (Figure 5a). These aggregates were similar to those grown at lower $\mathrm{pH}$, but individual crystals were more well-defined. These were then overgrown by euhedral hexagonal needle-shaped crystals soon after nucleation (Figure 5b). The needle-shaped crystals grew at different rates outward from their axial center, resulting in "cracks" at the edges of the crystals. Smaller needle-shaped crystals grew on the "crack" surfaces and were partially overgrown as the cracks filled in (Figure 5c). This process finally resulted in balls of radiating needle-shaped,
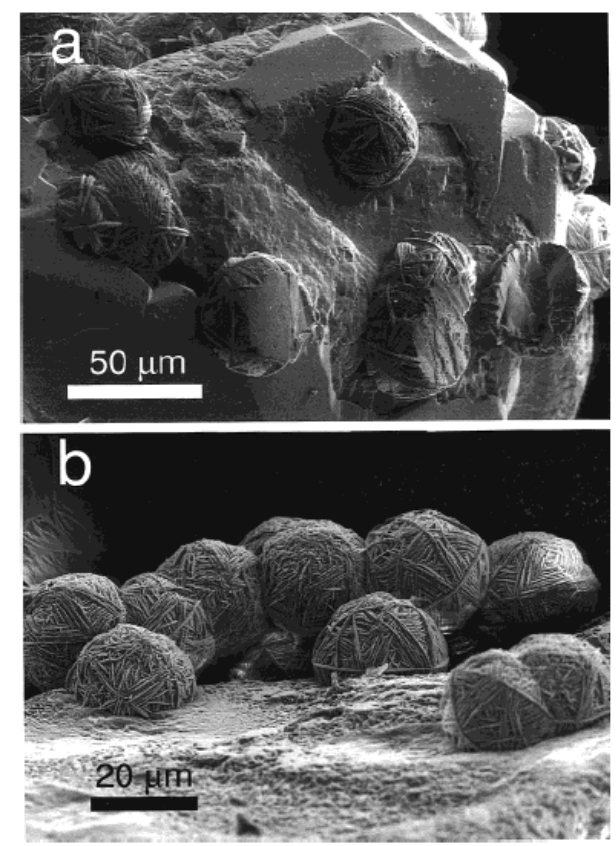

FIGURE 2. (a) FESEM micrograph of nitrate-cancrinite precipitated on quartz sand from a $0.1 \mathrm{~m} \mathrm{OH}^{-}, 2.12 \mathrm{~m} \mathrm{Na}^{+}, 2.015 \mathrm{~m} \mathrm{NO}_{3}^{-}$, and $\mathbf{0 . 0 0 5 ~} \mathrm{m} \mathrm{Al}(\mathrm{OH})_{4}{ }^{-}$solution after $\sim \mathbf{2 4}$ days of reaction. Flat surfaces on some clusters indicate they had grown against another quartz surface. (b) Balls of nitrate-cancrinite precipitate on quartz sand surfaces after $\sim 13$ days from a solution of $0.1 \mathrm{~m} \mathrm{OH}^{-}, 2.14 \mathrm{~m} \mathrm{Na}^{+}$, $2.03 \mathrm{~m} \mathrm{NO}_{3}{ }^{-}$, and $0.01 \mathrm{~m} \mathrm{Al}(\mathrm{OH})_{4}{ }^{-}$. Balls have grown together laterally and vertically.

euhedral crystals, exhibiting hexagonal prism and pyramid forms (Figure 5d).

Elemental maps obtained by EMPA of cross-sections of precipitate spheres grown at the lower $\mathrm{pH}$ show a uniform distribution of $\mathrm{Si}$ and $\mathrm{Al}$ but an enrichment of $\mathrm{Na}$ at the outer rims. The shape of the precipitates in cross-section appeared to be hexagonal, similar to the crystals in the aggregate. Elemental maps of crystal aggregates grown at the higher $\mathrm{pH}$ show Na-depletion in the central mass as compared to the euhedral crystals radiating outward from the edges (Figure 1, Supporting Information). Thus, earlier intergrown masses in precipitates at both $\mathrm{pHs}$ have a different composition than single euhedral crystals. The observed zonation of $\mathrm{Na}^{+}$is consistent with reported chemical formulas for synthesized nitrate-cancrinites, which can deviate from ideal composition with respect to the amount of $\mathrm{Na}^{+}$and $\mathrm{NO}_{3}{ }^{-}$in the zeolitelike channels (25).

Average microprobe analyses of lower and higher $\mathrm{pH}$ precipitates showed no significant compositional difference between the two and a large deficiency in Na (Table 2, Supporting Information). Some of this apparent deficiency may be real, due to the Na-poor intergrown masses. However, some is likely due to rapid volatilization of $\mathrm{Na}$ from the zeolitelike channels, even though a 1 s collection time was used. Time-series analyses for Na exhibited an exponential decrease. It was not possible to extrapolate $\mathrm{Na}$ content to zero time, so it was necessary to choose a short, but arbitrarily determined, collection time. Measurements of Na content for $5 \mathrm{~s}$ indicated that the high $\mathrm{pH}$ precipitates lost $\mathrm{Na}$ at about twice the mean rate of the low $\mathrm{pH}$ precipitates, and a two-sample $t$-test assuming unequal variances showed the measurement populations to be statistically distinct at the $99.9 \%$ confidence level. Although $\mathrm{NO}_{3}{ }^{-}$resides in the cancrinite channels with $\mathrm{Na}^{+}, \mathrm{N}$ did not volatilize significantly 


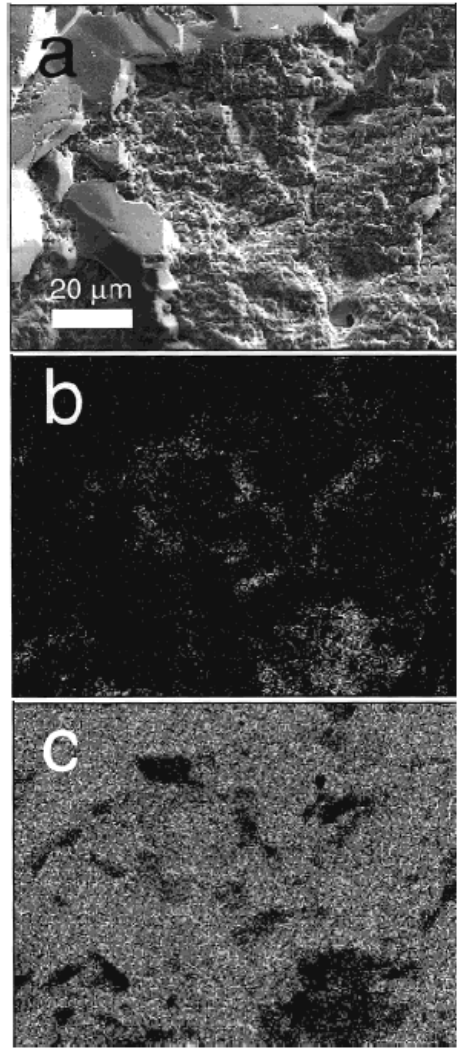

FIGURE 3. FESEM micrograph and elemental maps of a quartz surface on which films of cancrinite have precipitated in and around pits or depressions: (a) FESEM micrograph, (b) AI map with bright areas indicating high concentrations, and (c) Si map.

during analysis. The compositions reported in Table 2, Supporting Information indicate an excess of $\mathrm{N}$ relative to the ideal formula, which can be attributed to inherent difficulties in microprobe analysis of $\mathrm{N}$.

Nitrate-Cancrinite Solubility. Equilibrium constants (the inverse of the $K_{\mathrm{sp}}$ ) calculated with eq 2 for $1.0 \mathrm{~m} \mathrm{OH}^{-}$solutions are consistently higher than those calculated for $0.1 \mathrm{~m} \mathrm{OH}^{-}$ solutions, with the mean value of $\log K_{\text {eq }}$ for the higher $\mathrm{OH}^{-}$ concentration equal to $36.2 \pm 0.6$ and that for the lower $\mathrm{OH}^{-}$ concentration equal to $30.4 \pm 0.8$ (95\% confidence interval). A two-sample $t$-test assuming unequal variances showed the two mean $\log K_{\text {eq }}$ values to be statistically distinct at the $99.9 \%$ confidence level. Calculation of the log Ion Activity Product (IAP) for the solutions at the point when precipitation was estimated to have started yielded values of $34.9 \pm 1.9$ $(\log \mathrm{SI}=1.3)$ and $28.7 \pm 1.3(\log \mathrm{SI}=1.7)$ for the higher and lower $\mathrm{pH}$ solutions, respectively (see Table 3 , Supporting Information). Two-sample $t$-tests showed the log IAP values to be lower than the calculated $\log K_{\text {eq }}$ values at the $90 \%$ confidence level.

Reasons for the difference in calculated $K_{\text {eq }}$ values include possible errors in the thermodynamic database resulting in incorrect speciation or actual differences in the two precipitates. For instance, a few workers (e.g., ref 29) reported third and fourth ionization constants for monomeric silica, which we did not include in our solution model. However, the discrepancy in calculated $K_{\text {eq }}$ values is only exacerbated if $\mathrm{HSiO}_{4}{ }^{3-}$ or $\mathrm{SiO}_{4}{ }^{4-}$ is the dominant silica species in these solutions, rather than $\mathrm{H}_{2} \mathrm{SiO}_{4}{ }^{2-}$. On the other hand, if $\mathrm{H}_{3} \mathrm{SiO}_{4}{ }^{-}$ is dominant, the calculated equilibrium constants for the solutions with different concentrations of free $\mathrm{OH}^{-}$are
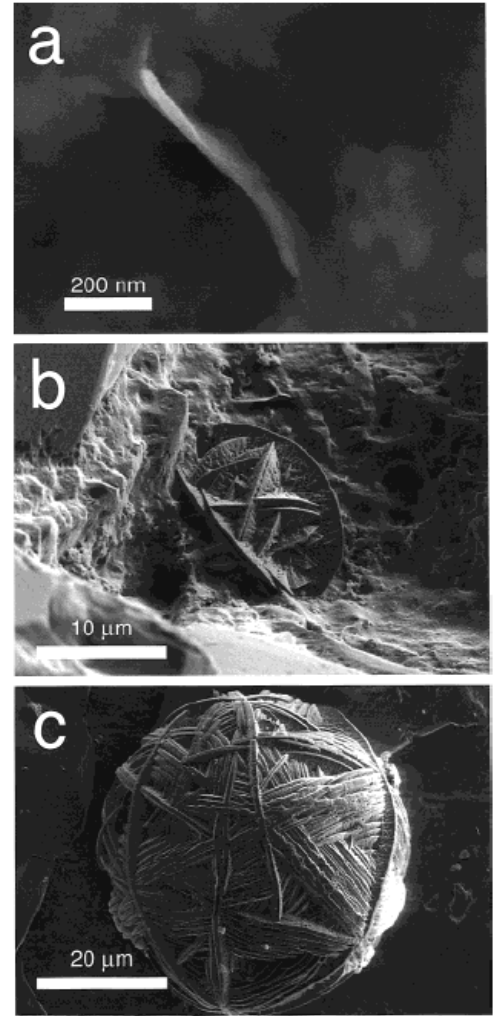

FIGURE 4. FESEM micrographs of nitrate-cancrinite precipitated from $0.1 \mathrm{~m} \mathrm{OH}^{-}$solutions, showing various reaction stages: (a) a platy crystal grown outward from a precipitate film, (b) twinning of platy crystals creates an initial precipitate aggregate, and (c) a precipitate ball at a late reaction stage, exhibiting intergrown platy crystals, some with a crude hexagonal outline.
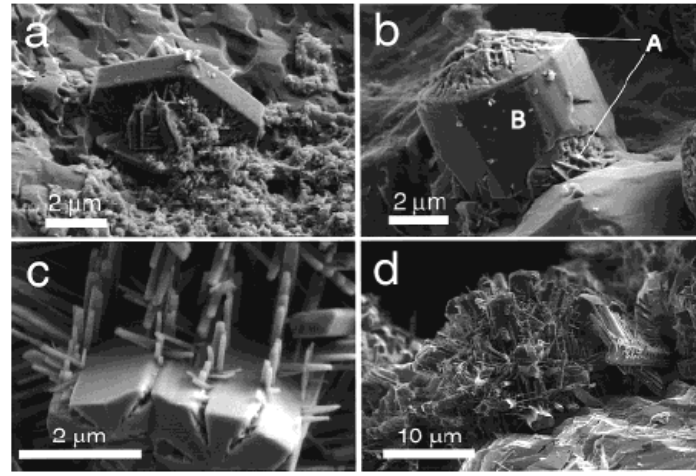

FIGURE 5. FESEM micrographs of nitrate-cancrinite precipitated from $1.0 \mathrm{~m} \mathrm{OH}^{-}$solutions, showing various stages of the reaction. (a) Initially, tiny intergrown crystallites cover part of the quartz surface, after which larger, hexagonal platelets grow from the initial precipitate and form twinned aggregates. (b) Just after initial precipitation, intergrown plates $(" A$ ") are overgrown by single hexagonal needle-shaped crystals ("B"). (c) Smaller needle-shaped crystals grow on "cracks" in the larger crystals and then are partially overgrown as precipitation proceeds. (d) Final products are balls of radiating euhedral, hexagonal, needle-shaped crystals.

indistinguishable. Speciation of our solution compositions using the recent Pitzer model of Felmy et al. (30) showed that $\mathrm{H}_{2} \mathrm{SiO}_{4}{ }^{2-}$ is dominant at $25^{\circ} \mathrm{C}$. Deprotonation constants for the monomeric $\mathrm{Si}$ species shift to lower $\mathrm{pH}$ with increasing 
temperature (16); therefore, we are reasonably certain that $\mathrm{H}_{2} \mathrm{SiO}_{4}{ }^{2-}$ dominates at $89^{\circ} \mathrm{C}$, also.

NMR studies have shown that various aluminosilicate species exist in alkaline $\mathrm{Al}$ - and Si-bearing solutions (e.g. refs 31-33) but are probably metastable (33). However, Gout et al. (34) recently used Raman spectroscopy to show that in solutions similar to ours, a significant proportion of $\mathrm{Si}$ in solution is complexed with $\mathrm{Al}$ at $20^{\circ} \mathrm{C}$. We did not find any applicable thermodynamic data for aluminosilicate species and therefore assumed that the activities of $\mathrm{Al}(\mathrm{OH})_{4}{ }^{-}$and $\mathrm{H}_{2} \mathrm{SiO}_{4}{ }^{2-}$ did not deviate significantly from their calculated values. However, this may be an incorrect assumption, and aluminosilicate speciation remains a pressing problem for zeolite synthesis studies, as well as for modeling high-pH nuclear waste solutions containing dissolved $\mathrm{Si}$ and $\mathrm{Al}$. It should also be noted that aluminosilicate species are thought to be precursors to the formation of zeolites in industrial synthesis (35), and therefore may play a significant role in the precipitation process, even at low concentrations.

The most plausible explanation for the difference in apparent $K_{\mathrm{eq}}$ values appears to be actual differences in the precipitated phases. The relative enrichment of $\mathrm{Na}$ at the edges of the precipitate aggregates, where euhedral crystals dominate, suggests a compositional difference between the well-formed crystals and the aggregate masses. FESEM micrographs of the precipitates (Figures 4 and 5) clearly show differences in crystal form, and the higher $\mathrm{pH}$ precipitates appear to have a more well-formed crystal habit, suggesting a greater degree of crystallinity.

Microprobe analyses of Na support a difference in crystallinity, related to stacking fault density. The Na in the precipitate formed at higher $\mathrm{pH}$ volatilized more quickly than that in the lower $\mathrm{pH}$ precipitate. Given that stacking faults block zeolitic channels in the cancrinite structure (26), a ready explanation for this volatilization phenomenon is apparent. The higher calculated $K_{\mathrm{eq}}$ at the higher $\mathrm{pH}$ (corresponding to a lower solubility product) is consistent with that expected for a more perfect crystalline structure.

Precipitation Kinetics. Estimates of initial cancrinite precipitation rates were obtained from the evolution of $\mathrm{Al}$ concentration in the experimental solutions. The precipitation rate did not correlate significantly with the $\mathrm{Na}^{+}, \mathrm{NO}_{3}{ }^{-}$, or $\mathrm{OH}^{-}$concentrations or quartz surface area. However, the precipitation rate (mol cancrinite/s) did correlate with the total concentration of $\mathrm{Al}$ and $\mathrm{Si}$ at the onset of precipitation (Figure 2, Supporting Information; cf. Table 3, Supporting Information). Using the equation

rate $(\mathrm{mol}$ cancrinite $/ \mathrm{s})=$

$$
1.03 \pm 0.05 \times 10^{-6}[\mathrm{Al}]^{1.22 \pm 0.00}[\mathrm{Si}]^{0.23 \pm 0.00}
$$

most of the estimated rates were calculated to within $\pm 20 \%$ (Figure 2, Supporting Information; cf. Table 3, Supporting Information). (Rates are normalized to a $1 \mathrm{~kg} \mathrm{H}_{2} \mathrm{O}$ solution.) This formulation is consistent with the hypothesis that $\mathrm{Na}^{+}$, $\mathrm{NO}_{3}{ }^{-}$, and $\mathrm{OH}^{-}$are in excess and therefore do not control precipitation rate. The rate may depend less strongly on [Si] because it is locally higher in concentration near the dissolving quartz surface.

The evolution of Si concentration in the experiment with $1.0 \mathrm{~m} \mathrm{OH}^{-}, 3.04 \mathrm{~m} \mathrm{Na}^{+}, 2.03 \mathrm{~m} \mathrm{NO}_{3}{ }^{-}$, and $0.01 \mathrm{~m} \mathrm{Al}^{-}(\mathrm{OH})_{4}{ }^{-}$ was modeled, taking into account the dependence of quartz dissolution rate on $\mathrm{Al}(\mathrm{OH})_{4}{ }^{-}$concentration (Table 4, Supporting Information) (23), the stoichiometric precipitation of $\mathrm{Si}$ and $\mathrm{Al}$ in cancrinite, and the masking of reactive quartz surface area by the precipitated cancrinite. Image analysis of reacted sand grains indicated that the average surface coverage reached $\sim 33 \%$. Evolution of the cancrinite coverage was assumed to be inversely proportional to the evolution of $\mathrm{Al}(\mathrm{OH})_{4}{ }^{-}$concentration. This same model also was applied

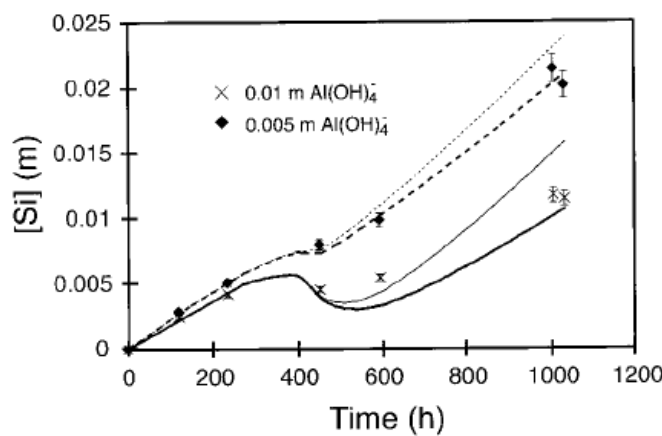

FIGURE 6. Si concentrations with time for experiments with $1.0 \mathrm{~m}$ $\mathrm{OH}^{-}, 3.04 \mathrm{~m} \mathrm{Na}^{+}, 2.03 \mathrm{~m} \mathrm{NO}_{3}^{-}$, and $0.01 \mathrm{~m} \mathrm{Al}^{-}(\mathrm{OH})_{4}^{-}$(crosses), and $1.0 \mathrm{~m} \mathrm{OH}^{-}, 3.02 \mathrm{~m} \mathrm{Na}^{+}, 2.015 \mathrm{~m} \mathrm{NO}_{3}^{-}$, and $0.005 \mathrm{~m} \mathrm{Al}^{-}(\mathrm{OH})_{4}{ }^{-}$(diamonds). Evolution of [Si] with time modeled with (solid lines) and without (dashed lines) reduced quartz dissolution rate due to increasing surface coverage by cancrinite.

to an experiment with $1.0 \mathrm{~m} \mathrm{OH}^{-}, 3.02 \mathrm{~m} \mathrm{Na}^{+}, 2.015 \mathrm{~m} \mathrm{NO}_{3}{ }^{-}$, $0.005 \mathrm{~m} \mathrm{Al}(\mathrm{OH})_{4}{ }^{-}$, and a final mean surface coverage of $\sim 32 \%$. The rate of Si release during both experiments is predicted well (Figure 6), although it is not clear how important it is to consider the reduction in quartz dissolution rate due to surface coverage by cancrinite.

Implications for Radionuclide Mobility in the Hanford Subsurface. Recently, it was reported that ${ }^{137} \mathrm{Cs}$ was associated with frayed edges on micas at depths of $40-47 \mathrm{~m}$ in a well drilled through a contaminant plume between leaking tanks at the SX Tank Farm (36). If nitrate-cancrinites precipitated from interaction of leaked nuclear waste fluids with Hanford sediments closer to the undersides of the tanks, radionuclide mobility could have been affected in other ways. For example, precipitates could have cemented sand grains together, decreasing porosity and permeability and altering the flow pathway of subsequent leaked fluids. Synthesized cancrinites can contain Cs in 11-hedral cages, where it is not exchangeable $(37,38)$. The ability of the cancrinite phase to retard radionuclide migration may depend strongly on the prevalence of stacking defects, which decrease the zeolitic exchange capacity. It has been shown here that the apparent stability of nitrate-cancrinite precipitates depends on the solution conditions. Further study of the kinetics and thermodynamics of nitrate-cancrinite precipitation is necessary to predict accurately both the magnitude and nature of its formation in the Hanford subsurface as well as its effects on radionuclide mobility. Such work is also important because cancrinite recently has been shown to be a secondary alteration product of CST (crystalline silicotitanite) materials proposed for use as ion exchangers that would remove $\mathrm{Cs}^{+}$from high level waste streams at the DOE's Savannah River Site (39).

\section{Acknowledgments}

The U.S. Department of Energy Environmental Management Science Program provided support under grant DE-FG0799ER 15009 to K. Nagy and contract DE-AC06-76RLO 1830 to J. Serne and S. Yabusaki at Pacific Northwest National Laboratory (PNNL). We thank the W.R. Wiley Environmental Molecular Sciences Laboratory for analytical time granted in response to a user proposal. We also thank A. Gray and P. Sandlin for their laboratory work, and A. Felmy for running our solution compositions in his Pitzer model and advice on modeling Si speciation.

\section{Supporting Information Available}

Table 1 (solution conditions in precipitation experiments with time), Table 2 (microprobe analyses on nitrate-cancrinite 
precipitates), Table 3 (solution conditions at the estimated onset of precipitation), Table 4 (quart dissolution rates), Figure 1 (microprobe elemental maps for a cross-section of a nitrate-cancrinite precipitate ball), and Figure 2 (calculated rate of nitrate-cancrinite precipitation vs measured rate at the onset of precipitation). This material is available free of charge via the Internet at http://pubs.acs.org.

\section{Literature Cited}

(1) Gephart, R. E.; Lundgren, R. E. Hanford Tank Cleanup; Battelle: Columbus, $\mathrm{OH}, 1998$.

(2) Serne, R. J.:Conca, J.L.:LeGore, V. L.:Cantrell, K. J.:Lindenmeier, C. W.; Campbell, J. A.; Amonette, J. E.; Wood, M. I. Solid-waste leach characteristics and contaminant-sediment interactions. Volume 1: Batch leach and adsorption tests and sediment characterization; PNL-8889; Pacific Northwest National Laboratory: Richland, WA, 1993

(3) Dove, P. M. In Reviews in Mineralogy, White, A. F., Brantley, S. L., Eds.: Mineral Society of America: Washington, DC, 1995; Vol. 31, pp 235-290.

(4) Blum, A. E.; Stillings, L. L. In Reviews in Mineralogy; White, A. F., Brantley, S. L., Eds.; Mineral Society of America: Washington, DC, 1995; Vol. 31, pp 291-351.

(5) Nagy, K. L. In Reviews in Mineralogy; White, A. F., Brantley, S. L., Eds.; Mineral Society of America: Washington, DC, 1995; Vol. 31, pp 173-233.

(6) Brantley, S. L.; Chen, Y. In Reviews in Mineralogy; White, A. F., Brantley, S. L., Eds.; Mineral Society of America: Washington, DC, 1995; Vol. 31, pp 119-172.

(7) Nyman, M.; Krumhansl, J. L.; Zhang, P.; Anderson, H.; Nenoff, T. M. Mater. Res. Soc. Symp. Proc. 2000, 608, 225-230.

(8) Koroleff, F. In Methods of Seawater Analysis, 2nd ed.; Grasshoff, K., Ehrhardt, M., Kremling, K., Eds.; Verlag Chemie: New York, 1983; pp 174-183.

(9) Dougan, W. K.; Wilson, A. L. Analyst 1974, 99, 413-430.

(10) McMillan, G. K. Chem. Eng. Prog. 1991, 87(10), 33-37.

(11) McMillan, G. K. Intech 1993, 40(2), 35-39.

(12) Bates, R. G. Determination of $p H$; Wiley: New York, 1964.

(13) Stumm, W.; Morgan, J. J. Aquatic Chemistry, 3rd ed.; Wiley: New York, 1996.

(14) Bethke, C. M. The Geochemist's Workbench, Release 3.0; University of Illinois at Urbana-Champaign; 1998

(15) Wesolowski, D. J. Geochim. Cosmochim. Acta 1992, 56, 10651091.

(16) Busey, R. H.; Mesmer, R. E. Inorg. Chem. 1977, 16, 2444-2450.

(17) Sjöberg, S.; Öhmann, L. O.; Ingri, N. Acta Chem. Scand. A, Phys., Inorg. Chem. 1985, 39, 93-107.

(18) Pitzer, K. S. In Activity Coefficients in Electrolyte Solutions, 2nd ed.; Pitzer, K. S., Ed.; CRC: Boca Raton, FL, 1991; pp 435-490.
(19) Hershey, J. P.; Millero, F. J. Marine Chem. 1986, 18, 101-105

(20) Azaroual, M.; Fouillac, C.; Matray, J. M. Chem. Geol. 1997, 140, 155-165.

(21) Chemical Thermodynamics of Uranium; Wanner, H., Forest, I., Eds.; North-Holland: Amsterdam, 1992.

(22) Barnes, M. C.; Addai-Mensah, J.; Gerson, A. R. Colloids Surf. A 1999, 157, 101-116.

(23) Bickmore, B. R.; Nagy, K. L.; Gray, A. K.; Moschetti, M. Eleventh Annual V. M. Goldschmidt Conference; Abstract \#3296, LPI Contribution No. 1088, Lunar and Planetary Institute: Houston (CD-ROM).

(24) Hund, F. Z. Anorg. Allg. Chem. 1984, 509, 153-160.

(25) Buhl, J.-C.; Stief, F.; Fechtelkord, M.; Gesing, T. M.; Taphorn, U.; Taake, C. J. Alloy. Compd. 2000, 305, 93-102.

(26) Hackbarth, K.; Gesing, Th. M.; Fechtelkord, M.; Stief, F.; Buhl, J.-Ch. Micropor. Mesopor. Mater. 1999, 30, 347-358.

(27) Hassan, I.; Grundy, H. D. Can. Mineral. 1991, 29, 377-383.

(28) Hassan, I.; Grundy, H. D. Can. Mineral. 1984, 22, 333-340.

(29) Babushkin, V. I.; Matveyev, G. M.; Mchedlov-Petrossyan, O. P. Thermodynamics of Silicates, Springer-Verlag: New York, 1985

(30) Felmy, A. R.; Cho, H.; Rustad, J. R.; Mason, M. J. J. Sol. Chem. 2001, 30, 509-525.

(31) McCormick, A. V.; Bell, A. T.; Radke, C. J. J. Phys. Chem. 1989, 93, 1741-1744.

(32) Harris, R. K.; Samadi-Maybodi, A.; Smith, W. Zeolites 1997, 19 , 147-155.

(33) North, M. R.; Swaddle, T. Inorg. Chem. 2000, 39, 2661-2665

(34) Gout, R.; Pokrovski, G. S.; Schott, J.; Zwick, A. J. Sol. Chem. 2000, $29,1173-1186$

(35) McCormick, A. V.; Bell, A. T. Catal. Rev., Sci. Eng. 1989, 31, 97-127.

(36) McKinley J. P.; Zeissler C. J.; Zachara J. M.; Serne R. J.; Lindstrom R. M.; Schaef H. T.; Orr R. D. Environ. Sci. Technol. 2001, 35 , 3433-3441.

(37) Norby, P.; Krogh Andersen, I. G.; Krogh Andersen, E.; Colella, C.; de'Gennaro, M. Zeolites 1991, 11, 248-253.

(38) Colella, C.; de'Gennaro, M. In Zeolite Synthesis, Occelli, M. L., Robson, H. E., Eds.; ACS Symposium Series Vol. 398; American Chemical Society: Washington, DC, 1989; pp 196-208.

(39) Steele, W. F.; Weber, C. F.; Bostick, D. A. Waste and simulant precipitation issues; ORNL/TM-2000/348; Oak Ridge National Laboratory: Oak Ridge, TN, 2001.

Received for review April 4, 2001. Revised manuscript received August 23, 2001. Accepted August 27, 2001.

ES0108234 


\title{
Quantifying surface areas of clays by atomic force microscopy
}

\author{
Barry R. Bickmore, * Kathryn L. Nagy, Paul E. Sandlin, and Terry S. Crater
}

\author{
Department of Geological Sciences, University of Colorado at Boulder, Boulder, Colorado 80309-0399, U.S.A.
}

\begin{abstract}
Rapid and accurate determination of the surface area of three kaolinite clay standards, taking into account the complex microtopography of the particles, was achieved using atomic force microscopy images and computerized image analysis. All surface areas were determined to within $3 \%$. Edge surface area is $18.2-30.0 \%$ of the total surface area depending on the particular kaolinite standard. Specific surface areas agree to within $4 \%$ of published values determined by the BET method. The approach can be applied to clay and nanoparticle samples too small in quantity for BET analysis, since it requires $\sim 11$ orders of magnitude less material.
\end{abstract}

\section{INTRODUCTION}

One important application of atomic force microscopy (AFM) in mineralogy has been to quantify dimensions of distinct faces on finely divided crystallites or nanoparticles and relate these to chemical reactivity measured by other techniques such as sorption isotherms, reaction rate experiments, or EXAFS spectroscopy (e.g., Nagy 1994; Brady et al. 1996; Nagy et al. 1999; Sutheimer et al. 1999; Schlegel et al. 1999; Manceau et al. 2000). Such measurements are significant when the types and abundance of surface functional groups on faces of a single grain vary widely. Phyllosilicate surfaces offer a prime example of this phenomenon because of the extreme anisotropy of their crystal structures, in which the dominant basal (001) surfaces are generally characterized by siloxane or hydroxyl groups that are charge-satisfied (except where isomorphous substitution has occurred), and particle edges are dominated by charge-unsatisfied broken bonds. Kaolinite is a common phyllosilicate clay mineral that is a component of many industrial products, can control porosity and permeability of sedimentary rocks, and can sorb contaminants and nutrients in soils. Uncertainty over the magnitude of the ratio of edge surface area (ESA) to total surface area (TSA) has in part led to significantly differing conclusions about the relative reactivity of kaolinite edge and basal surfaces (e.g., Zhou and Gunter 1992; Brady et al. 1996; Ma and Eggleton 1999).

AFM images should be routinely useful for vertical measurements at the angstrom-scale and lateral measurements at the nanoscale. However, many researchers have pointed out that tip-sample convolution can result in errors in quantifying crystallite dimensions (e.g., Blum 1994; Maurice 1996). Despite recognition of this imaging artifact, such corrections are rarely, if ever, applied. For example, Dias et al. (1997) calculated the surface area of approximately spherical MnZn ferrite particles using AFM to measure the "average diameter" (10$40 \mathrm{~nm}$ ). The surface areas were $17-22 \%$ lower than those obtained by BET (Brunauer et al. 1938) and the difference was

* Present address: Department of Geology, Brigham Young University, S389 ESC, P.O. Box 24606, Provo, Utah 846024606. E-mail: brb88@geology.byu.edu

0003-004X/02/0506-780\$05.00 attributed to tip-sample convolution. Also, a rigorous approach for selecting the number of particles needed for accurate quantitative analysis of a bulk sample has not yet been determined.

We report a method of obtaining and processing AFM images that allows rapid accurate measurement of the edge (ESA), total (TSA), and specific surface (SSA) areas for three kaolinite standards. Tip/sample artifacts are quantitatively considered, and the number of particles necessary for statistically significant quantitative measurements is determined. Measuring the SSA of a clay or other powder sample based on AFM imaging of a small number of particles should prove valuable, especially in cases where small sample size precludes applying the BET method. For example, atmospheric dust, microbiological mineral products, or synthetic nanocrystals could be characterized in this way.

\section{MATERIALS AND METHODS}

Standards KGa-1, KGa-1b, and KGa-2 were obtained from the Source Clays Repository of the Clay Minerals Society. KGa1 and $\mathrm{KGa}-1 \mathrm{~b}$ are low-defect kaolinites from Washington County, Georgia, and $\mathrm{KGa}-2$ is a high-defect kaolinite from Warren County, Georgia. Data on these clay standards can be found in van Olphen and Fripiat (1979) and Costanzo and Guggenheim (2001).

The key to obtaining a statistically valid sampling of particles is to disperse the clay well on the substrate. Dispersion was achieved by mixing a drop of $0.2 \mathrm{MNaOH}$ into $3 \mathrm{~mL}$ deionized water, and adding $\sim 0.1-0.2 \mathrm{mg}$ kaolinite. A substrate of freshly cleaved muscovite was attached to a steel sample disk and heated on a hotplate while dispersing the suspension ultrasonically for 2 minutes. A drop of suspension was placed onto the heated disk and flash-boiled immediately after ultrasonification. This procedure separated particles typically by several micrometers.

A Digital Instruments Multimode AFM was operated in tapping mode using etched silicon probes. Height images were used for dimensional analysis, while amplitude images were used to verify the sharpness and accuracy of the height images. Areas of $100-400 \mu \mathrm{m}^{2}$ were imaged randomly, and each particle in that area was imaged individually at higher resolution. 
A few particles obviously tilted with respect to the substrate were excluded from subsequent analysis. Random variations in baseline height were removed from height images by applying a second-order "flattening" routine, with corrections based only on areas of exposed mica substrate. Six passes of a $5 \times 5$ median filter removed random noise without broadening edge features in the image, as occurs with lowpass (neighborhood averaging) filters (Russ 1990) (Fig. 1).

Edge-broadening due to tip-sample convolution can be significant when imaging relatively tall features like kaolinite particles, but can be minimized by using a relatively sharp tip such as an etched silicon probe. Another method for minimizing edge-broadening is to deconvolute the shape of the tip from the image. The program Deconvo 1.1 (Silicon-MDT) was used to reconstruct tip shape using the "blind reconstruction" algorithm of Villarrubia (1997). For each set of images taken with the same tip, tip shape was reconstructed from the image with the tallest features, which give the best approximation of tip shape, and then deconvoluted from the entire set of filtered images. The blind reconstruction method calculates an outer bound for the tip shape, and is preferable to methods employing a model tip. However, the reconstruction is sometimes inappropriately scaled for certain image features, causing unrealistic erosion of an image upon deconvolution. For instance, small hexagonal steps might be eroded to spikes if the radius of curvature of the reconstructed tip is large relative to the step height.

Deconvolution was applied successfully to KGa-1 and KGa$1 \mathrm{~b}$ images, and tests on $\mathrm{KGa}-1 \mathrm{~b}$ particles showed that ESA/ TSA and SSA changed by only $\sim 3 \%$ overall. Ideally, deconvolution should have less of an effect for the KGa-2 standard because its average particle has a smaller height to width ratio; however, unreasonable erosion of these images resulted. Therefore, KGa-2 images were not corrected for tip shape. As long as a sharp tip is used, tip-sample convolution is not a criti$\mathrm{cal}$ issue for the measurements made on these particles.

Image analysis was performed using Image SXM (Barrett 1997). This environment allows the user to define a region of interest (ROI) of any shape and exclude unwanted features from calculations or operations performed on the ROI. Pascal-like macros can be created to perform pixel-by-pixel or line-byline operations, and mathematical calculations (Barrett et al. 1998; Bickmore et al. 1999). We customized the computational analysis for particles with a platy habit, but algorithms specific to other morphologies could be programmed easily.

After selecting a ROI outlining a kaolinite particle, the basal surface area (BSA) was measured using macro code modified from that described in Bickmore et al. (1999). Briefly, the procedure employs a "chain code" algorithm and pixel counting (Russ 1990) to calculate the perimeter and area of horizontal slices of the particle at each gray level. The derivative of the perimeter vs. gray level (height) curve was used to distinguish sidewalls and terraces. The height for the BSA measurement was chosen just below the lowest terrace on the particle (Russ 1990; Bickmore et al. 1999), and BSA is defined as twice the measured horizontal area at that height.

To measure ESA, a baseline height was first defined using a gray level histogram of the image. Then, the particle's perim-
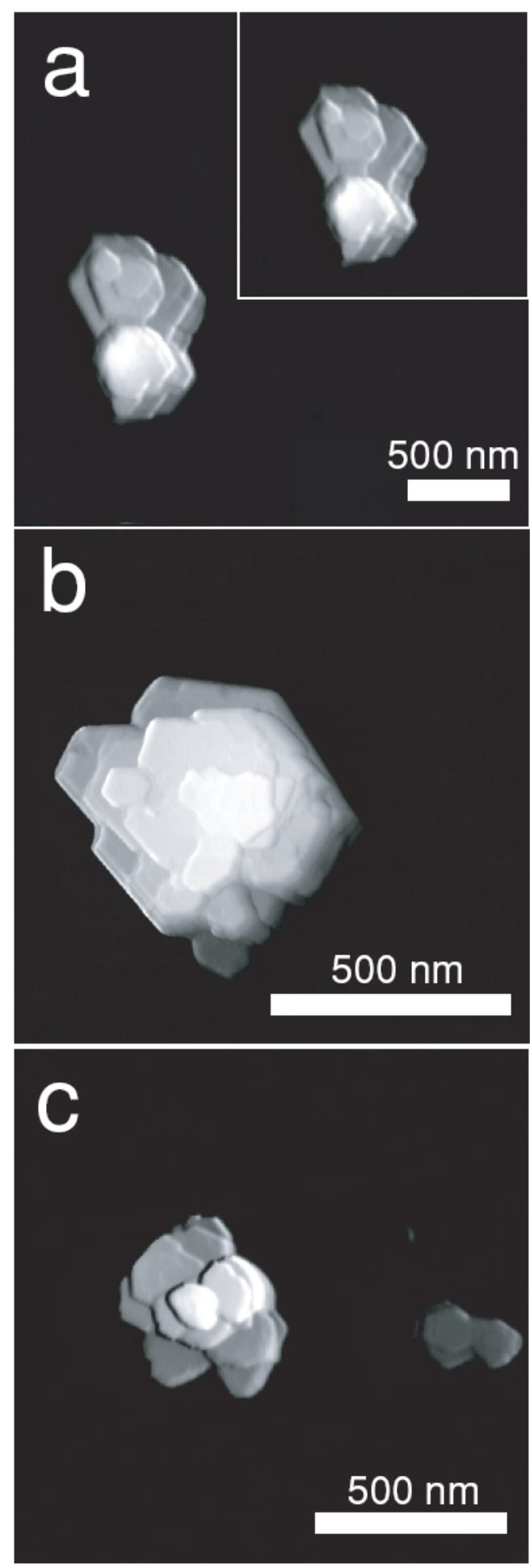

FigURE 1. AFM height images that have been subjected to a shadowing routine to make topographical details apparent. (a) KGa-1 particle, maximum height $=218 \mathrm{~nm}$. Lower left: convoluted image. Upper right: deconvoluted image. (b) $\mathrm{KGa}-1 \mathrm{~b}$ particle, maximum height $=76 \mathrm{~nm}$. (c) KGa-2 particles, maximum height $=145 \mathrm{~nm}$. 
eter at each gray level above the baseline was determined, and multiplied by the height of one gray level. This effectively yields ESA values for horizontal slices, which when summed, yield the total ESA. TSA equals BSA plus ESA.

Particle volumes were determined using the defined baseline height. The average pixel height relative to the baseline was multiplied by the area of the ROI (Russ 1995). This method implicitly assumes image noise is distributed symmetrically about the true height values.

One limitation of AFM imaging is that the topography of only a particle top can be measured; the bottom is assumed to lie flat on the substrate. However, kaolinite surfaces often exhibit complex microtopography, and it is reasonable to imagine similar complexity for the hidden undersides. If so, the algorithms could either overestimate or underestimate ESA, and overestimate particle volume. Therefore, a correction was applied to these calculations.

The ESA for the top half of the particle was measured by summing the ESA of "slices" one pixel in height; the volume of these slices was also calculated and summed by multiplying the horizontal area of the slices by the height of one gray level. Correction of ESA and particle volume assumes the bottom half of each particle is a mirror image of the top. While this is untrue for any single particle, on average it is a reasonable approximation.

Particle volumes and the density of kaolinite $\left(2.62 \mathrm{~g} / \mathrm{cm}^{3}\right)$ were used along with calculated TSA values to calculate specific surface areas (SSA) for comparison with reported BET SSA's. To properly weight measured values for each particle, running totals of ESA, TSA, and volume were recorded as successive particles in a sample were measured. Cumulative ESA/ TSA ratios and SSA values were calculated using these sums. Particles were imaged and analyzed until the cumulative values settled into a range having $\sim 5 \%$ relative variation. Measurements of large particles had little effect on cumulative values. Excluding the particle bottom correction, these methods were tested on "synthetic" images of shapes with known geometry (Bickmore et al. 1999) and on images of kaolinite particles with simple geometry. Measured values of ESA, TSA, and particle volume consistently fell within $\sim 5 \%$ of expected values for synthetic images, and $\sim 12 \%$ for images of kaolinite particles. The larger discrepancy for the kaolinite particles shows the importance of even a small amount of microtopography.

\section{RESULTS AND DISCUSSION}

Corrected ESA/TSA and SSA values indicate that the lowdefect kaolinite has an ESA/TSA ratio 1.5-1.6 times greater than that of the high-defect kaolinite, although the high-defect kaolinite has the greater SSA (Table 1). ESA/TSA ratios and SSA values for individual particles (Fig. 2) show lognormal distributions. KGa-1 and $\mathrm{KGa}-1 \mathrm{~b}$ have similar distributions, and $\mathrm{KGa}-2$ has a distribution skewed toward lower ESA/TSA and higher SSA. These observations are consistent with the idea that high-defect kaolinite represents a material with a higher density of nucleation and growth sites, and hence smaller average particle size, whereas low-defect kaolinite likely grew more slowly from fewer nucleation sites and resulted in a larger average particle size. Slower growth rates also compatible with thicker particles in the $\mathrm{c}^{*}$ direction for $\mathrm{KGa}-1$, indicating that the basal surfaces had more time to advance.

Applying the particle bottom correction led to SSA values that agreed to within $4 \%$ with at least one published SSA value determined by the BET method for each kaolinite (Table 2). The error in the AFM measurements is estimated to be $<3 \%$ (or $1 / 2$ of the $\sim 5 \%$ variability attained in the cumulative totals), much less than the $10 \%$ error typically assigned to a BET measurement. Therefore, the excellent agreement with published BET SSAs validates use of the AFM analysis for this
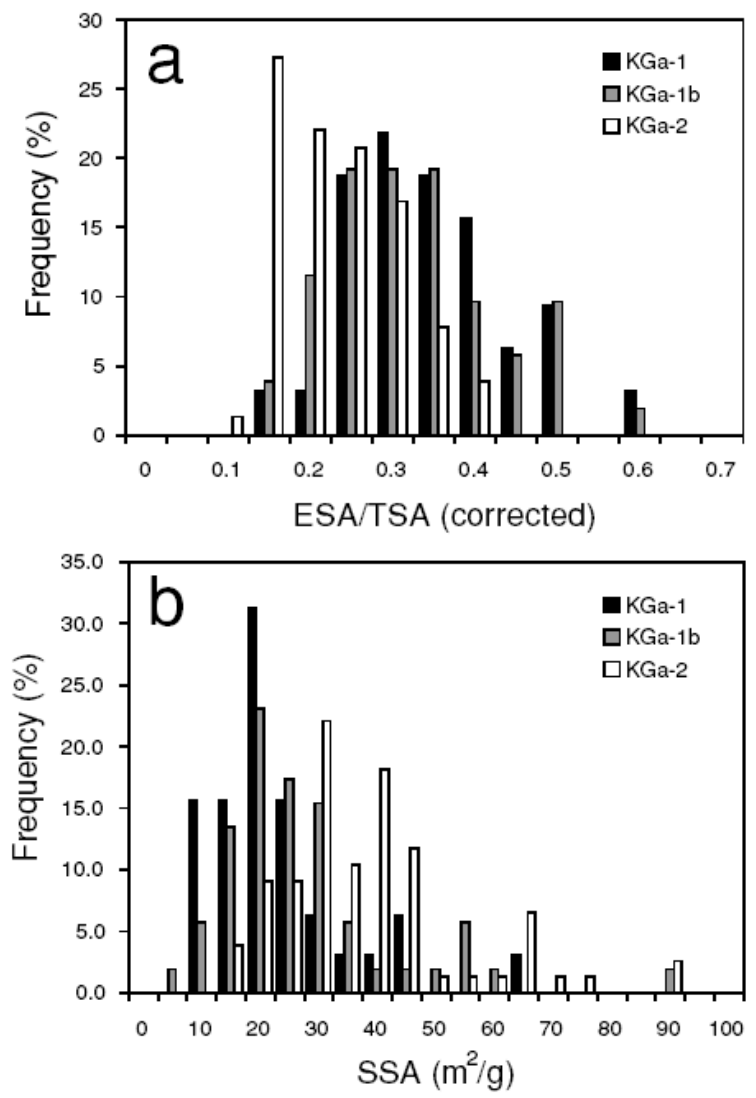

FigURE 2. Frequency histograms for corrected (a) ESA/TSA ratios, and (b) SSA measurements of single kaolinite particles in all three samples.

TABLE 1. Cumulative values of ESATTSA and SSA with and without particle bottom correction

\begin{tabular}{|c|c|c|c|c|c|c|}
\hline Sample & No. particles & $\begin{array}{c}\text { Mass }(g) \\
\text { (corrected) }\end{array}$ & $\begin{array}{c}\text { ESA/TSA\% } \\
\text { (uncorrected) }\end{array}$ & $\begin{array}{l}\text { ESA/TSA\% } \\
\text { (corrected) }\end{array}$ & $\begin{array}{c}\mathrm{SSA}\left(\mathrm{m}^{2} / \mathrm{g}\right) \\
\text { (uncorrected) }\end{array}$ & $\begin{array}{l}\mathrm{SSA}\left(\mathrm{m}^{2} / \mathrm{g}\right) \\
\text { (corrected) }\end{array}$ \\
\hline $\begin{array}{l}\text { KGa-1 } \\
\text { KGa-1b } \\
\text { KGa-2 }\end{array}$ & $\begin{array}{l}32 \\
52 \\
77\end{array}$ & $\begin{array}{l}5.19 \cdot 10^{-12} \\
5.67 \cdot 10^{-12} \\
2.35 \cdot 10^{-12}\end{array}$ & $\begin{array}{l}33.1 \pm 0.8 \\
38.3 \pm 1.0 \\
23.4 \pm 0.6\end{array}$ & $\begin{array}{l}27.3 \pm 0.7 \\
30.0 \pm 0.8 \\
18.2 \pm 0.5\end{array}$ & $\begin{array}{c}6.0 \pm 0.2 \\
4.7 \pm 0.1 \\
11.5 \pm 0.3\end{array}$ & $\begin{array}{l}10.1 \pm 0.3 \\
11.3 \pm 0.3 \\
24.1 \pm 0.6\end{array}$ \\
\hline
\end{tabular}


TABLE 2. Published BET SSA values for kaolinite standards

\begin{tabular}{lcl}
\hline \hline Sample & SSA $\left(\mathrm{m}^{2} / \mathrm{g}\right)$ & Reference \\
\hline KGa-1 & 10 & Madsen 1977 \\
& 10.05 & Van Olphen and Fripiat 1979 \\
& 8.4 & Pruett and Webb 1993 \\
& 8.16 & Huertas et al. 1999 \\
& 11.2 & Carroll-Webb and Walther 1988 \\
KGa-1b & 11.7 & Pruett and Webb 1993 \\
& 12.5 & Bereznitski et al. 1998 \\
KGa-2 & 24 & Madsen 1977 \\
& 23.50 & Van Olphen and Fripiat 1979 \\
& 22.4 & Bereznitski et al. 1998 \\
\hline
\end{tabular}

measurement. We note also that only $32-77$ particles were needed to obtain relatively invariant cumulative surface area values, with more particles needed for particle distributions skewed toward smaller sizes. Analyzed particles had cumulative masses (Table 1) of only a few picograms, whereas $\mathrm{N}_{2}$ BET analysis of these materials requires $\sim 100 \mathrm{mg}$.

Several studies have been conducted to quantify ESA/TSA ratios of kaolinite particles from AFM images, often on the same samples examined here. Zbik and Smart (1998) measured $120 \mathrm{KGa}-1$ particles and determined an ESA/TSA ratio of $>30 \%$. This agrees well with our result, especially considering that it should correspond more closely to the value calculated without bottom correction $(33.1 \pm 1.7 \%)$. Brady et al. (1996) performed similar measurements of a small number of KGa-1 particles, and found ESA/TSA ratios ranging from 0.13-0.47. Sutheimer et al. (1999) and Zhou (1996) (two reports of the same study) performed less exact measurements of $170 \mathrm{KGa}$ $1 \mathrm{~b}$ and $\mathrm{KGa}-2$ particles, defining an average diameter and average height for each particle and then calculating surface area values assuming a perfect hexagonal plate shape. They reported mean ESA/TSA values of 0.17 for $\mathrm{KGa}-1 \mathrm{~b}$ and 0.18 for $\mathrm{KGa}$ 2. However, these ratios do not include contributions to the ESA from basal plane step edges, which they estimated would raise the ratio by $20-30 \%$. Therefore, their estimate for $\mathrm{KGa}-2$ is in good agreement with ours, but the estimate for KGa- $1 \mathrm{~b}$ disagrees substantially.

In all previous studies, mean, rather than cumulative, ESA/ TSA ratios were calculated. Cumulative values correctly weight the contribution of each particle, whereas mean values weight all particles equally. Also, Zhou (1996) and Sutheimer et al. (1999) stated that they excluded many undispersed aggregated particles from their measurements, which might bias their particle size distributions. It is interesting to note that Zhou (1996) calculated mode SSA values for $\mathrm{KGa}-1 \mathrm{~b}$ and $\mathrm{KGa}-2$ that were within $4 \%$ of at least one BET measurement in Table 2. However, mean and median SSA values were higher by $20-68 \%$, and no rigorous statistical argument was given for why the mode value should reproduce the BET SSAs more accurately.

The excellent agreement between SSA values calculated from AFM images and the BET method indicates that the AFM technique should prove exceptionally useful for the characterization of clay or nanoparticle samples too small for BET analysis. The precise determination of edge vs. basal surface area of clays should lead to improved understanding of bulk powder reactivity in industrial and natural processes.

\section{ACKNOWLEDGMENTS}

We thank the U.S. Department of Energy (DE-FG07-99ER15009 and DEFG03-99ER14979) and the National Science Foundation (EAR-9909561) for research support. We also thank S. Barrett for generously implementing suggested modifications to his Image SXM software.

\section{REFERENCES CITED}

Barrett, S.D. (1997) Image analysis and the intemet. Scientific Data Management, 1, 18 25.

Barrett, S.D., Bickmore, B.R., Rufe, E., Hochella, M.F. Jr., Torzo, G., and Cerolini, D. (1998) The use of macros in AFM image analysis and image processing. Journal of Computer Assisted Microscopy, 10, 77-82.

Bereznitski, Y., Jaroniec, M., and Maurice, P. (1998) Adsorption characterization of two clay minerals society standard kaolinites. Joumal of Colloid and Interface Science, 205, 528-530.

Bickmore, B.R., Rufe, E., Barrett, S., and Hochella, M.F. Jr. (1999) Measuring discrete feature dimensions in AFM images with Image SXM. Geological Materials Research, 1, n. 5. See http://gmr.minsocam.org. Mineralogical Society of America, Washington, D.C.

Blum, A.E. (1994) Determination of illite/smectite particle morphology using scanning force microscopy. In K.L. Nagy and A.E. Blum, Eds, Scanning probe microscopy of clays, p. 172-202. CMS Workshop Lectures, The Clay Minerals Society, Boulder.

Brady, P.V., Cygan, R.T., and Nagy, K.L. (1996) Molecular controls on kaolinite surface charge. Journal of Colloid and Interface Science, 183, 356-364.

Brunauer, S., Emmett, P.H., and Teller, E. (1938) Adsorption of gases in multimolecular layers. Journal of the American Chemical Society, 60, 309-319.

Carroll-Webb, S.A. and Walther, J.V. (1988) A surface complex reaction model for the $\mathrm{pH}$-dependence of corundum and kaolinite dissolution rates. Geochimica et Cosmochimica Acta, 52, 2609-2623.

Costanzo, P.M. and Guggenheim, S., eds. (2001) Baseline studies of the Clay Minerals Society source clays. Clays and Clay Minerals, 49, 371-452.

Dias,A., Buono, V.T.L., Vilela, J.M.C., Adrade, M.S., and Lima, T.M. (1997) Particle size and morphology of hydrothermally processed $\mathrm{MnZn}$ ferrites observed by atomic force microscopy. Journal of Materials Science, 32, 4715-4718.

Huertas, FJ., Chou, L., and Wollast, R. (1999) Mechanism of kaolinite dissolution at room temperature and pressure. Part II. Kinetic study. Geochimica et Cosmochimica Acta, 63, 3261-3275.

Ma, C. and Eggleton, R.A. (1999) Cation exchange capacity of kaolinite. Clays and Clay Minerals, 47, 174-180.

Madsen, FT. (1977) Surface area measurements of clay minerals by glycerol sorption on a thermobalance. Thermochimica Acta, 21, 89-93.

Manceau, A., Nagy, K.L., Spadini, L., and Ragnarsdottir, K.V. (2000) Influence of anionic layer structure of $\mathrm{Fe}$-oxyhydroxides on the structure of $\mathrm{Cd}$ surface complexes. Joumal of Colloid and Interface Science, 228, 306-316.

Maurice, P.A. (1996) Application of atomic-force microscopy in environmental colloid and surface chemistry. Colloids and Surfaces A, 107, 57-75.

Nagy, K.L. (1994) Application of morphological data obtained using scanning force microscopy to quantification of fibrous illite growth rates. In K.L. Nagy and A.E. Blum, Eds., Scanning probe microscopy of clays, p. 204-239. CMS Workshop Lectures, The Clay Minerals Society, Boulder.

Nagy, K.L., Cygan, R.T., Hanchar, J.M., and Sturchio, N.C. (1999) Gibbsite growth kinetics on gibbsite, kaolinite, and muscovite substrates: Atomic force microscopy evidence for epitaxy and an assessment of reactive surface area. Geochimica et Cosmochimica Acta, 63, 2337-2351

Pruett, RJ. and Webb, H.L. (1993) Sampling and analysis of KGa-1b well-crystallized kaolin source clay. Clays and Clay Minerals, 41, 514-519.

Russ, J.C. (1990) Computer-Assisted Microscopy: The Measurement and Analysis of Images, 453 p. Plenum, New York.

(1995) The Image Processing Handbook, $2^{\text {nd }}$ ed., 674 p. CRC, London.

Schlegel, M., Charlet, L., and Manceau, A. (1999) Sorption of metal ions on clay minerals. II. Mechanism of Co sorption on hectorite at high and low ionic strength, and impact on the sorbent stability. Journal of Colloid and Interface Science, 220, 392405

Sutheimer, S.H., Maurice, P.A., and Zhou, Q.(1999) Dissolution of well and poorly crystallized kaolinites: Al speciation and effects of surface characteristics. American Mineralogist, 84, 620-628.

van Olphen, H. and Fripiat, J.J. (1979) Data handbook for clay materials and other nonmetallic minerals, 346 p. Pergamon, New York

Villarrubia, J.S. (1997) Algorithms for scanned probe microscope image simulation, surface reconstruction, and tip estimation. Journal of Research of the National Institute of Standards and Technology, 102, 425-454.

Zbik, M. and Smart, R.St.C. (1998) Nanomorphology of kaolinites: Comparative SEM and AFM studies. Clays and Clay Minerals, 46, 153-160.

Zhou, Q. (1996) Surface characteristics and dissolution kinetics of two standard kaolinites, 213 p. Master's Thesis, Kent State University.

Zhou,Z and Gunter, W.D. (1992) The nature of the surface charge of kaolinite. Clays and Clay Minerals, 40, 365-368.

MANUSCRIPT RECEIVED AUguST 21, 2001

MANUSCRIPT ACCEPTED JANUARY 24, 2002

MANUSCRIPT HANDLED BY LEE A. GROAT 


\title{
$A b$ Initio Determination of Edge Surface Structures for Dioctahedral 2:1 Phyllosilicates: Implications for Acid-Base Reactivity
}

\author{
Published in Clays and Clay Minerals, 2003, V. 4, p. 359-371
}

\author{
Barry R. Bickmore ${ }^{1}$, Kevin M. Rosso ${ }^{2}$, Kathryn L. Nagy ${ }^{3}$, Randall T. Cygan ${ }^{4}$, and \\ Christopher J. Tadanier ${ }^{5}$
}

\begin{abstract}
The atomic structure of dioctahedral 2:1 phyllosilicate edge surfaces was calculated using pseudopotential planewave density functional theory. Bulk structures of pyrophyllite and ferripyrophyllite were optimized using periodic boundary conditions, after which crystal chemical methods were used to obtain initial terminations for ideal (110)- and (010)-type edge surfaces. The edge surfaces were protonated using various schemes to neutralize the surface charge, and total minimized energies were compared to identify which schemes are the most energetically favorable. The calculations show that significant surface relaxation should occur on the (110)-type faces, as well as in response to different protonation schemes on both surface types. This result is consistent with atomic force microscopy observations of phyllosilicate dissolution behavior. Bond-valence methods incorporating bond lengths from calculated structures can be used to predict intrinsic acidity constants for surface functional groups on (110)- and (010)-type edge surfaces. However, the occurrence of surface relaxation poses problems for applying current bond-valence methods. An alternative method is proposed that considers bond relaxation, and accounts for the energetics of various protonation schemes on phyllosilicate edges.

Key Words - Density functional theory, clay edge surfaces, MUSIC, dissolution kinetics, $a b$ initio, pyrophyllite, surface structure
\end{abstract}

\footnotetext{
${ }^{1}$ Department of Geology, Brigham Young University, Provo, UT 84602-4606. E-mail: barry_bickmore@byu.edu

${ }^{2}$ Environmental Molecular Sciences Laboratory, Pacific Northwest National Laboratory, P.O. Box 999, MSIN K896, Richland, WA 99352.

${ }^{3}$ Department of Earth and Environmental Sciences, University of Illinois at Chicago, Chicago, IL 60607-7059

${ }^{4}$ Geochemistry Department, Sandia National Laboratories, Albuquerque, NM 87185-0750

${ }^{5}$ Department of Geological Sciences and Charles E. Via Department of Civil and Environmental Engineering, Virginia Tech, Blacksburg, VA 24061.
} 


\section{INTRODUCTION}

Phyllosilicate surface chemistry is an important control on ion mobility and $\mathrm{pH}$ in natural waters, permeability reduction in reservoir rocks, groundwater flow through engineered barriers, and clay rheology. In addition, phyllosilicate clays have a number of industrial applications due to their distinctive surface chemical properties. Therefore, a detailed atomic-scale understanding of phyllosilicate surface chemistry is desirable. While the basal surfaces of phyllosilicates have been the subject of numerous studies, the reactivity of edge surfaces is less well known because edges are difficult to isolate experimentally, and more difficult to model atomistically.

Edge and basal surfaces of phyllosilicates vary greatly in reactivity due to the extreme anisotropy of phyllosilicate crystal structures. For example, edge surfaces exhibit pH-dependent surface charging behavior, whereas siloxane-terminated basal surfaces do not (White and Zelazny, 1988; Bleam, 1993; Bleam et al., 1993). Furthermore, acid dissolution of phyllosilicates proceeds almost exclusively at edge surfaces (Kaviratna and Pinnavaia, 1994; Turpault and Trotignon, 1994; Rufe and Hochella, 1999; Bosbach et al., 2000; Bickmore et al., 2001). These differences in acid-base reactivity arise because edge surfaces are terminated by valence unsaturated oxygen atoms, whereas oxygen atoms on siloxane-terminated basal surfaces are valence saturated. Underbonded oxygen atoms electrostatically attract protons, and participate in $\mathrm{pH}$-dependent charging behavior or bond dissociation (Xiao and Lasaga, 1994; Ganor et al., 1995; Bickmore et al., 2001). Solution-chemical investigations of dissolution and $\mathrm{pH}$-dependent charging cannot be interpreted on a molecular level without assuming some sort of surface structural model.

The most useful models of phyllosilicate edge surfaces take into account site type, distribution, and density. First attempts included schematic representations of surface site types (Schofield and Samson, 1953; Muljadi et al., 1966), but did not address site density or distribution. White and Zelazny (1988), Bleam (1993), Bleam et al. (1993), Brady et al. (1996), and Bickmore et al. (2001) used crystal chemical methods to predict site type, distribution, and density. The precise termination of each edge surface is determined by cutting the crystal structure parallel to the plane of interest in such a way as to break the weakest bonds and preserve stoichiometry (Bleam et al., 1993). The same results are achieved by terminating each surface at the edges of periodic bond chains, as defined by Hartman-Perdock periodic bond chain (PBC) theory (Hartman and Perdock, 1955a; 1955b; 1955c; White and Zelazny, 1988; Bickmore et al., 2001). Crystal chemical methods predict that only two types of edge surfaces should exist, (010) and (110) (Fig. 1) (White and Zelazny, 1988; Bickmore et al., 2001). (This assignment of Miller indices assumes a $1 M$ polytype. The (110) face is not symmetrically equivalent to the $(1 \overline{1} 0)$ face in triclinic structures, but bond lengths and single-layer unit cell parameters are nearly identical for $1 M$ and $1 T c$ pyrophyllite structures (Bleam et al., 1993), so the two faces are treated as equivalent here.) Edge surfaces are stabilized in the presence of water by chemisorption of water species (Bleam et al., 1993). However, crystal chemical rules cannot always be used to distinguish between different surface protonation schemes, and there are differences in this regard among the edge surface models mentioned above (Fig. 2). Another complication is surface relaxation (i.e. shifts in electron density, and hence bond lengths, with respect to the bulk structure), which Bleam et al. (1993) did not consider. White and Zelazny (1988) proposed a protonation scheme for the (110) surface based on relaxation patterns observed for related minerals (Fig. 2e), but this model remains hypothetical. 
Molecular modeling methods can be used to calculate simultaneously the lowest-energy configuration of attached protons and surface structural relaxation. Yet few molecular modeling calculations are available for edge structures of phyllosilicates, and none at the $a b$ initio level of theory to our knowledge (Bleam, 1993; Bleam et al., 1993). In this paper we report results of calculations using pseudopotential plane wave density functional theory (PPW-DFT) for neutral, protonated, edge-surface structures of dioctahedral 2:1 phyllosilicates. The calculations test and improve the models discussed above by treating edge structures at a more fundamental level than has been attempted before. Among other things, we specifically investigated the structural relaxation and energetic stability of proton configurations postulated by White and Zelazny (1988). Implications of these calculations were explored with respect to the $\mathrm{pH}$-dependent charging behavior and acid dissolution of dioctahedral phyllosilicates.

\section{METHODS}

All structures and total energies were calculated using the PPW-DFT method as implemented in CASTEP (Payne et al., 1992). The generalized gradient approximation (GGA) and generalized gradient local spin approximation (GGS) were applied using the Perdew-Wang (Perdew and Wang, 1992) parameterization of the exchange-correlation functional, modified to work with planewave calculations (White and Bird, 1994). We used the CASTEP parameterization of ultrasoft pseudopotentials (Vanderbilt, 1990) without core corrections. Pseudopotentials were generated using the local density approximation (LDA/LSDA), meaning that the screening effect of the core electrons was modeled using LDA/LSDA, whereas the screening effect of the valence electrons was modeled using GGA/GGS. This approach has been validated previously (Garcia et al., 1992) and successfully applied to structure optimizations of 2:1 phyllosilicates (Rosso et al., 2001).

Pyrophyllite edge structure models with $\mathrm{Al}^{3+}$ or $\mathrm{Fe}^{3+}$ occupying the octahedral sites were generated from optimized bulk structures $\left((\mathrm{Al}, \mathrm{Fe}) \mathrm{Si}_{2} \mathrm{O}_{5}(\mathrm{OH})\right)$. The atomic coordinates and cell parameters of bulk 1 Tc pyrophyllite were optimized simultaneously without symmetry constraint (i.e., in the $\mathrm{P} 1$ space group). GGA was used for $\mathrm{Al}_{2} \mathrm{Si}_{2} \mathrm{O}_{5}$ and GGS for $\mathrm{Fe}_{2} \mathrm{Si}_{2} \mathrm{O}_{5}$. For the latter, knowledge of the ordering of unpaired spins in ferripyrophyllite is incomplete, but antiferromagnetic coupling of high-spin $\mathrm{Fe}^{3+}$ within ideal dioctahedral layers has been observed (Coey, 1988). Thus, in our calculations, a net spin of zero was assigned to the unit cell so as to impose an anti-ferromagnetic spin distribution for each 2:1 layer. One k-point was used (gamma point), which gave satisfactory results for closely related mineral structures (Bridgeman et al., 1996; Chatterjee et al., 2000; Rosso et al., 2001). Optimization was performed using a cutoff energy of $300 \mathrm{eV}$ and a conjugate gradient electronic minimizer using a density mixing scheme (Kresse and Furthmuller, 1996). Finite basis set error estimations using methods described in Payne et al. (1992) were $<0.1 \mathrm{eV} /$ atom, indicating that the bulk structure calculations were converged with respect to basis set size. Although these computational conditions are chosen in part due to the need for computational efficiency for our large structures, similar conditions were found to provide accurate structures and energetics in a previous study on phyllosilicates (Rosso et al., 2001).

Edge structures were then excised from optimized bulk configurations. Because the PPW calculations in this study always have three-dimensional periodic boundary conditions, surfaces were constructed by building in a vacuum layer (Rosso, 2001). In our case, two mutually perpendicular vacuum layers were present for each edge model. Because we used only one 2:1 
layer for the edge structure calculations, the first vacuum layer is oriented parallel to the basal plane. The other vacuum layer in each model separates the edge surfaces of interest. Thus, the edge models are best described as polymer-like, because they are structurally contiguous and are treated as infinitely periodic units along only one dimension. Edge terminations, generated by PBC theory, were identical to those described in White and Zelazny (1988) and other previous studies cited above. The vacuum layers separating the edge models between adjacent cells were always > $10 \AA$; and models were designed with an inversion center to ensure that interactions across the vacuum layers were negligible. The infinitely repeating chains were chosen to run along the [110] and [100] vectors, generating edge surfaces of the (110) and (010) types, respectively (Fig. 3). Protons were added to edge sites to correspond with neutral protonation schemes proposed by White and Zelazny (1988) and Bleam (1993), as well a one that has never before been suggested (see Fig. 2), while keeping the basal surfaces unchanged (vacuum terminated). The coordinates of all atoms in each of the protonated edge models were energy optimized using the same treatment as described for the bulk structures above, except with fixed lattice parameters, where the unit cell dimension along the edge vector was determined from the corresponding bulk optimization.

\section{RESULTS AND DISCUSSION}

\section{Bulk Structures}

Atomic positions and unit cell parameters derived from the bulk structure optimizations are reported in Table 1. Although these calculations were performed without symmetry constraints, the bulk structures converge to their proper space group symmetries $\left(\mathrm{C}_{\overline{1}}\right)$, as determined using a structural search tolerance of $\sim 0.1 \AA$. The accuracy of the calculated structures can be evaluated further in two ways.

First, calculated unit cell parameters can be compared with experimental values for 1Tc pyrophyllite (Lee and Guggenheim, 1981) and a 2M ferripyrophyllite (Chukhrov et al., 1979) (Table 2). Unit cell parameters for the calculated structures are given in the $\mathrm{C} \overline{1}$ space group for direct comparison to the 1Tc pyrophyllite structure. However, only the calculated $a$ and $b$ cell dimensions are directly comparable to those measured for ferripyrophyllite (Chuckhrov et al., 1979), which was a $2 M$ polytype. Calculated ferripyrophyllite values agree well with those measured. Calculated unit cell parameters for pyrophyllite are close to measured values, except that the calculated $c$ dimension is larger by $0.49 \AA$. Overestimated $c$-axis lengths may be due to the particular computational conditions applied. Our results for pyrophyllite and those from Teppen et al. (2002) were obtained using slightly different methods and produced slightly different c-axis dimensions. Their c-axis estimate is also overestimated, but is closer to the experimental value (larger by $0.16 \AA$ ). The overestimated lengths also could be related to the incomplete description of van der Waals attractive forces in DFT (Wu et al., 2001). Pyrophyllite layers are held together predominantly by van der Waals forces, and the c-axis dimension is sensitive to the description of interactions across the interlayer (Giese, 1975). However, the accuracy of the c-axis dimension becomes insignificant in the context of the edge surface calculations because the calculations are based on single isolated 2:1 layers making interlayer interactions irrelevant.

Second, we suggest that the set of predicted bond lengths in each structure should show systematic correspondence with the bond valence model of Brown and Altermatt (1985). The 
total Brown (1981) bond strength reaching each cation in the structure, computed using the relevant bond lengths predicted ab initio, should equal the cation's formal charge. This evaluation method has at least one advantage - systematic deviations in the computed bond lengths can be identified for structures (such as that of pyrophyllite) comprised of asymmetrically distorted polyhedra. For example, it is not clear that simply tabulating and averaging all computed $\mathrm{Al}-\mathrm{O}$ bond lengths for comparison with a "grand universal" mean observed Al-O distance would be sensitive to subtle computational errors. In fact, Brown's (2002) "distortion theorem" states, "For any ion, lengthening some of its bonds and shortening others, keeping the bond valence sum the same, will always increase the average bond length." Thus, comparing average Al-O bond length with some idealized value could lead to the conclusion that the computations overestimate bond lengths when, in fact, the opposite might be the case.

Brown and Altermatt (1985) fit the following bond valence expression to a large number of crystal structures in the Inorganic Crystal Structure Database:

$$
s=\exp \left[\left(r_{0}-r\right) / B\right]
$$

where $s$ is bond valence in valence units (v.u.), $r$ is bond length, $r_{0}$ an arbitrary bond length fitted for each pair of atoms, and B is a fitted parameter usually equal to $0.37 \AA$. The summed strength of bonds reaching a cation should be equal to its formal charge. Based on our models, calculated total bond strengths reaching the $\mathrm{Si}$ atoms in pyrophyllite were 4.08-4.11 v.u. and 4.09 v.u. in ferripyrophyllite. Total bond strengths reaching Al atoms were 3.09-3.10 v.u. in pyrophyllite and total bond strengths reaching Fe atoms in ferripyrophyllite were 3.19-3.20 v.u. This means that the calculated bond lengths were, on average, $\sim 0.01 \AA$ too short for $\mathrm{Si}-\mathrm{O}$ and $\mathrm{Al}-\mathrm{O}$ bonds, and $\sim 0.02 \AA$ too short for $\mathrm{Fe}-\mathrm{O}$ bonds. Estimated standard deviations for these bond lengths, reported by Brown and Altermatt (1985), range from 0.001 to $0.003 \AA$. Thus, the bond length underestimation is likely a real artifact of the PPW-DFT calculations. Nonetheless, the agreement between calculated and expected bond lengths is still quite good.

\section{Edge Structures}

Using the PPW-DFT optimizations, lowest energy configurations of protons were sought for each of the edge models, and the extent of surface relaxation was explored. For both (010)and (110)-type faces, the protonation schemes suggested by White and Zelazny (1988) were clearly energetically favorable. Furthermore, the surface relaxation predicted for the (110)-type faces by White and Zelazny (1988) was qualitatively confirmed.

Edge structure calculations were based on models that were infinitely periodic in one direction. To avoid excessive computational costs, the models were designed to be no more than $\sim 10 \AA$ wide perpendicular to the edges. In cases where models are "thin," it is important to verify that relaxation effects from the opposing surfaces do not penetrate the full width of the model. To test for such an effect, distortion of bond lengths in the relaxed structures was checked. Table 3 shows the range of distortion for each type of bond in the interior polyhedra of each edge structure (Fig. 2), with respect to the same bonds in unrelaxed structures. These bond shifts are relatively small, so we conclude that the edge structure models are of sufficient width to adequately mimic both the bulk and edge structural environments.

Our surface structure calculations did not include an overlying bulk water phase, which might affect the relative stabilities of surface proton configurations. However, we will show that the valences of $\mathrm{O}-\mathrm{H}$ bonds in the surface hydroxyl groups in our calculations were similar to those of $\mathrm{O}-\mathrm{H}$ bonds in bulk water. That is, the $\mathrm{O}-\mathrm{H}$ bonds were about 0.8 v.u., leaving 0.2 v.u. 
on the $\mathrm{H}$ to donate to $\mathrm{H}$-bonds. Therefore, the vacuum-terminated surface structures probably would not be affected much by the addition of bulk water.

The structures of (010)-type faces were calculated with the protonation schemes shown in Fig. 2a-b, and their total energies compared. The (010)-type faces are terminated by silanol and aluminol or ferrinol groups, and the proton configuration to neutralize this surface typically has been assumed to be like that depicted in Fig. 2a. The proton configuration depicted in Fig. 2b also should be considered as a possibility, based on the results of this study which show that deprotonation of a silanol group occurs at a lower $\mathrm{pH}$ than deprotonation of one of the aluminols. However, when the starting structure in Fig. $2 b$ was optimized, it was so energetically unfavorable that a proton on one of the aluminol (pyrophyllite)/ferrinol (ferripyrophyllite) groups "hopped" over to the adjacent deprotonated silanol group. This result is discussed further below.

(110)-type edge structures with starting proton configurations as shown in Fig. 2c-d were also optimized. The minimal edge unit of the vacuum-terminated (110)-type edge exposes four underbonded oxygen atoms for each 2:1 layer, consisting of two silanol groups, one $\mathrm{Si}-\mathrm{O}-\mathrm{Al}$ bridging oxygen, and one aluminol/ferrinol group. Each edge has a net charge of -4 that must be neutralized with protons. Adding one proton to each underbonded $\mathrm{O}$ atom at an edge is a commonly assumed scheme (Bleam, 1993) (Fig. 2c). Assuming that surface relaxation tends toward the neutralization of unsaturated valence on individual surface groups, White and Zelazny (1988) proposed an alternative protonation scheme that differs simply by doubly protonating the aluminol/ferrinol and leaving the bridging $\mathrm{O}$ atom unprotonated (Figs. 2d-e). Note that this difference requires only a small translocation of a proton from its optimized location on the bridging oxygen atom to the aluminol/ferrinol oxygen atom (a distance of $\sim 2.2 \AA$ ). We optimized both configurations to assess their relative stabilities. Total energies of the two configurations indicate that White and Zelazny's (1988) scheme is lower in energy by $-0.44 \mathrm{eV}$ for pyrophyllite and $-0.25 \mathrm{eV}$ for ferripyrophyllite per $2: 1$ edge. This indicates that the singly protonated aluminol/ferrinol groups have a higher proton affinity; i.e., they are more basic than the bare bridging $\mathrm{O}$ atom. Such a configuration appears to be partly stabilized by the participation of one of the $\mathrm{Al}-\mathrm{OH}_{2} / \mathrm{Fe}-\mathrm{OH}_{2}$ protons in hydrogen bonding to the bridging $\mathrm{O}$ atom. This result agrees in principle with the electrostatic calculations of Bleam et al. (1993) and the predictions of White and Zelazny (1988). The hydrogen-bonding interaction between the proton on the aluminol/ferrinol groups and the bridging $\mathrm{O}$ atom on the (110)-type surface is weak (0.026-0.032 v.u.). Thus, although it is probable that this interaction would be screened by intervening water molecules, we would not expect the screening to cause a reversal in the relative stabilities of the two protonation schemes. Therefore, it is concluded that the protonation scheme in Fig. 2c is less likely to be important than the scheme proposed by White and Zelazny (1988) (Figs. 2d-e).

White and Zelazny (1988) also predicted a certain amount of structural relaxation at the (110)-type surfaces, resulting in the configuration illustrated in Fig. 2e. Table 4 shows the total strength of bonds reaching the oxygen atoms of the surface functional groups on the (010)- and (110)-type surfaces shown in Figs. $2 \mathrm{a}$ and $2 \mathrm{~d}-\mathrm{e}$, excluding $\mathrm{O}-\mathrm{H}$ bonds. The values in Table 4 are corrected for the tendency of our calculations to underpredict bond lengths by subtracting the average overestimation of bond valence for each type of bond in our calculated bulk structures. That is, 0.017 v.u. was subtracted from the computed valence of Al-O bonds, 0.033 v.u. from that of $\mathrm{Fe}-\mathrm{O}$ bonds, and 0.025 v.u. from $\mathrm{Si}-\mathrm{O}$ bonds. The $\mathrm{O}-\mathrm{H}$ bonds on the surface functional groups were computed to have bond strengths of 0.75-0.80 v.u., in good agreement with the assumption of Hiemstra et al. (1996) that surface hydroxyl bond strengths are close to $\mathrm{O}-\mathrm{H}$ bond 
strengths for bulk water (0.80 v.u.). White and Zelazny (1988) predicted that $\mathrm{Si}-\mathrm{O}, \mathrm{Al}-\mathrm{O}$, and $\mathrm{Fe}-\mathrm{O}$ bond lengths reaching the bridging oxygens should contract significantly, and the $\mathrm{Al}-\mathrm{O}$ and $\mathrm{Fe}-\mathrm{O}$ bond lengths in the aluminol and ferrinol groups should expand significantly. Therefore, due to this relaxation of the edge structure, the total strength of bonds reaching the bridging oxygens on (110)-type surfaces was predicted to be 2.00 v.u., and the strength of the $\mathrm{Al}-\mathrm{O}$ and $\mathrm{Fe}-\mathrm{O}$ bonds in the aluminol and ferrinol groups was predicted to be $0.00 \mathrm{v} . \mathrm{u}$. On the other hand, if no structural relaxation occurs (Bleam et al., 1993), the total strength of bonds reaching the bridging oxygens should be $\sim 1.50$ v.u., and the strength of the $\mathrm{Al}-\mathrm{O}$ and $\mathrm{Fe}-\mathrm{O}$ bonds in the aluminol/ferrinol groups would be $\sim 0.50 \mathrm{v} . \mathrm{u}$.

The PPW-DFT calculations confirm the structural relaxation predicted by White and Zelazny (1988), although the degree of relaxation is not so extreme as they envisaged. The $\mathrm{Si}-$ $\mathrm{O}, \mathrm{Al}-\mathrm{O}$, and $\mathrm{Fe}-\mathrm{O}$ bonds reaching the bridging oxygens do contract by $0.04-0.14 \AA$, and the $\mathrm{Al}-\mathrm{O}$ and $\mathrm{Fe}-\mathrm{O}$ bonds in the aluminol and ferrinol groups expand by $0.10-0.13 \AA$. The total corrected valence of bonds reaching the bridging oxygen is computed to be $1.861 \mathrm{v} . \mathrm{u}$. for pyrophyllite and 1.757 v.u. for ferripyrophyllite. The Al-O bond strength in the aluminol (pyrophyllite) is 0.327 v.u., and the $\mathrm{Fe}-\mathrm{O}$ bond strength on the ferrinol (ferripyrophyllite) is 0.316 v.u. Therefore, most of the structural relaxation predicted by White and Zelazny (1988) for the bonds reaching the bridging oxygens occurs, whereas predicted relaxation for the Al-O and $\mathrm{Fe}-\mathrm{O}$ bonds in the aluminol/ferrinol groups is less.

The small relaxation of the aluminol/ferrinol groups on (110)-type surfaces takes on added meaning when compared to similar functional groups on the (010)-type surfaces. In the unrelaxed bulk structures, the Al-O bond on the (110)-type aluminol has a corrected bond valence of 0.431 v.u., and the $\mathrm{Fe}-\mathrm{O}$ bond on the equivalent ferripyrophyllite site has a bond valence of 0.460 v.u.. Unrelaxed Al-O and Fe-O bonds on the (010)-type surfaces have bond strengths of 0.569 and $0.551-0.569$ v.u., respectively. Table 4 shows that the $\mathrm{Al}-\mathrm{O}$ and $\mathrm{Fe}-\mathrm{O}$ bonds of singly-protonated (010)-type aluminol/ferrinol groups have bond strengths of 0.674 and 0.698 v.u., respectively. On the other hand, the $\mathrm{Al}-\mathrm{O}$ and $\mathrm{Fe}-\mathrm{O}$ bonds of doubly-protonated (010)-type aluminol/ferrinol groups have bond strengths of 0.290 and 0.332 v.u. These values are close to the bond strengths of doubly-protonated $\mathrm{Al}-\mathrm{O}$ and $\mathrm{Fe}-\mathrm{O}$ bonds in (110)-type aluminol/ferrinol groups - 0.327 and 0.316 v.u., respectively. Since the Al-O and Fe-O bond valences for aluminol/ferrinol groups are different between unrelaxed (010)- and (110)-type surfaces, but nearly identical on relaxed surfaces when the protonation is the same, it can be argued that the valence of $\mathrm{Al}-\mathrm{O}$ and $\mathrm{Fe}-\mathrm{O}$ bonds in the aluminol/ferrinol groups is controlled largely by the degree of protonation.

Finally, the corrected bond valences of the $\mathrm{Si}-\mathrm{O}$ bonds of the silanol groups on the surfaces studied ranged from $0.99-1.05$ v.u. These values bracket the ideal bond strength of 1.00 for $\mathrm{Si}-\mathrm{O}$ bonds in silica tetrahedra.

\section{Acidity of phyllosilicate edges}

In the past, treatments of phyllosilicate surface-charging behavior have employed various surface complexation models (e.g., constant capacitance, triple-layer, etc.) to rationalize potentiometric titration data (e.g. , Brady et al., 1996; Kraepiel et al., 1998). However, most previous modeling has assumed the existence of two or three generic functional groups with integer charges, and the possibility of fractional charges has been ignored. Furthermore, with few exceptions (Chang and Sposito, 1994; Brady et al., 1996; Chang and Sposito, 1996) surface complexation models of clay minerals have not separated permanent structural charge located at 
the siloxane basal surfaces from $\mathrm{pH}$-dependent charge on the edge surfaces (Kraepiel et al., 1998). Neither have crystallographically distinct edge surfaces been treated separately.

In this section, we attempt to provide the basis for a more realistic treatment of phyllosilicate acid-base reactivity by using calculated surface structures to estimate acidity constants for specific functional groups. However, the current model (Hiemstra et al., 1996) designed for predicting site acidity may be oversimplified with respect to surface relaxation. Therefore, site acidities will be predicted using the model of Hiemstra et al. (1996), and also by combining $a b$ initio surface structure calculations with a revised bond-valence approach.

The current model (MUSIC). Hiemstra and coworkers (e.g., Hiemstra et al., 1989; Hiemstra et al., 1996; Hiemstra et al., 1999) developed a multisite complexation (MUSIC) modeling approach capable of considering the contribution of specific sites on distinct crystalline surfaces. Site types are defined by crystallographic methods and intrinsic acidity constants are predicted based on the valence saturation of the oxo- and hydroxo- surface groups (Hiemstra et al., 1996). Valence saturation is calculated using the model of Brown and Altermatt (1985).

It should be possible to create MUSIC models for the acid-base behavior of euhedral clay samples using the information gained from the $a b$ initio calculations reported here, including site coordination and bond lengths. Although we will not fit a MUSIC model to potentiometric titration data for phyllosilicates in this paper, the location, density, coordination, unsaturated valence, and predicted intrinsic acidity constants of reactive sites on dioctahedral phyllosilicate edge surfaces are calculated.

Hiemstra et al. (1996) predicted site acidities using a modified form of the following equation:

$$
p K_{a}=-A\left(\sum s_{j}+V\right)
$$

where $K_{a}$ is the intrinsic acidity constant, $A$ equals $19.8, V$ is the valence of the surface oxygen $(-2)$, and $\sum s_{j}$ is the valence saturation of the surface oxygen, defined by:

$$
\sum s_{j}=\left\{s_{M e}+m s_{H}+n\left(1-s_{H}\right)\right\}
$$

Here $s_{M e}$ is the valence of the $\mathrm{Me}-\mathrm{O}$ bond, and $s_{H}$ is the valence of the $\mathrm{O}-\mathrm{H}$ bond to the surface oxygen if the base is a hydroxo- group. (This value was assumed by Hiemstra et al. (1996) to be 0.80 v.u., close to that for H-O bonds in bulk water.) Some of the surface oxygen valence is assumed to be neutralized by hydrogen bonds from surrounding water molecules. Oxygens have four empty orbitals with which to form $\mathrm{Me}-\mathrm{O}, \mathrm{O}-\mathrm{H}$, or hydrogen bonds, and $n$ is the number free to form hydrogen bonds. However, for oxygens coordinated to one metal cation, it is usually assumed that one of the free orbitals is sterically hindered from hydrogen bonding at surfaces $(m+n=2$ in equation 3$)$, unless the surface structure is relatively open, in which case $m+n=3$. One of the free orbitals may or may not be sterically hindered on surface oxygens coordinated by two metal cations. (For solution monomers, it is assumed that none of the orbitals are sterically hindered from bonding.)

Even though the bond valence method is an attempt to create physically realistic surface complexation models, it still requires several simplifying assumptions. For instance, Hiemstra et al. (1996) assumed the bond strength of $\mathrm{H}-\mathrm{O}$ bonds on surface functional groups to be 0.80 v.u. Similarly, acidity constants for crystallographically distinct surface groups can sometimes be treated as equivalent, even though slight variations in bond valence exist. Also, surface reactions are written assuming Pauling bond valences for simplicity in charge bookkeeping (Hiemstra et al., 1996). 
We calculated $\mathrm{pK}_{\mathrm{a}}$ values for reactions taking place on the various surface functional groups on (010)- and (110)-type surfaces using the MUSIC model (Table 5). Bulk bond lengths were used to calculate unsaturated valence.

Generally, the calculated $\mathrm{pK}_{\mathrm{a}}$ values are similar to those assigned to analogous functional groups on simple oxides. For instance, we calculate $\mathrm{pK}_{\mathrm{a}}$ values of 7.6-8.7 for silanol groups, and Hiemstra et al. (1996) assigned an average $\mathrm{pK}_{\mathrm{a}}$ of 7.9 for these groups on silica surfaces. Similarly, calculated $\mathrm{pK}_{\mathrm{a}}$ values for the loss of a proton from a doubly-protonated silanol group ranged from -4.3 to -3.1 , whereas Hiemstra and coworkers used a value of -4.0 . Aluminol groups were calculated to have $\mathrm{pK}_{\mathrm{a}}$ values of 8.5-10.6, whereas Hiemstra et al. (1999) assigned an average $\mathrm{pK}_{\mathrm{a}}$ of 9.9 for aluminols on gibbsite surfaces. The calculated $\mathrm{pK}_{\mathrm{a}}$ values for ferrinol groups (8.5-10.7) are somewhat higher than the value of 7.7 assigned to these groups on goethite surfaces (Hiemstra et al., 1996). However, this is easily explained by the highly distorted nature of $\mathrm{Fe}^{3+}$ octahedra in the 2:1 structure.

Problems with the current model. The above assignment of $\mathrm{pK}_{\mathrm{a}}$ values is somewhat unsatisfying for the following reasons. First, the bond-valence method of Hiemstra et al. (1996) explicitly assumes that no surface relaxation occurs, and therefore, bulk Me-O bond lengths can be used to calculate the unsaturated valence of surface oxygens. On the contrary, our calculations show that the $\mathrm{Me}-\mathrm{O}$ bond lengths in the aluminol/ferrinol groups relax rather dramatically, the singly-protonated forms having shorter, and the doubly-protonated forms having longer, bond lengths than in the bulk structure. This difficulty is especially acute with respect to the estimation of $\mathrm{pK}_{\mathrm{a}}$ values for bridging oxygens on (110)-type faces. We have shown that the bonds to these oxygens relax considerably on neutral surfaces, so it is not apparent why bulk bond lengths should be adequate for predicting the acidity of these groups. Alternatively, we cannot simply substitute bond valences from calculated surface structures into Eq. 3 and expect to obtain realistic $\mathrm{pK}_{\mathrm{a}}$ values. For example, if the relaxed $\mathrm{Al}-\mathrm{O}$ bond valence for singly-protonated aluminol groups on (010)-type surfaces were used (0.674 v.u.) in Eq. 3, the calculated $\mathrm{pK}_{\mathrm{a}}$ for the deprotonation of doubly-protonated aluminol groups would be 6.5 , instead of 8.5-10.6.

Second, the treatment of solvation in this method is inconsistent. For instance, singlycoordinated surface oxygens are defined to have only two orbitals available for proton binding or H-bonding interactions $(m+n=2$ in Eq. 3) because of steric constraints, but in order to properly predict the acidity constants for silanol groups, it has to be assumed that three orbitals are available $(m+n=3)$. Similarly, surface oxygens bound to two metal atoms can have either one or two orbitals available $(m+n=1$ or 2$)$ for proton binding or H-bonding interactions (Hiemstra et al., 1996). Thus, the number of free oxygen orbitals is effectively another fitting parameter.

Third, the idea that acidity constants would be correlated with total unsaturated valence on surface oxygens of the base is also surprising. Since O-H bonds involve only one O orbital, it seems more likely that acidity would correlate with the unsaturated valence available in a single orbital of the basic form.

Finally, application of the current bond-valence model predicts that silanol groups on (010)-type faces should be slightly more acidic than adjacent aluminol groups, but our calculations show that the protonation scheme in Fig. $2 \mathrm{~b}$ is quite unstable.

An older model revised. It appears that bond relaxation may actually be a key to understanding surface acidity constants. Experimentation with different methods of predicting acidity constants for functional groups on our relaxed surfaces has led us to propose a revision of the bond-valence model first proposed by Brown $(1981 ; 2002)$. This model is capable of 
incorporating surface relaxation, does not require inconsistent treatment of solvation, and properly divides bonding power among orbitals. While full development of this model awaits more computational and experimental data, early results for the calculated phyllosilicate surface structures are promising.

Brown's (1981) model is based on a correlation between the Lewis base strength of the base in an acid-base reaction and measured $\mathrm{pK}_{\mathrm{a}}$ values of solution monomers. The correlation equation is

$$
\mathrm{pK}_{\mathrm{a}}=14.3 \ln \left(\mathrm{S}_{\mathrm{b}} / 0.135\right)
$$

where $\mathrm{S}_{\mathrm{b}}$ is the base strength, which is the total unsaturated valence divided by the number of free possible bonds. Consider, for example, the following reaction.

$$
\mathrm{HSO}_{4}{ }^{-} \Leftrightarrow \mathrm{SO}_{4}{ }^{2-}+\mathrm{H}^{+}
$$

The valence of sulfur $(+6)$ is divided among four $\mathrm{S}-\mathrm{O}$ bonds, so that each $\mathrm{S}-\mathrm{O}$ bond has a valence of 1.5. This leaves a total unsaturated valence of 2 v.u. Since oxygen is 4-coordinated on average, we assume that there are four bonding "orbitals" per oxygen, one of which is taken up by an S-O bond. Since there are three remaining possible external bonds per oxygen, and 4 oxygens, we divide the total unsaturated valence by 12 to obtain a Lewis base strength of 0.17 (2 v.u./12 possible external bonds). Substituting this value into Eq. 4, we obtain a $\mathrm{pK}_{\mathrm{a}}$ of 3.0. This is fairly close to the value reported by Perrin (1982) of 1.99 .

It is somewhat more complicated to calculate the Lewis base strength of a protonated oxyanion. Consider the following reaction.

$$
\mathrm{H}_{4} \mathrm{SiO}_{4} \Leftrightarrow \mathrm{H}_{3} \mathrm{SiO}_{4}{ }^{-}+\mathrm{H}^{+}
$$

Assuming Si-O bonds of 1.00 v.u. and $\mathrm{O}-\mathrm{H}$ bonds of 0.80 v.u., each of the oxygen atoms not connected to a hydrogen would have 1.00 v.u. of unsaturated valence. In the previous example, it was assumed that each oxygen atom could form four bonds, but Brown (2002) maintained that the protonated oxygen atoms only have enough unsaturated valence for one weak bond, so we assume that each of these is 3-coordinated, while the deprotonated oxygen is 4-coordinated. This leaves 6 possible external bonds among which to divide the unsaturated valence. Since there is 0.2 v.u. of unsaturated valence on each protonated oxygen, and $1.0 \mathrm{v}$.u. on the deprotonated oxygen, we divide the total $1.6 \mathrm{v}$.u. unsaturated valence between 6 possible external bonds to obtain a Lewis base strength of 0.27. Substituted into Eq. 4, this yields a $\mathrm{pK}_{\mathrm{a}}$ of 9.9, which exactly matches the experimentally determined value of 9.9 reported by Perrin (1982).

There are, however, potential problems with this method of calculating Lewis base strength. First, it is not clear why the unsaturated valence would be evenly distributed about the possible external bonds. Would not the base strength of possible bonds to the bare oxygen necessarily be greater than that of the possible bonds to protonated oxygens? Second, our calculations show that $\mathrm{Me}-\mathrm{O}$ bond lengths tend to contract or expand in response to varying protonation of the oxygen. Therefore, it is not clear that all the $\mathrm{Si}-\mathrm{O}$ bond valences in $\mathrm{H}_{3} \mathrm{SiO}_{4}{ }^{-}$ should be 1.00 v.u.

It is probable that similar base strengths can be estimated if bond relaxation is taken into account. For example, results from PPW-DFT optimizations of charged pyrophyllite and ferripyrophyllite edge surfaces (K.M. Rosso, unpublished results) produce $\mathrm{Si}-\mathrm{O}$ bond valences of 1.1-1.3 v.u. for deprotonated silanol groups, whereas the calculations of neutral surface structures yield $\mathrm{Si}-\mathrm{O}$ bond valences of around 1.00 for singly-protonated silanol groups. If we substitute 1.2 v.u. for the $\mathrm{Si}-\mathrm{O}$ bond valence on the deprotonated oxygen, then divide the unsaturated valence of that specific oxygen between the three non-bonded orbitals, we obtain a Lewis base strength of 0.27 v.u. (0.8 v.u./3 possible bonds). This is exactly the same base 
strength as calculated above, and can be used directly in Eq. 4 to predict a pK $\mathrm{a}_{\mathrm{a}}$ of 9.7. Sefcik and Goddard (2001) recently used DFT methods to calculate silicate anion geometries. Calculated $\mathrm{Si}-\mathrm{O}$ bond lengths for the deprotonated oxygen in gas and aqueous phases yielded bond strengths of 1.17 and 1.18 v.u., respectively. Following the procedure outlined above, these values yield respective base strength values of 0.28 and 0.27 , and $\mathrm{pK}_{\mathrm{a}}$ values of 10.4 and 9.9.

Will this method of Lewis base strength and $\mathrm{pK}_{\mathrm{a}}$ estimation hold true for oxyanions in general? Structural calculations on oxyanions with well-defined acidities need to be carried out to test this hypothesis. However, at this point the method can be used with our calculated phyllosilicate surfaces to obtain reasonable $\mathrm{pK}_{\mathrm{a}}$ values (Table 6). Furthermore, the approach can explain aspects of our data that the model of Hiemstra et al. (1996) cannot.

Acid-base reactions on neutral surfaces are supplemented by those on charged surfaces containing fewer protons (K. Rosso, unpublished results) in Table 6. Comparison of $\mathrm{pK}_{\mathrm{a}} \mathrm{s}$ with those in Table 5 shows that the new method predicts values near those predicted using the method of Hiemstra et al. (1996). Exceptions include silanol groups on (110)-type surfaces and (110)-type bridging oxygens. (We note that calculated $\mathrm{pK}_{\mathrm{a}}$ values for the deprotonation of doubly-protonated silanol groups varied widely in the negative range. This is likely due to the sensitivity of Eq. 4 in this range, but even still several of the calculated values agree well with those in Table 5.)

The values of silanol $\mathrm{pK}_{\mathrm{a}} \mathrm{s}$ on (110)-type surfaces can be rationalized by observing that significant relaxation takes place on these faces, corresponding to shifts in bond valence. For example, since the Si atom bonded to the bridging oxygen shifts some of its bond valence to that oxygen, it cannot transfer as much valence to the adjacent silanol if that group is deprotonated. Therefore, the silanol becomes more basic.

If the relaxation of bonds between a metal cation and one functional group can affect the acidity of another functional group bonded to the same metal cation, this new method of $\mathrm{pK}_{\mathrm{a}}$ calculation may help explain our inability to optimize the surface structure in Fig. $2 \mathrm{~b}$. It is possible that doubly protonating both aluminols causes adjacent bonds in the structure to relax, with the net effect of making the silanol more basic. Thus, it would be energetically favorable for a proton to hop from one of the doubly-protonated aluminols to the silanol.

Implications of the proposed model. More calculations and experiments must be performed to test and refine this model of acidity constant prediction, but if the model premise is correct then there are profound implications for multisite complexation modeling.

First, the relaxation effects described above imply that one cannot simply assign a single $\mathrm{pK}_{\mathrm{a}}$ to each type of surface group. Acidity of one group may be strongly affected by the protonation state of adjacent groups. In retrospect, this conclusion should hardly be surprising, and we are not the first to put forward this idea (Stumm, 1992). Existing surface complexation models are not equipped to deal with shifting acidity constants, but detailed $a b$ initio studies may correct this deficiency by providing information on the proportion of various site types that can be expected to exhibit a given $\mathrm{pK}_{\mathrm{a}}$.

Second, our proposed model for $\mathrm{pK}_{\mathrm{a}}$ prediction treats the solvation of surface functional groups consistently. In fact, no differences in solvation are postulated, whether between surface functional groups with different coordination, or between functional groups on surfaces and solution monomers. This conclusion contradicts recent work postulating that differences in solvation behavior contribute significantly to differences in the acidity of surface functional groups and analogous groups on solution monomers. Sverjensky and Sahai (1996) and Sahai (2002) showed that points of zero charge for simple oxide surfaces can be correlated to equations 
that take into account both average bond valence and average dielectric constant for the mineral structures. Although the correlation is completely empirical, the contribution of the dielectric constant was qualitatively related to Born solvation theory. We suggest that the correlation of the dielectric constant with surface acidity is due to the fact that the dielectric constant is a measure of the "polarizability" of the crystal structure, and might thus be related to the ability of bonds at the solid surface to relax. It may be differences in bond relaxation on surfaces and analogous solution monomers that control differences in acidity.

Acid dissolution of phyllosilicates

It is generally agreed that acid dissolution of phyllosilicates proceeds almost exclusively at edge surfaces, and recent in situ atomic force microscopy (AFM) observations of the process confirm this (Rufe and Hochella, 1999; Bosbach et al., 2000; Bickmore et al., 2001). However, different mechanisms of proton attack have been proposed. After fitting a surface complexation model to kaolinite, Wieland and Stumm (1992) noted that the dissolution rate could be modeled as a first-order function of the concentration of protonated aluminol sites at the edge faces. It was proposed that the rate-controlling activated complex in the dissolution reaction has a stoichiometry of $1 \mathrm{H}$ to $1 \mathrm{Al}$, and protonated aluminol groups are precursors to the activated complex. On the other hand, results of ab initio cluster calculations (Xiao and Lasaga, 1994) showed that the key step in the dissolution of aluminosilicate groups should be proton attack at the bridging oxygen. Protons sorbed at neighboring locations did not significantly affect the dissolution reaction. Ganor et al. (1995) proposed that the rate-controlling dissolution step is the breaking of bonds to $\mathrm{Si}-\mathrm{O}-\mathrm{Al}$ bridging oxygen atoms. They also showed that kaolinite dissolution rates were approximately proportional to the total surface proton concentration, explaining this by hypothesizing equilibrium between the various types of surface sites. Zysset and Schindler (1996) showed that the dissolution rate of montmorillonite is proportional to the total surface proton concentration, including protons sorbed in charged interlayers. As did Ganor et al. (1995), they proposed equilibrium among all surface protons, but noted that they could not use their data to distinguish whether the rate-determining step in acid dissolution is hydrolysis of $\mathrm{Si}-\mathrm{O}-\mathrm{Al}$ or $\mathrm{Al}-\mathrm{O}-\mathrm{Al}$ bonds at edge surfaces.

Bickmore et al. (2001) attempted to settle this controversy by observing phyllosilicate dissolution with in situ AFM. Lath-shaped particles of nontronite (a dioctahedral smectite with mainly $\mathrm{Fe}^{3+}$ in the octahedral sites) and hectorite (a trioctahedral smectite with mainly $\mathrm{Mg}^{2+}$ in the octahedral sites) were fixed on a polyelectrolyte-coated mica surface (Bickmore et al., 1999) and dissolved $\mathrm{pH} 2 \mathrm{HCl}$ in the AFM fluid cell. The hectorite dissolution data were previously reported by Bosbach et al. (2000). It was observed that both minerals dissolved inward from the edges, but the reaction fronts on nontronite quickly became pinned at the pseudohexagonal face angles and then dissolution slowed to an imperceptible rate. In contrast, the hectorite reaction fronts showed no preferential orientation. Why were the pseudohexagonal nontronite faces so much more stable than the randomly oriented edges of nontronite and all the hectorite edges? Bickmore et al. (2001) used periodic bond chain theory to generate models of trioctahedral and dioctahedral edge faces. It was shown that if the surface relaxation proposed by White and Zelazny (1988) for the dioctahedral (110)-type surface occurs (Fig. 2e), all the stable faces have valence saturated bridging oxygen atoms, whereas the bridging oxygens on unstable faces are valence unsaturated. No scheme of bond relaxation could be conceptualized at the unstable faces that would neutralize the entire unsaturated valence of bridging oxygens. Underbonded bridging oxygens would electrostatically attract protons, and if the protons bonded to bridging oxygens, they would become overbonded, destabilizing the structure. If the predicted surface relaxation 
does not occur (Fig. 2d), no such differences between stable and unstable faces could be detected. The acid dissolution behavior described seems to indicate that the rate-controlling step is the breaking of bonds to bridging oxygens at the edge surfaces. Furthermore, it seems to support White and Zelazny's (1988) surface structure model, but the evidence is indirect and Bickmore et al. (2001) concluded that "molecular modeling calculations are needed to theoretically justify the predicted surface relaxation."

As discussed above, the PPW-DFT calculations reported here confirm the structural relaxation predicted by White and Zelazny (1988), but the calculated relaxation is not so severe that the formal charge on the (110)-type bridging oxygens is fully neutralized. In fact, the bridging oxygens are predicted to be slightly underbonded, but less so than bridging oxygens on trioctahedral (110)-type surfaces (Bickmore et al., 2001). This conclusion is consistent with a modified form of the explanation of Bickmore et al. (2001) for hectorite and nontronite dissolution behavior. That is, the rate-determining step of the dissolution process is the breaking of bonds to bridging oxygens at the edge surfaces, and hence the most stable edge faces during acid dissolution are those with little or no unsaturated valence on the bridging oxygens.

\section{CONCLUSIONS}

The structure of ideal pyrophyllite and ferripyrophyllite neutral edge surfaces has been calculated $a b$ initio using PPW-DFT methods. Results of the calculations favor the surface protonation scheme predicted by White and Zelazny (1988) and Bleam et al. (1993), and predict that much of the surface relaxation envisaged by White and Zelazny (1988) for (110)-type surfaces should occur. Relaxed surface structures were also used to predict intrinsic acidity constants for acid-base reactions involving the surface functional groups present on (110)- and (010)-type edge surfaces. It was demonstrated that surface relaxation must be taken into account in the prediction of surface acidity constants, and a revision of the bond-valence method for $\mathrm{pK}_{\mathrm{a}}$ prediction was proposed for this purpose. Collectively, these results are consistent with the atomic force microscopy observations of phyllosilicate dissolution behavior made by Bickmore et al. (2001).

\section{ACKNOWLEDGMENTS}

This work was made possible by a user grant from the Environmental Molecular Sciences Laboratory, Pacific Northwest National Laboratory. Portions of this work were funded by a grant to KLN from the U.S. Department of Energy Environmental Management Science Program (DE-FG07-99ER15009), and internal support funds to BRB from the BYU College of Physical and Mathematical Sciences. Also, work by RTC was made possible by funding provided by the U.S. Department of Energy, Office of Basic Energy Sciences, Geosciences Research Program. Sandia is a multiprogram laboratory operated by Sandia Corporation, a Lockheed Martin company, for the United States Department of Energy under contract DE-AC04-94AL85000. We also thank B. Teppen and J. Kubicki for helpful reviews of the initial manuscript. In particular, B. Teppen suggested we try the protonation scheme illustrated in Fig. 2b. I. D. Brown also offered valuable advice about calculating Lewis basicity. 


\section{REFERENCES}

Bickmore, B. R., Hochella, M. F., Jr., Bosbach, D. and Charlet, L. (1999) Methods for performing atomic force microscopy imaging of clay minerals in aqueous solutions. Clays and Clay Minerals, 47, 573-581.

Bickmore, B. R., Bosbach, D., Hochella, M. F., Jr., Charlet, L. and Rufe, E. (2001) In situ atomic force microscopy study of hectorite and nontronite dissolution: Implications for phyllosilicate edge surface structures and dissolution mechanisms. American Mineralogist, 86, 411-423.

Bleam, W. F. (1993) Atomic theories of phyllosilicates: Quantum chemistry, statistical mechanics, electrostatic theory, and crystal chemistry. Reviews of Geophysics, 31, 51-73.

Bleam, W. F., Welhouse, G. J. and Janowiak, M. A. (1993) The surface Coulomb energy and proton Coulomb potentials of pyrophyllite $\{010\},\{110\},\{100\}$, and $\{130\}$ edges. Clays and Clay Minerals, 41, 305-316.

Bosbach, D., Charlet, L., Bickmore, B. and Hochella, M., Jr (2000) The dissolution of hectorite: In-situ, real-time observations using atomic force microscopy. American Mineralogist, 85, 1209-1216.

Brady, P. V., Cygan, R. T. and Nagy, K. L. (1996) Molecular controls on kaolinite surface charge. Journal of Colloid and Interface Science, 183, 356-364.

Bridgeman, C. H., Buckingham, A. D., Skipper, N. T. and Payne, M. C. (1996) Ab initio total energy study of uncharged 2:1 clays and their interaction with water. Molecular Physics, 89, 879-888.

Brown, I. D. (1981) The bond-valence method: An empirical approach to chemical structure and bonding. Pp. 1-30 in: Structure and Bonding in Crystals (O'Keefe, M. and Navrotsky, A., eds.). Academic Press, New York.

Brown, I. D. and Altermatt, D. (1985) Bond-valence parameters obtained from a systematic analysis of the inorganic crystal structure database. Acta Crystallographica, B41, 244247.

Brown, I. D. (2002) The Chemical Bond in Inorganic Chemistry: The Bond Valence Model. Oxford University Press, New York, 278 pp.

Chang, F.-R. C. and Sposito, G. (1994) The electrical double layer of a disk-shaped clay mineral particle: Effect of particle size. Journal of Colloid and Interface Science, 163, 19-27.

Chang, F.-R. C. and Sposito, G. (1996) The electrical double layer of a disk-shaped clay mineral particle: Effects of electrolyte properties and surface charge density. Journal of Colloid and Interface Science, 178, 555-564.

Chatterjee, A., Iwasaki, T. and Ebina, T. (2000) A novel method to correlate layer charge and the catalytic activity of 2:1 dioctahedral smectite clays in terms of binding the interlayer cation surrounded by monohydrate. Journal of Physical Chemistry A, 104, 8216-8223.

Chukhrov, F. V., Zvyagin, B. B., Drits, V. A., Gorshkov, A. I., Ermilova, L. P., Goilo, E. A. and Rudnitskaya, E. S. (1979). The ferric analogue of pyrophyllite and related phases. Proceedings of the International Clay Conference, Oxford, 1978, Oxford, 55-64.

Coey, J. M. D. (1988) Magnetic properties of iron in soil iron oxides and clay minerals. Pp. $397-$ 466 in: Iron in Soils and Clay Minerals (Stucki, J. W., Goodman, B. A. and Schwertmann, U., eds.). D. Reidel, Boston. 
Ganor, J., Mogollón, J. L. and Lasaga, A. (1995) The effect of pH on kaolinite dissolution rates and on activation energy. Geochimica et Cosmochimica Acta, 59, 1037-1052.

Garcia, A., Elsasser, C., Zhu, J., Louie, S. G. and Cohen, M. L. (1992) Use of gradient-corrected functionals in total energy calculations for solids. Physical Review B: Condensed Matter, 46, 9829-9832.

Giese, R. F. (1975) Interlayer bonding in talc and pyrophyllite. Clays and Clay Minerals, 23, 165-166.

Hartman, P. and Perdock, W. G. (1955a) On the relations between structure and morphology of crystals. I. Acta Crystallographica, 8, 49-52.

Hartman, P. and Perdock, W. G. (1955b) On the relations between structure and morphology of crystals. II. Acta Crystallographica, 8.

Hartman, P. and Perdock, W. G. (1955c) On the relations between structure and morphology of crystals. III. Acta Crystallographica, 8, 525-529.

Hiemstra, T., Van Riemsdijk, W. H. and Bolt, G. H. (1989) Multisite proton adsorption modeling at the solid/solution interface of (hydr)oxides: A new approach. I. Model description and evaluation of intrinsic reaction constants. Journal of Colloid and Interface Science, 133, 91-104.

Hiemstra, T., Venema, P. and Van Riemsdijk, W. H. (1996) Intrinsic proton affinity of reactive surface groups of metal (hydr)oxides: The bond valence principle. Journal of Colloid and Interface Science, 184, 680-692.

Hiemstra, T., Yong, H. and Van Riemsdijk, W. (1999) Interfacial charging phenomena of aluminum (hydr)oxides. Langmuir, 15, 5942-5955.

Kaviratna, H. and Pinnavaia, T. J. (1994) Acid hydrolysis of octahedral $\mathrm{Mg}^{2+}$ sites in 2:1 layered silicates: an assessment of edge attack and gallery access mechanisms. Clays and Clay Minerals, 42, 717-723.

Kraepiel, A. M., Keller, K. and Morel, F. M. M. (1998) On the acid-base chemistry of permanently charged minerals. Environmental Science and Technology, 32, 2829-2838.

Kresse, G. and Furthmuller, J. (1996) Efficient iterative schemes for ab initio total-energy calculations using a plane-wave basis set. Physical Review B: Condensed Matter, 54, 11169-11186.

Lee, J. H. and Guggenheim, S. (1981) Single crystal X-ray refinement of pyrophyllite - 1Tc. American Mineralogist, 66, 350-357.

Muljadi, D., Posner, A. M. and Quirk, J. P. (1966) The mechanism of phosphate adsorption by kaolinite, gibbsite, and pseudoboehmite. Journal of Soil Science, 17, 212-247.

Payne, M. C., Teter, M. P., Allan, D. C., Arias, T. A. and Joannopoulos, J. D. (1992) Iterative minimization techniques for ab initio total-energy calculations: Molecular dynamics and conjugate gradients. Reviews of Modern Physics, 64, 1045-1097.

Perdew, J. P. and Wang, Y. (1992) Accurate and simple analytic representation of the electrongas correlation-energy. Physical Review B: Condensed Matter, 45, 13244-13249.

Perrin, D. D. (1982) Ionization Constants of Inorganic Acids and Bases in Aqueous Solution. Pergamon, Oxford,pp.

Rosso, K. M. (2001) Structure and reactivity of semiconducting mineral surfaces: Convergence of molecular modeling and experiment. Pp. 199-271 in: Molecular Modeling Theory: Applications in the Geosciences (Cygan, R. T. and Kubicki, J. D., eds.). Mineralogical Society of America, Washington D. C. 
Rosso, K. M., Rustad, J. R. and Bylaska, E. J. (2001) The Cs/K exchange in muscovite interlayers: An ab initio treatment. Clays and Clay Minerals, 49, 500-513.

Rufe, E. and Hochella, M., Jr. (1999) Quantitative assessment of reactive surface area of phlogopite dissolution during acid dissolution. Science, 285, 874-876.

Sahai, N. (2002) Is silica really an anomalous oxide? Surface acidity and aqueous hydrolysis revisited. Environmental Science and Technology, 36, 445-452.

Schofield, R. D. and Samson, H. R. (1953) The deflocculation of kaolinite suspensions and the accompanying change-over from positive to negative chloride adsorption. Clay Minerals Bulletin, 2, 45-51.

Sefcik, J. and Goddard, W. A. I. (2001) Thermochemistry of silicic acid deprotonation: Comparison of gas-phase and solvated DFT calculations to experiment. Geochimica et Cosmochimica Acta, 65, 4435-4443.

Stumm, W. (1992) The Chemistry of the Solid-Water Interface. Wiley, New York, 428 pp.

Sverjensky, D. A. and Sahai, N. (1996) Theoretical prediction of single-site surface-protonation equilibrium constants for oxides and silicates in water. Geochimica et Cosmochimica Acta, 60, 3773-3797.

Teppen, B. J., Yu, C. H., Newton, S. Q., Miller, D. M. and Schafer, L. (2002) Quantum molecular dynamics simulations regarding the dechlorination of trichloro ethene in the interlayer space of the 2:1 clay mineral nontronite. Journal of Physical Chemistry A, 106, 5498-5503.

Turpault, M.-P. and Trotignon, L. (1994) The dissolution of biotite single crystals in dilute $\mathrm{HNO}_{3}$ at $24^{\circ} \mathrm{C}$ : Evidence of an anisotropic corrosion process of micas in acidic solutions. Geochimica et Cosmochimica Acta, 58, 2761-2775.

Vanderbilt, D. (1990) Soft self-consistent pseudopotentials in a generalized eigenvalue formalism. Physical Review B: Condensed Matter, 41, 7892-7895.

White, G. N. and Zelazny, L. W. (1988) Analysis and implications of the edge structure of dioctahedral phyllosilicates. Clays and Clay Minerals, 36, 141-146.

White, J. A. and Bird, D. M. (1994) Implementation of gradient-corrected exchange-correlation potentials in Car-Parrinello total energy calculations. Physical Review B: Condensed Matter, 50, 4954-4957.

Wieland, E. and Stumm, W. (1992) Dissolution kinetics of kaolinite in acidic aqueous solutions at $25^{\circ} \mathrm{C}$. Geochimica et Cosmochimica Acta, 56, 3339-3355.

Wu, X., Vargas, M. C., Nayak, S., Lotrich, V. and Scoles, G. (2001) Towards extending the applicability of density functional theory to weakly bound systems. Journal of Chemical Physics, 115, 8748-8757.

Xiao, Y. and Lasaga, A. C. (1994) Ab initio quantum mechanical studies of the kinetics and mechanisms of silicate dissolution: $\mathrm{H}^{+}\left(\mathrm{H}_{3} \mathrm{O}^{+}\right)$catalysis. Geochimica et Cosmochimica Acta, 58, 5379-5400.

Zysset, M. and Schindler, P. W. (1996) The proton promoted dissolution kinetics of Kmontmorillonite. Geochimica et Cosmochimica Acta, 60, 921-931. 
Pyrophyllite 1Tc Unit Cell Parameters:

\begin{tabular}{cccccc}
\hline $\boldsymbol{a}(\AA)$ & $\boldsymbol{b}(\AA)$ & $\boldsymbol{c}(\AA)$ & $\alpha\left(^{\circ}\right)$ & $\beta\left(^{\circ}\right)$ & $\gamma\left({ }^{\circ}\right)$ \\
\hline \hline 5.1488 & 8.9979 & 9.8409 & 91.2047 & 100.7358 & 89.6576
\end{tabular}

\section{Fractional Atomic Coordinates:}

\begin{tabular}{rlll}
\hline \hline & $x$ & $y$ & $z$ \\
$\mathrm{Al}$ & 0.4972 & 0.1672 & 0.0034 \\
$\mathrm{Si}(1)$ & 0.7487 & 0.9947 & 0.2743 \\
$\mathrm{Si}(2)$ & 0.7566 & 0.3233 & 0.2787 \\
$\mathrm{O}(1)$ & 0.6432 & 0.0012 & 0.1097 \\
$\mathrm{O}(2)$ & 0.7280 & 0.3089 & 0.1126 \\
$\mathrm{O}(3)$ & 0.2272 & 0.1930 & 0.1059 \\
$\mathrm{O}(4)$ & 0.0325 & 0.4005 & 0.3402 \\
$\mathrm{O}(5)$ & 0.7548 & 0.1595 & 0.3380 \\
$\mathrm{O}(6)$ & 0.5264 & 0.4236 & 0.3193 \\
$\mathrm{H}$ & 0.1668 & 0.1144 & 0.1572
\end{tabular}

Ferripyrophyllite 1Tc Unit Cell Parameters:

\begin{tabular}{cccccc}
\hline $\boldsymbol{a}(\AA)$ & $\boldsymbol{b}(\AA)$ & $\boldsymbol{c}(\AA)$ & $\alpha\left(^{\circ}\right)$ & $\beta\left(^{\circ}\right)$ & $\gamma\left({ }^{\circ}\right)$ \\
\hline \hline 5.2137 & 9.1105 & 9.9606 & 90.7711 & 100.6439 & 89.7720
\end{tabular}

\begin{tabular}{rccc}
\hline \multicolumn{4}{c}{ Fractional Atomic Coordinates: } \\
\hline \hline & $x$ & $y$ & $z$ \\
$\mathrm{Fe}$ & 0.4985 & 0.1656 & 0.0012 \\
$\mathrm{Si}(1)$ & 0.7555 & 0.9946 & 0.2811 \\
$\mathrm{Si}(2)$ & 0.7565 & 0.3243 & 0.2839 \\
$\mathrm{O}(1)$ & 0.6707 & 0.0007 & 0.1171 \\
$\mathrm{O}(2)$ & 0.7217 & 0.3153 & 0.1192 \\
$\mathrm{O}(3)$ & 0.2232 & 0.1860 & 0.1115 \\
$\mathrm{O}(4)$ & 0.0302 & 0.4026 & 0.3418 \\
$\mathrm{O}(5)$ & 0.7585 & 0.1599 & 0.3396 \\
$\mathrm{O}(6)$ & 0.5247 & 0.4211 & 0.3235 \\
$\mathrm{H}$ & 0.1529 & 0.1041 & 0.1538
\end{tabular}

Table 1. Calculated unit cell parameters and atomic coordinates for the pyrophyllite and ferripyrophyllite $1 T c$ structures, assuming $\mathrm{C}^{\overline{1}}$ symmetry. 
Pyrophyllite 1Tc (Lee and Guggenheim, 1981)

\begin{tabular}{cccccc}
\hline $\boldsymbol{a}(\AA)$ & $\boldsymbol{b}(\AA)$ & $\boldsymbol{c}(\AA)$ & $\alpha\left(^{\circ}\right)$ & $\beta\left(^{\circ}\right)$ & $\gamma\left(\mathbf{(}^{\circ}\right)$ \\
\hline \hline 5.160 & 8.966 & 9.347 & 91.18 & 100.46 & 89.64
\end{tabular}

Ferripyrophyllite $2 M$ (Chukhrov et al., 1979)

\begin{tabular}{cccc}
\hline $\boldsymbol{a}(\AA)$ & $\boldsymbol{b}(\AA)$ & $\boldsymbol{c}(\AA)$ & $\beta\left(^{\circ}\right)$ \\
\hline \hline 5.26 & 9.10 & 19.1 & 95.5
\end{tabular}

Table 2. Experimentally determined unit cell parameters for pyrophyllite $1 T c$ and ferripyrophyllite $2 M$.

\begin{tabular}{lccc}
\hline & \multicolumn{3}{c}{ Bond Length Shifts $(\AA)$} \\
\hline Bond Type & $\begin{array}{c}\text { (010)-type } \\
\text { (See Fig. 2a) }\end{array}$ & $\begin{array}{c}\text { (110)-type } \\
\text { (See Fig. 2c) }\end{array}$ & $\begin{array}{c}\text { (110)-type } \\
\text { (See Fig. 2d-e) }\end{array}$ \\
\hline \hline Si-O & -0.030 to +0.011 & -0.033 to +0.009 & -0.037 to +0.016 \\
Al-O & -0.058 to +0.030 & -0.061 to +0.068 & -0.046 to +0.053 \\
Fe-O & -0.021 to +0.056 & -0.015 to +0.061 & -0.022 to +0.067 \\
\hline
\end{tabular}

Table 3. Calculated bond length shifts for interior polyhedra in the pyrophyllite and ferripyrophyllite edge structures, relative to the same bond lengths in calculated bulk structures. 


\begin{tabular}{|c|c|c|c|}
\hline \multicolumn{4}{|c|}{$\begin{array}{c}\text { Total Bond Strength (v.u.) Reaching Surface Oxygens, Excluding H- } \\
\text { O Bonds (Pyrophyllite) }\end{array}$} \\
\hline \multicolumn{2}{|c|}{$\begin{array}{l}\text { (010)-type } \\
\text { (See Fig. 2a) }\end{array}$} & \multicolumn{2}{|l|}{$\begin{array}{l}\text { (110)-type } \\
\text { (See Fig. 2d-e) }\end{array}$} \\
\hline$>\mathrm{Si}-\mathrm{O}$ & 1.051 & $>\mathrm{Si}-\mathrm{O}$ & 1.025 \\
\hline$>\mathrm{Al}-\mathrm{OH}$ & 0.674 & $>$ SiAl-O (bridging O) & 1.861 \\
\hline$>\mathrm{Al}-\mathrm{OH}_{2}$ & 0.290 & $>\mathrm{Al}-\mathrm{OH}_{2}$ & 0.327 \\
\hline$>\mathrm{Si}-\mathrm{O}$ & 1.002 & $>\mathrm{Si}-\mathrm{O}$ & 0.986 \\
\hline \multicolumn{4}{|c|}{$\begin{array}{c}\text { Total Bond Strength (v.u.) Reaching Surface Oxygens, Excluding H- } \\
\text { O Bonds (Ferripyrophyllite) }\end{array}$} \\
\hline \multicolumn{2}{|c|}{$\begin{array}{c}\text { (010)-type } \\
\text { (See Fig. 2a) }\end{array}$} & \multicolumn{2}{|l|}{$\begin{array}{c}\text { (110)-type } \\
\text { (See Fig. 2d-e) }\end{array}$} \\
\hline$>\mathrm{Si}-\mathrm{O}$ & 1.042 & $>\mathrm{Si}-\mathrm{O}$ & 1.031 \\
\hline$>\mathrm{Fe}-\mathrm{OH}$ & 0.698 & $>\mathrm{SiFe}-\mathrm{O}$ (bridging O) & 1.757 \\
\hline$>\mathrm{Fe}-\mathrm{OH}_{2}$ & 0.332 & $>\mathrm{Fe}-\mathrm{OH}_{2}$ & 0.316 \\
\hline$>\mathrm{Si}-\mathrm{O}$ & 0.989 & $>\mathrm{Si}-\mathrm{O}$ & 0.991 \\
\hline
\end{tabular}

Table 4. Total calculated Brown bond strength (v.u.) reaching the surface $\mathrm{O}$ atoms (excluding $\mathrm{H}-\mathrm{O}$ bonds) on each type of edge structure studied. 


\begin{tabular}{|c|c|c|c|}
\hline \multicolumn{4}{|c|}{ (010)-type Surface Reactions (Pyrophyllite) } \\
\hline Site Type & $\begin{array}{l}\text { Sites/unit } \\
\text { cell face }\end{array}$ & Reactions & $\mathrm{pK}_{\mathrm{a}}$ \\
\hline $\begin{aligned} & \text { Si-OH (silanol) } \\
> & \text { Al- } \mathrm{OH}_{2} \text { (aluminol) }\end{aligned}$ & 2 & $\begin{aligned}>\mathrm{Si}-\mathrm{OH} & =>\mathrm{Si}-\mathrm{O}^{-}+\mathrm{H}^{+} \\
>\mathrm{Si}^{-} \mathrm{OH}_{2}^{+} & =>\mathrm{Si}-\mathrm{OH}+\mathrm{H}^{+} \\
>\mathrm{Al}_{-} \mathrm{OH}_{2}^{+1 / 2} & =>\mathrm{Al}-\mathrm{OH}^{-1 / 2}+\mathrm{H}^{+}\end{aligned}$ & $\begin{array}{l}8.3,8.4^{*} \\
-3.6,-3.5 \\
8.5\end{array}$ \\
\hline \multicolumn{4}{|c|}{ (010)-type Surface Reactions (Ferripyrophyllite) } \\
\hline $\begin{array}{l}\text { Si-OH (silanol) } \\
>\text { Fe-OH }{ }_{2} \text { (ferrinol) }\end{array}$ & 2 & $\begin{aligned} \mathrm{Si}-\mathrm{OH} & =>\mathrm{Si}-\mathrm{O}^{-}+\mathrm{H}^{+} \\
>\mathrm{Si}-\mathrm{OH}_{2}^{+} & =>\mathrm{Si}-\mathrm{OH}+\mathrm{H}^{+} \\
>\mathrm{Fe}^{-} \mathrm{OH}_{2}^{+1 / 2} & =>\mathrm{Fe}-\mathrm{OH}^{-1 / 2}+\mathrm{H}^{+}\end{aligned}$ & $\begin{array}{c}8.1 \\
-3.8 \\
8.5,8.9 \\
\end{array}$ \\
\hline \multicolumn{4}{|c|}{ (110)-type Surface Reactions (Pyrophyllite) } \\
\hline $\begin{aligned} & \text { Si-OH (silanol) } \\
&>\text { SiAl-OH (bridging O) } \text { Al-OH }{ }_{2} \text { (aluminol) } \\
&\end{aligned}$ & 4 & $\begin{aligned}>\mathrm{Si}-\mathrm{OH} & =>\mathrm{Si}-\mathrm{O}^{-}+\mathrm{H}^{+} \\
>\mathrm{Si}-\mathrm{OH}_{2}^{+} & =>\mathrm{Si}-\mathrm{OH}+\mathrm{H}^{+} \\
>\mathrm{SiAl}-\mathrm{OH}^{+1 / 2} & =>\mathrm{SiAl}-\mathrm{O}^{-1 / 2}+\mathrm{H}^{+} \\
>\mathrm{Al}_{-} \mathrm{OH}_{2}{ }^{+1 / 2} & =>\mathrm{Al}-\mathrm{OH}^{-1 / 2}+\mathrm{H}^{+}\end{aligned}$ & $\begin{array}{c}8.7,7.6 \\
-3.1,-4.3 \\
1.5(5.5)^{\#} \\
10.6 \\
\end{array}$ \\
\hline \multicolumn{4}{|c|}{ (110)-type Surface Reactions (Ferripyrophyllite) } \\
\hline $\begin{aligned} & \text { Si-OH (silanol) } \\
> & \text { SiFe-OH (bridging O) } \\
> & \text { Fe-OH } 2 \text { (aluminol) }\end{aligned}$ & $\begin{array}{l}2 \\
2\end{array}$ & $\begin{aligned}>\mathrm{Si}-\mathrm{OH} & =>\mathrm{Si}-\mathrm{O}^{-}+\mathrm{H}^{+} \\
>\mathrm{Si}-\mathrm{OH}_{2}^{+} & =>\mathrm{Si}-\mathrm{OH}+\mathrm{H}^{+} \\
>\mathrm{SiFe}-\mathrm{OH}^{+1 / 2} & =>\mathrm{SiFe}-\mathrm{O}^{-1 / 2}+\mathrm{H}^{+} \\
>\mathrm{Fe}-\mathrm{OH}_{2}^{+1 / 2} & =>\mathrm{Fe}-\mathrm{OH}^{-1 / 2}+\mathrm{H}^{+}\end{aligned}$ & $\begin{array}{c}8.1,7.8 \\
-3.8,-4.1 \\
0.8(4.8) \\
10.7\end{array}$ \\
\hline $\begin{array}{l}\text { Entries with a second pKa v } \\
\text { different calculated pKa valu } \\
\text { \#Entries outside the parenth } \\
\text { parentheses were calculatec }\end{array}$ & $\begin{array}{l}\text { le after a cc } \\
\text { s were cal } \\
\text { ith } m+n=1 \text {. }\end{array}$ & $\begin{array}{l}\text { dicate two different groups with identica } \\
\text { with } m+n=2 \text { in eq. } 3 \text {, and entries inside }\end{array}$ & y, but \\
\hline
\end{tabular}

Table 5. Site types, number of sites per unit cell face, possible surface acid-base reactions, and intrinsic acidity constants for surface functional groups on pyrophyllite and ferripyrophyllite edge surfaces. The acidity constants are calculated using the method of Hiemstra et al. (1996) 


\begin{tabular}{|c|c|c|c|}
\hline \multicolumn{4}{|c|}{ (010)-type Surface Reactions (Pyrophyllite) } \\
\hline Site Type & $\begin{array}{l}\text { Sites/unit } \\
\text { cell face }\end{array}$ & Reactions & $\mathrm{pK}_{\mathrm{a}}$ \\
\hline $\begin{aligned} & \text { Si-OH (silanol) } \\
> & \text { Al-OH }{ }_{2} \text { (aluminol) }\end{aligned}$ & 2 & $\begin{aligned}>\mathrm{Si}-\mathrm{OH} & =>\mathrm{Si}-\mathrm{O}^{-}+\mathrm{H}^{+} \\
>\mathrm{Si}_{-} \mathrm{OH}_{2}^{+} & =>\mathrm{Si}-\mathrm{OH}+\mathrm{H}^{+} \\
>\mathrm{Al}-\mathrm{OH}_{2}^{+1 / 2} & =>\mathrm{Al}-\mathrm{OH}^{-1 / 2}+\mathrm{H}^{+}\end{aligned}$ & $\begin{array}{l}7.6,7.8^{*} \\
-8.5,-4.5 \\
9.5\end{array}$ \\
\hline \multicolumn{4}{|c|}{$\begin{array}{cc}\text { (010)-type Surface Reactions (Ferripyrophyllite) } \\
\end{array}$} \\
\hline $\begin{array}{l}>\mathrm{Si}-\mathrm{OH} \text { (silanol) } \\
>\mathrm{Fe}-\mathrm{OH}_{2} \text { (ferrinol) }\end{array}$ & 2 & $\begin{aligned}>\mathrm{Si}-\mathrm{OH} & =>\mathrm{Si}-\mathrm{O}^{-}+\mathrm{H}^{+} \\
>\mathrm{Si}^{-} \mathrm{OH}_{2}^{+} & =>\mathrm{Si}-\mathrm{OH}+\mathrm{H}^{+} \\
>\mathrm{Fe}^{-} \mathrm{OH}_{2}^{+1 / 2} & =>\mathrm{Fe}-\mathrm{OH}^{-1 / 2}+\mathrm{H}^{+}\end{aligned}$ & $\begin{array}{l}8.0,7.9 \\
-7.7,-3.5 \\
8.9 \\
\end{array}$ \\
\hline \multicolumn{4}{|c|}{ (110)-type Surface Reactions (Pyrophyllite) } \\
\hline $\begin{array}{c}\text { > SiAl-OH (bridging O) } \\
>\text { >Al-OH } \mathrm{OH}_{2} \text { (aluminol) }\end{array}$ & $\begin{array}{l}2 \\
2\end{array}$ & 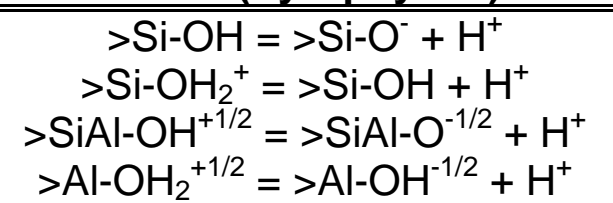 & $\begin{array}{c}11.1 \\
-6.2,-3.3 \\
-9.5 \\
11.3\end{array}$ \\
\hline \multicolumn{4}{|c|}{ (110)-type Surface Reactions (Ferripyrophyllite) } \\
\hline $\begin{array}{c}>\text { SiFe-OH (bridging O) } \\
>\text { Fe- } \mathrm{OH}_{2} \text { (aluminol) }\end{array}$ & $\begin{array}{l}2 \\
2\end{array}$ & $\begin{aligned}>\mathrm{Si}-\mathrm{OH} & =>\mathrm{Si}-\mathrm{O}^{-}+\mathrm{H}^{+} \\
>\mathrm{Si}-\mathrm{OH}_{2}^{+} & =>\mathrm{Si}-\mathrm{OH}+\mathrm{H}^{+} \\
>\mathrm{SiFe}-\mathrm{OH}^{+1 / 2} & =>\mathrm{SiFe}-\mathrm{O}^{-1 / 2}+\mathrm{H}^{+} \\
>\mathrm{Fe}-\mathrm{OH}_{2}^{+1 / 2} & =>\mathrm{Fe}-\mathrm{OH}^{-1 / 2}+\mathrm{H}^{+}\end{aligned}$ & $\begin{array}{c}11.6 \\
-6.7,-3.7 \\
-1.5 \\
12.5\end{array}$ \\
\hline
\end{tabular}

"Entries with a second pKa value after a comma indicate two different groups with identical topology, but different calculated pKa values.

Table 6. Site types, number of sites per unit cell face, possible surface acid-base reactions, and intrinsic acidity constants for surface functional groups on pyrophyllite and ferripyrophyllite edge surfaces. The acidity constants are calculated using a method modified from that of Brown (1981). See text for discussion. 


\section{Figure Captions}

Figure 1. Typical pseudohexagonal phyllosilicate morphology.

Figure 2. Proposed edge surface structures and protonation schemes resulting in an overall neutral charge. a) (010)-type edge structure. b) An alternate (010)-type edge structure that has not been suggested before. c) (110)-type edge structure proposed by Bleam (1993). d) (110)-type edge structure proposed by Bleam et al. (1993). e) (110)-type edge surface proposed by White and Zelazny (1988). Note that the protonation scheme is equivalent to that in c), but structural relaxation has resulted in an overall neutral charge for each functional group.

Figure 3. Ball and stick examples of the infinitely repeating chain structures used to calculate edge surface structures, in this case with $\mathrm{Al}$ in the octahedral sites. Equivalent models were used to calculate $\mathrm{Fe}_{2} \mathrm{Si}_{2} \mathrm{O}_{5}$ edge structures. a) Chain running parallel to the [100] vector, generating a (010)-type edge surface. b) Chain running parallel to the [110] vector, generating a (110)-type surface. 


\section{Permenate Uptake by Iron and Aluminum Oxyhydroxides: An Analogue for Pertechnetate Incorporation in Hanford Waste Tank Sludges}

BRADLEY WAKOFF AND

KATHRYN L. NAGY*

Department of Geological Sciences, University of Colorado, Boulder, Colorado 80309-0399

Perrhenate $\left(\mathrm{ReO}_{4}{ }^{-}\right)$, a nonradioactive surrogate for pertechnetate $\left({ }^{99} \mathrm{TCO}_{4}{ }^{-}\right)$, was partitioned during precipitation and aging of iron and aluminum oxyhydroxide solids from aqueous simulants of high-level nuclear waste stored at Hanford, WA. Neutralization of acidic metal nitrate solutions ( $\mathrm{Al} / \mathrm{Fe}$ mole ratio 0.25 and $13.5 ; 40 \mathrm{ppm} \mathrm{Re}$ ) to a final $\mathrm{pH}>13$, followed by aging at $90^{\circ} \mathrm{C}$ for up to 18 weeks, resulted in substantial amounts of reversibly sorbed $\mathrm{Re}$ $(\sim 1-10 \mathrm{ppm})$. Irreversibly sorbed Re increased in the Fe-dominated system with aging, reaching a final value of $\sim 83 \mathrm{ppb}$ after $168 \mathrm{~h}$, in a mixture of hematite with minor goethite. Irreversibly sorbed $\mathrm{Re}$ in the Al-dominated system generally decreased with time to $\sim 30 \mathrm{ppb}$ after 18 weeks in solids dominated by boehmite. Increasing the total amount of Re to $1000 \mathrm{ppm}$ increased the extent of irreversible sorption. The presence of $100 \mathrm{ppm}$ Si prevented transformation of and irreversible Re uptake by ferrihydrite in Fe-dominated systems. In Al-dominated systems, 200 ppm Ni prevented hematite formation but did not affect perrhenate uptake. Results suggest that $5 \%$ of the ${ }^{99} \mathrm{Tc}$ inventory in the Hanford waste tanks may be associated with the sludges, and $\sim 0.5 \%$ incorporated into the solids under oxidizing conditions.

\section{Introduction}

Between 1944 and 1988, the U.S. Department of Energy's Hanford Site in southeastern Washington State produced special nuclear materials for the nuclear weapons program, and as a byproduct, large volumes of nitric acid-based liquid waste streams. The acidic waste streams initially were neutralized with $\mathrm{NaOH}$ to a $\mathrm{pH}$ above 10 for storage in lowcarbon steel tanks and, over time, have been extensively reprocessed, leaving residuals of sludges, saltcake, and supernatant $(1)$. These waste residuals are stored underground in 149 single-shell steel-lined concrete tanks and 28 newer double-shell tanks. Sixty-seven single-shell tanks definitely or possibly have leaked (2). The tank contents are treated as high-level waste (HLW) and are a complex mixture of distinct phases. Because of the large number of chemical separation processes used at Hanford and the mixing of wastes over time, the variability among tanks is great $(1)$. Major solutes

* Corresponding author address: Department of Earth and Environmental Sciences, MC-186, University of Illinois at Chicago, Chicago, IL 60607; phone: (312) 355-3276; fax: (312) 413-2279; e-mail: klnagy@uic.edu. in the supernatants are $\mathrm{Na}^{+}, \mathrm{Al}(\mathrm{OH})_{4}^{-}, \mathrm{OH}^{-}, \mathrm{NO}_{3}{ }^{-}$, and $\mathrm{NO}_{2}{ }^{-}$, the saltcakes are predominately $\mathrm{NaNO}_{3}$, and the dominant solids in the sludges include aluminum and iron oxyhydroxides. U fission products in the HLW include ${ }^{137} \mathrm{Cs}\left(t_{1 / 2}\right.$ $=30$ years), ${ }^{90} \mathrm{Sr}\left(t_{1 / 2}=28\right.$ years), and ${ }^{99} \mathrm{Tc}\left(t_{1 / 2}=2.1 \times 10^{5}\right.$ years). It is generally considered that transuranic elements and ${ }^{90} \mathrm{Sr}$ are associated with the solids and ${ }^{137} \mathrm{Cs}$ and ${ }^{99} \mathrm{Tc}$ are associated with the liquids. ${ }^{99} \mathrm{Tc}$ is the major concern in longterm risk assessments because of its relatively long half-life and the chemical stability and solubility of the pertechnetate ion $\left(\mathrm{TcO}_{4}^{-}\right)$under aerobic conditions (3-5).

Approximately $32000 \mathrm{Ci}$ of ${ }^{99} \mathrm{Tc}$ were produced in the Hanford reactor fuels and reprocessed using three different Pu-recovery processes (1). Some ${ }^{99} \mathrm{Tc}$ was co-extracted with uranium in the tributyl phosphate/kerosene-based (i.e., PUREX) separation processes $(6,7)$, and some was lost to the soil during intentional liquid waste discharges and in singleshell tank leaks (8). The present ${ }^{99} \mathrm{Tc}$ tank inventory is estimated to be $26000 \mathrm{Ci}$, distributed about equally between the single-shell and double-shell tanks.

There is considerable uncertainty about the current chemical speciation and distribution of ${ }^{99} \mathrm{Tc}$ in the tanks. Early on, ${ }^{99} \mathrm{Tc}$ remained in the liquids generated during reprocessing of tank wastes and was generally ignored until the 1960 s when a few tens of kilograms were separated and recovered $(9,10)$. Large-scale recovery was not implemented, however, and most ${ }^{99} \mathrm{Tc}$ was left in ${ }^{137} \mathrm{Cs}$-recovery waste streams that were comingled with other waste streams during complex dewatering processes and ultimately returned to the single-shell tanks. The reprocessing and redistribution of ${ }^{99} \mathrm{Tc}$ resulted in the occurrence of significant amounts of nonwater leachable forms of ${ }^{99} \mathrm{Tc}$ in some single-shell tanks (11). In addition, it has been shown that Tc exhibits a wide range of redox and solubility characteristics in the radiation fields and chemical mixtures that existed in some tanks (12, 13). Developing a better understanding of interactions between ${ }^{99} \mathrm{Tc}$ and tank waste solids is critical in developing strategies for tank waste retrieval and closure.

With respect to tank sludges, it is generally known that, upon neutralization of acidic solutions, Fe and Al form poorly ordered oxyhydroxides that age to more stable crystalline phases. The initial Fe precipitate is commonly two-line ferrihydrite, which transforms to hematite and/or goethite. Early-formed amorphous Al phases or bayerite transforms to gibbsite and/or boehmite depending on temperature. There is a range of reported interactions of dissolved cations and anions with these oxides upon aging. For example, transition metals coprecipitated with ferrihydrite or amorphous aluminum oxyhydroxides can be either incorporated into or rejected from the crystalline solids with aging $(14-17)$. Oxyanions $(18-22)$ sorb strongly to iron oxides, can impede transformation reactions, and can be occluded in the solids.

Sorption of Tc or its chemical analogue $\operatorname{Re}(23)$ on oxides is minimal under oxic conditions above $\mathrm{pH} 7(24-27)$. Data on incorporation of Tc within solid oxides are less comprehensive, but indicative of conditions under which such uptake can occur. Trace amounts of Tc were incorporated into goethite and hematite upon aging of ferrihydrite in $10^{-11} \mathrm{M}$ Tc solutions at $60^{\circ} \mathrm{C}$ for $66 \mathrm{~h}(26)$. Under reducing conditions and from bicarbonate solutions containing $10^{-5} \mathrm{M} \mathrm{TCO}_{4}^{-}$, $4 \%$ of the total inventory of Tc was taken up in hematite formed at $60^{\circ} \mathrm{C}$ after $4 \mathrm{~h}$, ostensibly as a Tc(IV) - bicarbonate complex (26). Tc and Re were incorporated in goethite formed by oxidizing mackinawite (FeS) that contained coprecipitated Tc(IV) or $\operatorname{Re}(\mathrm{IV})$; Tc remained as reduced domains of $\mathrm{TcO}_{2}$,

VOL. 38, NO. 6, 2004 / ENVIRONMENTAL SCIENCE \& TECHNOLOGY = 1765 


\section{TABLE 1. Initial Experimental ${ }^{a}$ and Actual Reprocessing Solution Compositions}

$\begin{array}{ccc}{[\mathrm{Fe}]} & {[\mathrm{Al}]} & \mathrm{Al} / \mathrm{Fe} \\ (\mathrm{mol} / \mathrm{L}) & (\mathrm{mol} / \mathrm{L}) & \text { mole ratio }\end{array}$

$\begin{array}{llll}\mathrm{TBP}^{b} \mathrm{U} \text {-recovery } & 1.6 \times 10^{-2} & 0 & 0\end{array}$ bismuth phosphate $3.15 \times 10^{-2} 0$ to $8.25 \times 10^{-2} 0-2.62$ $\begin{array}{llll}\text { PUREX }^{c} & 0.4 & 0-1.32 & 0-3.3\end{array}$ $\begin{array}{llll}\text { PUREX }^{d} & 0.04-0.06 & 0 & 0\end{array}$

$\begin{array}{llll}\text { REDOX }^{e} & 4.8 \times 10^{-2} & 0.648 & 13.5\end{array}$

$\begin{array}{llll}\text { Fe system }^{f} & 0.05 & 0.0125 & 0.25\end{array}$

$\begin{array}{llll}\text { Al system }^{g} & 0.05 & 0.675 & 13.5\end{array}$

${ }^{a}$ Compositions refer to the acidic metal nitrate solutions prior to neutralization and precipitation of solids. ${ }^{b}$ Tributyl phosphate. ${ }^{c} \mathrm{Plu}$ tonium-uranium extraction (from J. Krumhansl, personal communication 1998) d From ${ }^{d} 29 .{ }^{e}$ Reduction-oxidation ${ }^{f}$ Bismuth phosphate and PUREX analogue; $\left[\mathrm{NO}_{3}{ }^{-}\right]=4.19 \mathrm{~mol} / \mathrm{L} ; \mathrm{pH}_{\text {final }}=13.7 .{ }^{g} \mathrm{REDOX}$ analogue; $\left[\mathrm{NO}_{3}^{-}\right]=6.18 \mathrm{~mol} / \mathrm{L} ; \mathrm{pH}_{\text {final }}=13.1$.

but Re was thought to oxidize and diffuse to channels in the goethite structure (28). Both perrhenate and pertechnetate were incorporated by Al-rich HLW simulants, but excluded by $\mathrm{Fe}$-rich simulants, aged overnight at room temperature (27). Approximately $30 \%$ of $40 \mathrm{ppm}$ added Re and $1 \mathrm{ppm}$ added Tc were retained by the $\mathrm{Al}$-rich sludges as determined by difference on the aqueous phase. However, long-term binding of perrhenate and pertechnetate in the solids was not assessed in any of the above studies.

To understand Tc uptake in tank sludges, we investigated Re partitioning during oxyhydroxide precipitation and aging in simplified $\mathrm{Fe}-\mathrm{Al} \mathrm{HLW}$ simulants at $90^{\circ} \mathrm{C}$, under oxidizing conditions. The influence of $\mathrm{Si}$ on Fe-dominated systems and $\mathrm{Ni}$ on Al-dominated systems also was investigated. $\mathrm{Si}$ and $\mathrm{Ni}$ are minor components in HLW sludges (1) and could affect aging kinetics and partitioning of Re through the formation of minor phases. Because of the importance of determining the long-term fate of ${ }^{99} \mathrm{Tc}$, we focused on quantifying and characterizing the extent of irreversible $\mathrm{Re}$ sorption in the synthetic sludge solids.

\section{Experimental Section}

Sample Synthesis. Sample synthesis mimicked HLW reprocessing procedures, and major component concentrations approximated those of reprocessing solutions (Table 1). Minor component ( $\mathrm{Si}, \mathrm{Ni}$, and analogue $\mathrm{Re}$ ) and $\mathrm{Na}$ concentrations approximated those of average HLW (Table 2). Minor component concentrations in sludge interstitial fluids vary greatly depending on the origin of the wastes and the presence of sludge solids that contain these components.

Two compositional systems characteristic of the range of $\mathrm{Al} / \mathrm{Fe}$ mole ratios in the tanks were investigated: an $\mathrm{Fe}-$ dominated system $(\mathrm{Al} / \mathrm{Fe}=0.25)$ and an $\mathrm{Al}$-dominated system $(\mathrm{Al} / \mathrm{Fe}=13.5)$. The $\mathrm{Fe}$ system was investigated with and without $100 \mathrm{ppm} \mathrm{Si}$ and the Al system with and without 200 $\mathrm{ppm} \mathrm{Ni.} \mathrm{Each} \mathrm{of} \mathrm{these} \mathrm{four} \mathrm{systems} \mathrm{was} \mathrm{investigated} \mathrm{with}$ and without $40 \mathrm{ppm}$ Re (equivalent to $21 \mathrm{ppm}$ Tc on a per mole basis). Some experiments in the Fe system without $\mathrm{Si}$ or in the Al system without Ni contained $1000 \mathrm{ppm} \operatorname{Re}(525$ ppm equivalent Tc), much higher than equivalent Tc concentrations in HLW ( $\sim-15 \mathrm{ppm})$. All chemicals were reagent grade except sources of $\operatorname{Re}(10000 \mathrm{ppm}$ ammonium perrhenate solution (SPEX Certiprep) and sodium perrhenate salt (>99\% purity, Aldrich)) and certain mineral acids. Si was added as sodium silicate, and all other components were added as nitrate salts.

$\mathrm{Fe}-\mathrm{Al}-\mathrm{Na}-\mathrm{NO}_{3}$ solutions with or without minor components (initial $\mathrm{pH}<1$ ) and open to the atmosphere were neutralized with $15 \mathrm{M} \mathrm{NaOH}$ to a final $\mathrm{pH}>13$ in $250 \mathrm{~mL}$ HDPE or 2 L PP bottles. The caustic suspensions were submerged and aged in a $90 \pm 1{ }^{\circ} \mathrm{C}$ water bath as either a series of $250 \mathrm{~mL}$ samples or a 1.5 or $2 \mathrm{~L}$ batch experiment from which $200-250 \mathrm{~mL}$ aliquots were drawn. Most experiments were conducted for $168 \mathrm{~h}$, except for a single 18 week experiment in the $\mathrm{Al}$ system.

Aged samples were withdrawn from the water bath and immediately centrifuged for $3-5 \mathrm{~min}$ at $1500 \mathrm{rpm}$. Supernatant was decanted, filtered $(0.45 \mu \mathrm{m}$ nylon), and analyzed for $\mathrm{pH}, \mathrm{Al}$, and $\mathrm{Re}$ where appropriate. Solids were centrifuged-washed twice with $\sim 150 \mathrm{~mL}$ of deionized water, transferred to dialysis tubing (Spectrum Spectra/Por molecular porous membrane, MWCO 12-14000), and dialyzed with 1 or $2 \mathrm{~L}$ of deionized water daily for up to 10 days and to a final conductivity of $<10 \mu \mathrm{S}$. Washed solids were freezedried. To assess the nature of Re retention, the dialysis step was omitted in some experiments.

For comparison to aged products in the Fe system experiments, pure goethite was synthesized (30) from a solution spiked with $40 \mathrm{ppm}$ Re. Samples were aged $\left(70^{\circ} \mathrm{C}\right.$, $\mathrm{pH} \approx 13$ ), dialyzed, and analyzed for Re. No attempt was made to assess Re uptake by other individual $\mathrm{Fe}$ or $\mathrm{Al}$ phases under the experimental aging conditions.

Solution Analysis. The final $\mathrm{pH}$ was measured at room temperature with an Orion glass combination electrode. The $\mathrm{pH}$ at $90^{\circ} \mathrm{C}$ and $I>6 \mathrm{~m}$ should be about $0.8 \mathrm{pH}$ unit lower than that measured (31). Given the complex thermodynamics of multicomponent brines and the poor response of glass electrodes in concentrated Na solutions (32), however, it is not possible to infer accurately hydroxyl concentrations at temperature from the measured $\mathrm{pH}$.

Al was measured by UV-vis spectroscopy (33), which required dilution to the micromolal range in $0.1 \mathrm{M} \mathrm{HCl}$. Fe was below the detection limit of the Ferrozine method (34; $\sim 7 \times 10^{-7} \mathrm{~m}$ ). Re was measured by ICP-AES (ARL model $3410+)$ using standards prepared from the $10000 \mathrm{ppm}$ standard in $1 \mathrm{M} \mathrm{HCl}$ (Fisher trace metal grade). To mitigate viscosity effects, samples were diluted 10 times in the same $1 \mathrm{M} \mathrm{HCl}$.

Solids Analysis. Solids were identified by X-ray diffraction (XRD) on a Scintag powder diffractometer, scanning at $2 \theta=$ $1 \%$ min using $\mathrm{Cu} \mathrm{K} \alpha$ radiation and a graphite beam monochromator. Hematite/goethite mass ratios were quantified by comparing the integrated intensities of the hematite (110) and goethite (110) peaks $\left(2 \theta=35-36.5^{\circ}\right.$ and $20-22.5^{\circ}$, respectively) scanned at $2 \theta=0.2 \% \mathrm{~min}$ to those of known mixtures of pure synthetic standards (35). Error in this analysis is probably minimal because the (110) and (111) peaks for goethite synthesized in the Al system were not shifted relative to peaks for pure Fe-goethite (36)

XRD data were used to estimate the rate of ferrihydrite transformation, which follows first-order kinetics (37):

$$
[\mathrm{fh}]_{t}=[\mathrm{fh}]_{0} \mathrm{e}^{-k_{\mathrm{fh}} t}
$$

where $[\mathrm{fh}]_{t}$ is the amount of ferrihydrite present at time $t$, $[\mathrm{fh}]_{0}$ is the initial amount of ferrihydrite, and $k_{\mathrm{fh}}$ is a rate constant with units of inverse time. Equation 1 suggests that the rate of hematite (or analogously goethite) appearance is first order in ferrihydrite:

$$
\frac{\mathrm{d}[\mathrm{hem}]_{t}}{\mathrm{~d} t}=k_{\mathrm{hem}}[\mathrm{fh}]_{t}=k_{\mathrm{hem}}[\mathrm{fh}]_{0} \mathrm{e}^{-k_{\mathrm{h}} t}
$$

This can be integrated to give

$$
[\text { hem }]_{t}=[\text { hem }]_{0}+\frac{k_{\mathrm{hem}}}{k_{\mathrm{fh}}}[\mathrm{fh}]_{0}\left(1-\mathrm{e}^{-k_{\mathrm{fh}} \mathrm{t}}\right)
$$

The proportion of a phase at time trelative to its final amount was quantified by normalizing the peak intensity of a sample to the final peak intensity for that experiment. This quantity 
TABLE 2. Experimental and Actual HLW Compositions

\begin{tabular}{|c|c|c|c|c|c|}
\hline & {$[\mathrm{Na}](\mathrm{mol} / \mathrm{L})$} & {$[\mathrm{Si}](\mu \mathrm{g} / \mathrm{g})$} & {$[\mathrm{Ni}](\mu \mathrm{g} / \mathrm{g})$} & {$[T c](\mu g / g)$} & {$[\operatorname{Re}](\mu \mathrm{g} / \mathrm{g})$} \\
\hline $\operatorname{tank}$ liquid $^{a}$ & $6.55(3.02)^{b}$ & $107.04(123.81)$ & $50.55(90.46)$ & $8.13(6.45)$ & $\mathrm{na}^{c}$ \\
\hline tank sludge $e^{a}$ & na & $8986(15041)$ & $117.56(\text { mode })^{d}$ & $6.81(1.66)$ & na \\
\hline Fe system & 5.90 & 100 & 0 & na & $40^{\circ}$ or 1000 \\
\hline
\end{tabular}

was multiplied by the mass fraction of the phase in the final sample to yield the mass fraction at time $t$. Model parameters $k_{\mathrm{fh}}, k_{\mathrm{hem}}, k_{\mathrm{gt}}$, $[\mathrm{hem}]_{0}$, and [gt $]_{0}$ were regressed from the data (38). The only parameter with independent physical significance is $k_{\mathrm{fh}}$, because the exact stoichiometry of the ferrihydrite was unknown and the transformation kinetics involved an induction time.

Re in the solids was analyzed by ICP-MS (Varian Ultramass 700 ). Because digested oxide solutions were highly concentrated and difficult to analyze by ICP-MS, Re was first purified and concentrated with a modified anion exchange technique (39).

A $2 \mathrm{~mL}$ sample of exchange resin (Dowex, Marathon A anion exchange resin, 30-40 mesh, chloride form) was added to a $10 \mathrm{~mL}$ PP syringe used as an exchange column. Only Fisher trace metal grade acids were used during the Re extraction procedure. Solid samples were digested in $\mathrm{HCl}$ ( $\sim 0.1 \mathrm{~g}$ of Fe solids in $\sim 10 \mathrm{~g}$ of $6 \mathrm{M} \mathrm{HCl} ; \sim 0.1 \mathrm{~g}$ of Al solids in $\sim 35 \mathrm{~g}$ of $12 \mathrm{M} \mathrm{HCl}$ ), usually in a $50{ }^{\circ} \mathrm{C}$ oven overnight. Since Fe(III) poisons the resin, $15 \mathrm{~mL}$ of $10 \%$ hydroxylamine hydrochloride solution (Aldrich) were added to form Fe(II). The Fe(II) solution was diluted with deionized water to a final acid concentration of $0.5 \mathrm{M}$.

The resin was washed prior to use with $10 \mathrm{~mL}$ of $12 \mathrm{M}$ $\mathrm{HNO}_{3}$ (initially at $\sim 80{ }^{\circ} \mathrm{C}$ ), $10 \mathrm{~mL}$ of $8 \mathrm{M} \mathrm{HNO}_{3}$ (at room temperature), $20 \mathrm{~mL}$ of deionized water, $10 \mathrm{~mL}$ of $6 \mathrm{M} \mathrm{HCl}$, and $20 \mathrm{~mL}$ of $0.5 \mathrm{M} \mathrm{HCl}$. Samples were then loaded onto the columns. Rhenium sorbed to the resin was removed with 30 $\mathrm{mL}$ of $8 \mathrm{M} \mathrm{HNO}_{3}$. The pale green eluate contained some $\mathrm{Fe}$, likely from residual solution in the column. However, this $\mathrm{Fe}$ did not significantly influence the results. To concentrate $\mathrm{Re}$, the solution was evaporated to either a soluble red solid or a small volume of dense, viscous liquid $(<0.1 \mathrm{~mL})$ which was taken up in $\sim 4.5 \mathrm{~mL}$ of $0.01 \mathrm{M} \mathrm{HNO}_{3}$. ICP-MS analyses were performed using standards prepared in the same matrix.

The procedure was tested by preparing a 0.6 wt \% Fe solution from $\mathrm{FeCl}_{3}$ (s) in $6 \mathrm{M} \mathrm{HCl}$. Aliquots of this solution were spiked with 5 and $10 \mathrm{ppb}$ Re and treated as described above. Reproducibility and accuracy were within $10 \%$.

\section{Results and Discussion}

Solid-Phase Transformations in Fe Systems. Initially twoline ferrihydrite precipitated in all experiments; however, the mineralogy of the aged solids depended on the system composition. Without Si, ferrihydrite transformed into hematite with minor goethite; in contrast, the presence of $100 \mathrm{ppm}$ Si prevented ferrihydrite transformation over the $168 \mathrm{~h}$ of the experiments, consistent with previous work (22). In the Si-absent system, 40 ppm Re delayed slightly the first appearances of both hematite and goethite (Figure 1), and enhanced the formation of hematite relative to that of goethite. However, ferrihydrite transformation was not substantially different with or without Re as indicated by the similar $k_{\mathrm{fh}}$ values. Aqueous Al remained constant in all experiments at $\sim 0.014 \mathrm{~m}$.

Preferential formation of hematite from ferrihydrite at high $\mathrm{pH}$ has been shown to occur in the presence of $\mathrm{Al}, \mathrm{NO}_{3}$, and low concentrations of $\mathrm{Si}(22,40)$. The slight delay in

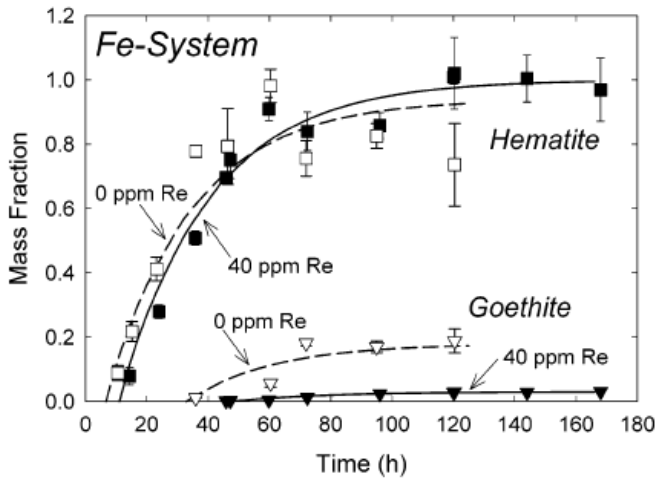

FIGURE 1. Transformation of iron oxyhydroxide phases with time, with (closed symbols) and without (open symbols) $40 \mathrm{ppm}$ Re. Final proportions of fh/hem/gt were $0 / 81 / 19$ and $0 / 97 / 3$, and transformation rate constants $k_{\mathrm{fh}}=0.036$ and $0.034 \mathrm{~h}^{-1}$ in the 0 and $40 \mathrm{ppm} \operatorname{Re}$ experiments, respectively.

recrystallization in the presence of $40 \mathrm{ppm}$ Re may be due to impedance of ferrihydrite transformation caused by Re sorption onto solid surfaces. Strongly sorbed oxyanions such as arsenate and silicate both impede ferrihydrite transformation $(18,37)$, possibly by enhancing grain adhesion during aggregation at near-neutral $\mathrm{pH}$. Perrhenate may have a similar, but weaker, effect. Enhanced aggregation of ferrihydrite particles also may inhibit the transformation to goethite, which is thought to occur dominantly by a dissolution/precipitation or "via solution" mechanism (41), in contrast to the transformation to hematite, which is described as a solid-state transformation or short-range dissolution/ precipitation mechanism (42).

Re Uptake in Fe Systems. In the experiments with 40 ppm Re, aqueous Re remained constant at $\sim 38 \mathrm{ppm}$ in the presence and absence of Si (Figure 2a). However, the Re content of the solids varied with the extent of washing, extent of aging, and Si concentration. Two types of sorbed Re were distinguished. Re removed during dialysis is termed "reversibly sorbed", and that retained by the solids after dialysis is termed "irreversibly sorbed".

$\mathrm{Re}$ in the dialyzed $\mathrm{Si}$-absent solids increased with time, reaching a final concentration of $\sim 83 \mathrm{ppb}$. In contrast, $\mathrm{Re}$ in the dialyzed Si-present solids was constant at $\sim 3 \mathrm{ppb}$, effectively the detection limit of the method (Figure 2b). Because the amounts of irreversibly sorbed Re were small, another set of Si-free experiments was performed in which total Re was increased from 40 to $1000 \mathrm{ppm}$. Increasing total Re by a factor of 25 resulted in a factor of 14 increase in $\mathrm{Re}$ in dialyzed solids ( $1170 \mathrm{ppb})$ at $168 \mathrm{~h}$ (Figure $2 \mathrm{c})$. However, at $4 \mathrm{~h}$ the Re contents of dialyzed solids in both Re-bearing Si-free systems were low ( $\sim 21 \mathrm{ppb})$, suggesting that a similar irreversible uptake mechanism operated at short times that was independent of total Re.

Variation in the Re content of dialyzed Si-absent solids after $45 \mathrm{~h}$ (Figure $2 \mathrm{~b}$ ) is outside the $10 \%$ error of the Reanalysis 

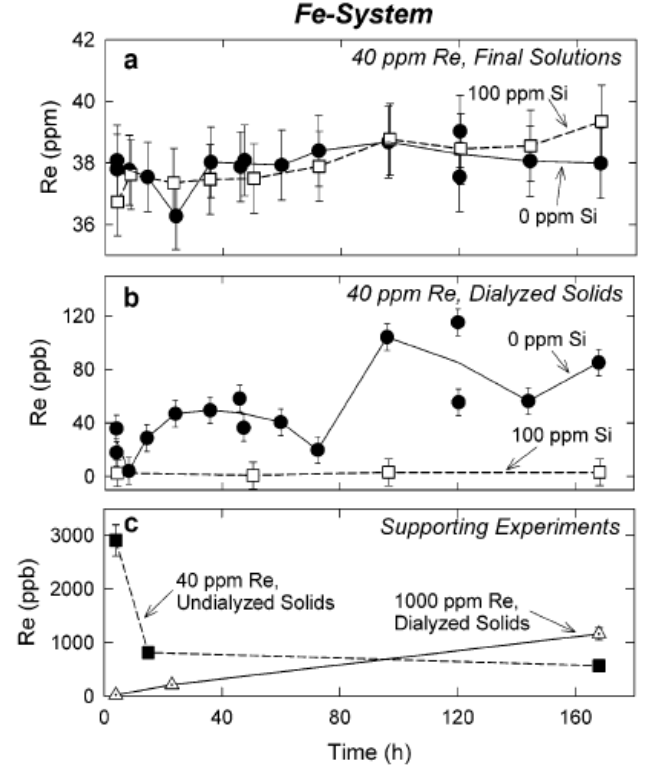

FIGURE 2. Evolution of aqueous $\operatorname{Re}(a)$ and dialyzed solid $\operatorname{Re}($ b) with time in the Fe-dominated system with (open squares) and without (closed circles) $100 \mathrm{ppm}$ Si. In each case analyses are from two replicate experiments. (c) Evolution of Re content in undialyzed low-Re (closed squares) and dialyzed high-Re (open triangles) solids.

and may result from mineralogical heterogeneity. After 120 $\mathrm{h}$ the mass fraction of hematite for all samples was fairly constant with an average standard deviation of $8 \%$. Assuming that all $\mathrm{Re}$ is in hematite and compounding this error with that of the Re analysis yields a total error of only $13 \%$, less than the $33 \%$ observed variation. In addition, samples were from two replicate experiments in which transformation rates may not have been exactly reproduced. Transformation rates depend on the nature of the initial ferrihydrite, which contains grains with a variety of structures resembling Fe-deficient hydroxylated hematite in pure Fe systems (43). In the presence of Al, Al-bearing ferrihydrite (44) and hydroxylated hematite also occur (45). These materials may retain variable amounts of Re at the grain scale and thus variable final $\mathrm{Re}$ contents of the crystalline phases. There may also have been inconsistency if the conductivity measured at the end of dialysis did not reflect the same degree of Re removal from the solids. Residual centrifuge wash water, with a pH between 10 and 11 , could have affected the leaching rate of Re from the solids through charge-dependent desorption and/or by dissolution or dispersion of fine-grained particles.

Undialyzed solids from the $40 \mathrm{ppm} \mathrm{ReSi-free} \mathrm{experiments}$ contained more Re than dialyzed solids as expected, but the trend with aging was opposite that observed after dialysis. After $4 \mathrm{~h}$, undialyzed solids contained $2.9 \mathrm{ppm}$ Re. This amount decreased to $0.8 \mathrm{ppm}$ after $24 \mathrm{~h}$, and more gradually to $0.6 \mathrm{ppm}$ at $168 \mathrm{~h}$ (Figure 2c).

Results from undialyzed experiments should be considered only semiquantitative; Re in undialyzed solids may be contaminated by residual supernatant. For example, approximately $150 \mathrm{~g}$ of water were used for each centrifuge wash. Assuming a maximum solution concentration of 40.3 ppm, $5 \mathrm{~g}$ of residual supernatant $(<5 \mathrm{~mL})$, and that no $\mathrm{Re}$ desorbed during washing, the Re concentration in the final wash water should be $\sim 0.045 \mathrm{ppm}$. This would give approximately $0.22 \mu \mathrm{g}(=5 \mathrm{~g} \times 0.045 \mathrm{ppm})$ of supernatant $\mathrm{Re}$ that remained with the solids. Each single-age experiment yielded $\sim 1$ g of solids, and so, supernatant Re contamination may have equaled $\sim 0.20 \mathrm{ppm}(200 \mathrm{ppb})$. Re in undialyzed samples ranged from 2.9 to $0.51 \mathrm{ppm}$, and $200 \mathrm{ppb}$ is $7-39 \%$ of these amounts. Therefore, the trend of decreasing $\mathrm{Re}$ content of undialyzed solids with aging is upheld even if the solids were contaminated by residual supernatant.

Mechanisms of Re Incorporation in Fe Solids. Reversible sorption typically describes ion adsorption resulting from electrostatic attraction (outer-sphere sorption) or stereochemical similarity and electron affinity (inner-sphere sorption). Such sorption on iron oxyhydroxides is $\mathrm{pH}$-dependent. Irreversible sorption, or uptake, in aging iron oxides may occur by three processes: adsorption within internal porosity, solid solution, and surface precipitation (14). The last two can be discarded for the experiments of this study. First, although the ionic radii of $\mathrm{Fe}(\mathrm{III})$ and $\mathrm{Re}$ (VII) are sufficiently close ( 0.64 and $0.53 \AA$, respectively), crystallographic substitution of Re for Fe is unlikely because Re(VII) has over twice the positive charge of $\mathrm{Fe}(\mathrm{III})$. This implies that a solid structure would need an excessive number of vacancies to compensate for the excess positive charge. Second, Re must be reduced to the VI or lower oxidation state before precipitating (23). At $\mathrm{pH} 12$, this requires a solution $E_{\mathrm{h}}$ below about $-0.5 \mathrm{~V}$, conditions not met in these experiments. Therefore, entrapment of perrhenate within internal porosity or crystal defects during the phase transformations is likely the primary process resulting in Re uptake in the solids.

In discussing this process, recall that initially the solutions were acidic and at room temperature. After the $\mathrm{pH}$ was raised to above 13 , the temperature was increased to $90^{\circ} \mathrm{C}$. At the beginning of aging at $90^{\circ} \mathrm{C}$, the only phase observed by XRD was two-line ferrihydrite, indicating that it formed from $\mathrm{Fe}$ dominated polymers as the $\mathrm{pH}$ passed through the solubility minimum for Fe phases at room temperature. The net charge on these species was positive until the point of zero charge was reached $(\mathrm{pH} \approx 7.5)$, above which the net surface charge became negative. Aggregation of ferrihydrite near neutrality was likely aided by the presence of nitrate (40) and perhaps perrhenate, which can compete successfully for surface sites with nitrate (27).

The mechanism(s) of ferrihydrite formation and subsequent transformation can explain the observed Re uptake and retention. In the absence of Si and presence of $40 \mathrm{ppm}$ total Re, the Re in dialyzed ferrihydrite after $4 \mathrm{~h}$ was $\sim 21 \mathrm{ppb}$, whereas undialyzed ferrihydrite contained $\sim 2700 \mathrm{ppb}$ (corrected for estimated supernatant contamination), indicating that $99 \%$ of the Re was reversibly sorbed. Upon transformation, total Re sorbed to the solids dropped to $350 \mathrm{ppb}$ (also corrected), while the amount of irreversibly sorbed $\mathrm{Re}$ increased to $83 \mathrm{ppb}$. Therefore, reversibly sorbed Re (total sorbed minus irreversibly sorbed) decreased to $270 \mathrm{ppb}$ at $168 \mathrm{~h}$.

This decrease in reversibly sorbed Re can be explained by surface area effects, temperature-dependent sorption, and/ or sorption strength. Hematite and goethite have lower specific surface areas than ferrihydrite (typically $20-25 \mathrm{~m}^{2} / \mathrm{g}$ for hematite and goethite, but up to $200 \mathrm{~m}^{2} / \mathrm{g}$ for ferrihydrite; 37). Assuming an equal surface density of Re on all phases, a lower surface area for the aged phases could account for the observed $90 \%$ decrease in reversibly sorbed Re. However, the rate of desorption does not correspond to the rate of recrystallization. At $24 \mathrm{~h}, 78 \%$ of the total Re had desorbed, but only $30 \%$ of the ferrihydrite had transformed. This may be related to the temperature dependence of surface complexation equilibrium constants that describe inner-sphere sorption of perrhenate. Oxyanions (i.e., silicate, arsenate, and molybdate) are known to sorb by inner-sphere sorption mechanisms at and slightly above the ferrihydrite pzc (46). Perrhenate probably behaves similarly although its sorption may be relatively weak, like that of sulfate (46). Weak sorption is supported by the observation that transformation was delayed for only a few hours in the presence of $40 \mathrm{ppm}$ 
perrhenate in contrast to a minimum of $168 \mathrm{~h}$ in the presence of $100 \mathrm{pm} \mathrm{Si}$. A decrease in the weak sorption as a result of increased temperature could explain the faster desorption than transformation rate upon aging.

Particle aggregation likely retained $\mathrm{Re}$ in the ferrihydrite at room temperature. At $90^{\circ} \mathrm{C}$, the transformation to hematite or goethite could have trapped Re in the crystalline products, the amount depending on the distribution of structures within, and composition of, the initial ferrihydrite as well as the rates of transformation and desorption. Both synthetic and natural ferrihydrites contain nanoscale domains of hematite $(43,47,48)$ which aggregate or grow to form larger hematite crystals over time (40). The occurrence of microstructural defects such as grain boundaries in the growing hematite provides sites in which incompatible components could reside, a process known as grain boundary segregation (49). It has been proposed previously that multidomainic goethite crystals may also irreversibly sorb oxyanions such as silicate along domain boundaries (22).

Pure synthetic goethite contained $135 \mathrm{ppb}$ irreversibly sorbed Re. In the presence of $40 \mathrm{ppm} \mathrm{Re}$, the amount of goethite in the Si-free experiments approached $20 \%$ of the solids. Using the amount of Re retained in the pure goethite, approximately $25-30 \mathrm{ppb}$ irreversibly sorbed Re could be in the sludge goethite, indicating that $50 \%$ or more of the irreversibly sorbed $\mathrm{Re}$ is in the hematite.

Solid-Phase Transformation in Al Systems. The solid evolution of the Al system followed the general trend toward more stable phases: bayerite $\rightarrow$ gibbsite $\rightarrow$ boehmite (50, $51)$. However, transformation kinetics varied greatly and did not correlate well with system composition (38). The mineralogy of aluminum oxyhydroxide precipitates is sensitive to solution saturation state and neutralization rate (52). The neutralization rate in the experiments was not strictly controlled ( $\mathrm{NaOH}$ was added slowly but manually), and thick slurries formed as the $\mathrm{pH}$ increased through the Al solubility minimum; it was not possible to stir the slurry and keep a homogeneous base concentration. Nonetheless, bayerite disappeared after no more than $\sim 24 \mathrm{~h}$, gibbsite persisted for up to 42 days, but in some experiments disappeared after only 3 days, and boehmite first appeared after $\sim 24 \mathrm{~h}$, increasing in amount with time.

Qualitative XRD detected a small amount of hematite in the Ni-absent system, but not goethite. XRD also could not detect a $\mathrm{Ni}-\mathrm{Al}$ layered double hydroxide (LDH) phase previously observed in complex synthetic sludges (J. Krumhansl, personal communication), a hypothesized sink for perrhenate. Ni inhibited the formation of hematite, in amounts observable by routine XRD ( $\sim 5 \mathrm{wt} \%$ ), for up to 168 $h$. The inhibition of goethite formation is not surprising given the high concentrations of $\mathrm{Al}$ in the experimental system (36).

Re Uptake in Al Systems. In the 40 ppm Re experiments with and without Ni higher initial amounts of irreversibly sorbed Re were observed after $4 \mathrm{~h}$ of aging than in the Fedominated system ( $\sim 60 \mathrm{ppb}$ vs $40 \mathrm{ppb}$ ) (Figure 3a). However, Re decreased rapidly; after $24 \mathrm{~h}$ the Re content of the Al solids was only slightly above background. After $168 \mathrm{~h}$ in the system with $\mathrm{Ni}$ and 18 weeks in the system without $\mathrm{Ni}$, irreversibly sorbed Re in the solids rose to about $30 \mathrm{ppb}$. This moderate increase in Re content does not correlate with the timing of hematite appearance and is probably not related to formation of an LDH phase since this phase could not have formed in the Ni-absent system. Increasing total Re to $1000 \mathrm{ppm}$ in the Ni-free system increased the amount sorbed irreversibly, although again less (132 ppb) was retained after $168 \mathrm{~h}$ of aging (Figure $3 \mathrm{~b}$ ) compared to the amount retained in the Fe system (1170 ppb), and the amount declined with time (from 226 to $132 \mathrm{ppb}$ between 4 and $168 \mathrm{~h}$ ).

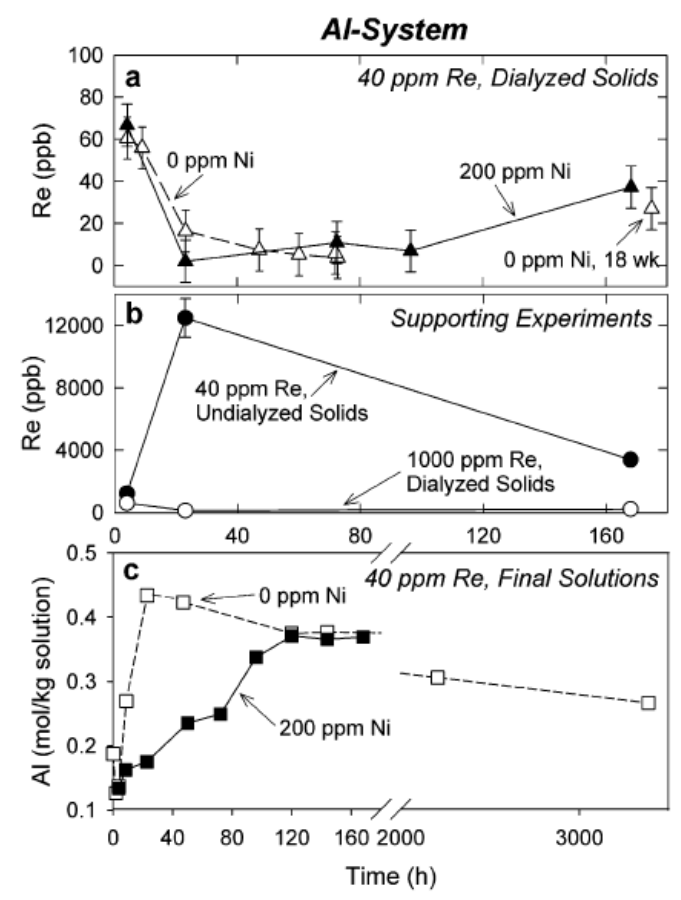

FIGURE 3. (a) Evolution of dialyzed solid Re with time in the Aldominated system with (closed triangles) and without (open triangles) $200 \mathrm{ppm} \mathrm{Ni}$. (b) Evolution of Re content in undialyzed low- $\operatorname{Re}$ (closed circles) and dialyzed high-Re (open circles) solids. (c) Evolution of dissolved Al with time in Al-dominated systems with (closed squares) and without (open squares) $200 \mathrm{ppm} \mathrm{Ni}$.

In the absence of $\mathrm{Ni}$, reversibly sorbed Re in the $40 \mathrm{ppm}$ experiment was as much as 10 times higher than in the Sifree Fe system, but did not follow the same decreasing trend with time (Figure $3 \mathrm{~b}$ ). Dissolved Al increased over the first few days in both Al systems (with and without $\mathrm{Ni}$ ) containing $40 \mathrm{ppm} \operatorname{Re}$ (Figure 3c). The increase in Al signals the dissolution of metastable $\mathrm{Al}$ phases that formed before the temperature was raised to $90^{\circ} \mathrm{C}$. Such phases could include microcrystalline gibbsite or solids composed of various polyoxometalate cations $(53,54)$ that can form during the initial neutralization of acidic $\mathrm{Al}$ solutions at room temperature. Dissolution of metastable phases occurred faster in the absence of $\mathrm{Ni}$, and caused initially trapped Re to be released to solution and excluded from recrystallizing stable solids at $90^{\circ} \mathrm{C}$. The greater amount of reversibly sorbed Re in the Al-dominant system agrees qualitatively with the results of ref 27; however, they observed no reversible uptake of Re in Fe-dominant systems, in contrast to our results showing both reversible and irreversible uptake in Fe phases. Differences in competitive sorption among minor components in the sludges of the two studies might explain this difference in reversible Re uptake in Fe-dominated systems.

Because of the variable mineralogy, it is difficult to draw firm conclusions about Re uptake in the Al-dominated systems. Re was clearly incorporated in the solids during neutralization and precipitation, but the mechanisms affecting the extent of long-term Re retention remain unclear.

Implications for the Hanford Tanks. Recent investigations $(12,13)$ have demonstrated likely mechanisms for $\gamma$-rayinduced reduction of $\mathrm{TcO}_{4}{ }^{-}$in the presence of certain organic compounds known to exist in Hanford waste tanks that contain residuals or degradation products of chelating agents used in isotope recovery processes. In the absence of such compounds, which consume oxidizing free radicals produced 
in the radiolysis of water, pertechnetate was found to be chemically stable. Although it is generally assumed that $\mathrm{TcO}_{2}(\mathrm{~s})$ would be the most likely candidate for incorporation of Tc into tank waste solid phases, structural information about Tc-containing tank solids remains elusive. However, results of this investigation, using perrhenate as a surrogate for pertechnetate, suggest a second mechanism by which Tc could have been incorporated into Hanford tank waste solids, particularly during the extensive waste solidification programs that were conducted over several decades (4).

The experimental data indicate that on average up to about $5 \%$ of the total ${ }^{99} \mathrm{Tc}$ inventory may reside in sludge solids under fully oxidizing conditions. Furthermore, up to $14 \%$ of the solids-inventory ${ }^{99} \mathrm{Tc}$ may be irreversibly sorbed in iron and aluminum oxide phases, with a greater amount sequestered in crystalline iron oxides. The amount of irreversible sequestration in crystalline iron oxides might be less in tanks with high Si concentrations, but predicting such a relationship may be complicated by the formation of various Si-containing phases and the timing of $\mathrm{Si}$ addition to the waste streams. Goethite, hematite, and X-ray amorphous iron oxides (presumably ferrihydrite) have been identified in some of the few analyses made of tank solids (55). Acid-leaching of C-106 and AY-102 tank sludges (56) showed that between $50 \%$ and $97 \%$ of the Fe residue consisted of hematite, even though these sludges contained significant amounts of total $\mathrm{Si}$ (identified in solid form as cancrinite or amorphous aluminosilicates). The solid-phase sequestration mechanism for Tc indicated in this study may apply to aged precipitated solids of other compositions as well. Current strategies for separating ${ }^{99} \mathrm{Tc}$ from remaining tanks, such as anion exchange and dilute caustic leaching, are designed to extract weakly sorbed and aqueous ${ }^{99} \mathrm{Tc}$ and may not reclaim all ${ }^{99} \mathrm{Tc}$ from the sludge.

\section{Acknowledgments}

This research was supported by the U.S. Department of Energy's Environmental Management Science Program through Grant DE-FG07-97ER14834. We thank Thomas E. Jones of CH2MHILL Hanford Group, Inc. for providing extensive discussion and current information on ${ }^{99} \mathrm{Tc}$ distribution in Hanford waste tanks and two anonymous reviewers for their comments.

\section{Literature Cited}

(1) Agnew, S. F.; Boyer, J.; Corbin, R. A.; Duran, T. B.; FitzPatrick, J. R.; Jurgensen, K. A.; Ortiz, T. P.; Young, B. L. Hanford Tank Chemical and Radionuclide Inventories: HDW Model; LA-UR96-3860; Los Alamos National Laboratory: Los Alamos, NM, 1997.

(2) Hanlon, B. M. Waste Status Summary Report for Month Ending April 30, 2003; HNF-EP-0182, Rev. 181; CH2MHILL Hanford Group: Richland, WA, 2003.

(3) Knepp, A. J. Field Investigation Report for Waste management Area S-SX; RPP-7884, Rev. 0; CH2MHILL Hanford Group: Richland, WA, 2002a.

(4) Knepp, A. J. Field Investigation Report for Waste management Area $B-B X-B Y$; RPP-10098, Rev. 0; CH2MHILL Hanford Group: Richland, WA, 2002b.

(5) Mann, F. M.; Puigh, R. J.; Finfrock, S. H.; Freeman, E. J.; Khaleel R.; Bacon, D. H.; Bergeron, M. P.; McGrail, B. P.; Wurstner, S. K.; Burgard, K.; Root, W. R.; LaMont, P. Hanford Immobilized Low-Activity Tank WastePerformance Assessment: 2001 Version; DOE/ORP-2000-24, Rev. 0; Office of River Protection, U.S. Department of Energy: Richland, WA, 2001.

(6) Boyd, G. E.; Larson Q. V. J. Phys. Chem. 1960, 64, 988-996.

(7) Pruett, D. J. Radiochim. Acta 1981, 28, 153-157.

(8) Simpson, B. C.; Corbin, R. A.; Agnew, S. F. Hanford Soil Inventory Model; BHI-01496; Bechtel Hanford Inc.: Richland, WA, 2001.

(9) Roberts, F. P.; Smith, F. M.; Wheelwright, E. J. Recovery and Purification of Technetium-99 from Neutralized PUREX Wastes, HW-73121; General Electric: Richland, WA, 1962.

(10) Buckingham, J. S. Waste Management Technical Manual; ISO100; Isochem, Inc.: Richland, WA, 1967.
(11) Crawford, B. A. Tank 241-AX-104 Residual Solids Leach Test Results; TWR-3548, Rev. 0; Numatec Hanford Corp.: Richland, WA, 1998.

(12) Lukens, W. W., Jr.; Bucher, J. J.; Edelstein, N. M.; Shuh, D. K Environ. Sci. Technol. 2002, 36, 1124-1129.

(13) Bernard, J. G.; Bauer, E.; Richards, M. P.; Arterburn, J. B.; Chamberlin, R. M. Radiochim. Acta 2001, 89, 59-61.

(14) Ford, R. G.; Bertsch, P. M.; Farley, K. J. Environ. Sci. Technol 1997, 31, 2028-2033.

(15) Martinez, C. E.; McBride, M. B. Clays Clay Miner. 1998, 46, 537545.

(16) Ford, R. G.; Kemner, K. M.; Bertsch, P. M. Geochim. Cosmochim. Acta $1999,63,39-48$

(17) Martinez, C. E.;McBride, M. B. Geochim. Cosmochim. Acta 2000, $64,1729-1737$

(18) Bibak, A.; Borggaard, O. K. Soil Sci. 1994, 158, 323-328.

(19) Waychunas, G. A.; Rea, B. A.; Fuller, C. C.; Davis, J. A. Geochim. Cosmochim. Acta 1993, 57, 2251-2269.

(20) Manceau, A.; Charlet, L. J. Colloid Interface Sci. 1994, 168, 87-

(21) Persson, P.; Nilsson, N.; Sjöberg, S. J. Colloid Interface Sci. 1996, 177, 263-275.

(22) Cornell, R. M.; Giovanoli, R.; Schindler, P. W. Clays Clay Miner. $1987,35,21-28$

(23) Brookins, D. G. Appl. Geochem. 1986, 1, 513-517.

(24) Palmer, D. A.; Meyer, R. E. J. Inorg. Nucl. Chem. 1981, 43, 29792984

(25) Vandergraaf, T. T.; Ticknor, K. V.; George, I. M. Geochemical Behavior of Disposed Radioactive Waste; ACS Symposium Series 246; American Chemical Society: Washington, DC; 1984, pp $25-43$.

(26) Walton, F. B.; Paquette, J.; Ross, J. P. M.; Lawrence, W. E. Nucl. Chem. Waste Manage. 1986, 6, 121-126.

(27) Zhang, P.-C.; Krumhansl, J. L.; Brady, P. V. Radiochim. Acta $2000,88,369-373$

(28) Wharton, M. J.; Atkins, B.; Charnock, J. M.; Livens, F. R.; Pattrick, R. A. D.; Collison, D. Appl. Geochem. 2000, 15, 347-354

(29) Cleveland, J. M. The Chemistry of Plutonium; Gordon and Beach: New York, 1970.

(30) Schwertmann, U.; Cornell, R. M. Iron Oxides in the Laboratory, VCH: New York, 1991; $137 \mathrm{pp}$

(31) Busey, R. H.; Mesmer, R. E. J. Chem. Eng. Data 1978, 23, 175176.

(32) Bates, R. G. Determination of $\mathrm{pH}$, Theory and Practice; John Wiley \& Sons: New York, 1973; $479 \mathrm{pp}$

(33) Dougan, W. K.; Wilson, A. L. Analyst 1974, 99, 413-430.

(34) Dawson, M. V.; Lyle, S. J. Talanta 1990, 37, 1189-1191.

(35) Snyder, R. L.; Bish, D. L. In Reviews in Mineral; Bish, D. L., Post, J. E., Eds.; Mineralogical Society of America: Washington, DC, 1989; Vol. 20, pp 101-144.

(36) Schulze, D. G. Clays Clay Miner. 1984, 32, 36-44

(37) Cornell, R. M.; Schwertmann, U. The Iron Oxides: Structure, Properties, Reactions, Occurrences and Uses: VCH: New York, 1996; $573 \mathrm{pp}$.

(38) Wakoff, B. Rhenium uptake by iron and aluminum oxy(hydr)oxide precipitates: an analog for the fate of technetium-99 in high level nuclear waste. Master of Science Thesis, University of Colorado, Boulder, CO, 2001; 187 pp.

(39) Colodner, D. C.; Boyle, E. A.; Edmond, J. M. Anal. Chem. 1993. $65,1419-1425$

(40) Schwertmann, U.; Friedl, J.; Stanjek, H. J. Colloid Interface Sci. 1999, 209, 215-223.

(41) Schwertmann, U.; Murad, E. Clays Clay Miner. 1983, 31, 277284.

(42) Johnston, J. H.; Lewis, D. G. Geochim. Cosmochim. Acta 1983, 47, 1823-1831

(43) Drits, V. A.; Sakharov, B. A.; Salyn, A. L.; Manceau, A. ClayMiner. $1993,28,185-207$

(44) Schwertmann, U.; Fitzpatrick, R. W.; Taylor, R. M.; Lewis, D. G. Clays Clay Miner. 1979, 27, 105-112.

(45) Stanjek, H.; Schwertmann, U. Clays Clay Miner. 1992, 40, 347354.

(46) Sposito, G. The Surface Chemistry of Soils, Oxford University Press: New York, 1984; p 234.

(47) Combes, J. M.; Manceau, A.; Calas, G. Geochim. Cosmochim. Acta 1990, 54, 1083-1091.

(48) Manceau, A.; Drits V. A. Clay Miner. 1993, 28, 165-184

(49) Kingery, W. D. J. Am. Ceram. Soc. 1974, 57, 74-83.

(50) Wefers, K.; Misra, C. Oxides and Hydroxides of Aluminum; Alcoa Technical Paper 19, Revised; Alcoa Laboratories: Alcoa Center. PA; $1987 ;$ p 92. 
(51) Pokrovskil, V. A.; Helgeson, H. C. Am. J. Sci. 1995, 295, 1255-1342.

(52) van Straten, H. A.; Holtkamp, B. T. W.; de Bruyn, P. L. J. Colloid Interface Sci. 1983, 98, 342-362.

(53) Bottero, J. Y.; Cases, J. M.; Fiessinger, F.; Poirier, J. E. J. Phys. Chem. 1980, 84, 2933-2939.

(54) Allouche, L.; Huguenard, C.; Taulelle, F. J. Phys. Chem. Solids 2001, 62, 1525-1531.

(55) Rapko, B. M.; Lumetta, G. J. Status Report on Phase Identification in Hanford Tank Sludges, PNNL-13394; Pacific Northwest National Laboratory: Richland, WA, 2000.
(56) Bechtold, D. B.; Cooke, G. A.; Herting, D. L.; Person, J. C.; Viswanath, R. S.; Warrant, R. W. Laboratory Testing of Oxalic Acid Dissolution of Tank 241-C-106 Sludge; RPP-17158; Fluor Hanford: Richland, WA, 2003.

Received for review August 8, 2003. Revised manuscript received December 12, 2003. Accepted December 26, 2003.

ES0348795 